\title{
PAGOS DIGITALES PARA LA INCLUSIÓN FINANCIERA DE POBLACIONES VULNERABLES EN ARGENTINA: UN ESTUDIO EMPÍRICO EN COMERCIANTES DEL BARRIO PADRE CARLOS MÚGICA (EX VILLA 31-31 BIS) DE LA CIUDAD AUTÓNOMA DE BUENOS AIRES
}

\author{
IGNACIO CARBALLO ${ }^{1}$ Y MATEO BARTOLINI ${ }^{2}$
}

\begin{abstract}
RESUMEN
Este trabajo se enmarca en el estudio de los pagos digitales y la inclusión financiera en comercios de asentamientos informales. Para ello se elaboró un instrumento de recolección de datos inédito con el cuál se entrevistó a 104 comerciantes del Barrio Padre Carlos Múgica de la Ciudad de Buenos Aires, Argentina. Nuestros hallazgos reivindican el potencial de incluir financieramente mediante pagos digitales. Se destaca la telefonía móvil como principal medio de acceso al mundo digital, pero también la falta de seguridad y confianza sobre esta tecnología. Se evidencia un efecto multiplicador en comercios que aceptan pagos digitales frente a otras dimensiones de inclusión financiera y se brinda información sobre los principales incentivos que perciben los comerciantes para adoptar pagos digitales en sus comercios.
\end{abstract}

Palabras clave: Inclusión financiera, pagos digitales, Fintech, asentamientos urbanos, pobreza.

\section{DIGITAL PAYMENTS FOR FINANCIAL INCLUSION OF VULNERABLE GROUPS IN ARGENTINA: AN EMPIRICAL STUDY IN NEIGHBORHOOD PADRE CARLOS MÚGINA (EX VILLA 31-31 BIS) OF THE CIUDAD AUTÓNOMA DE BUENOS AIRES}

\begin{abstract}
This paper addresses the problem of digital payments and financial inclusion in informal settlement merchants. To this end, an unprecedented quantitative survey was developed and 104 merchants from the Padre Carlos Múgica Neighborhood (ex Villa 31 and 31 bis) in the City of Buenos Aires, Argentina, were interviewed. Our findings claim the enormous potential to include financially through digital payments. Mobile is highlighted as the main sources of access to the digital world, but also highlight the lack of security and trust in this technology. Our result shows a multiplier effect on businesses that accept digital payments in relation to other dimensions of financial inclusion and provides information on what are the main incentives that low-income merchants receive to adopt or be interested in starting to accept digital payments in their businesses.
\end{abstract}

Keywords: Financial inclusion, digital payments, Fintech, urban settlements, poverty.

Clasificación JEL: G21, 016, C81

Recibido:28/04/2020. Aceptado: 17/12/2020

\footnotetext{
${ }^{1}$ Facultad de Ciencias Económicas, Pontificia Universidad Católica Argentina (UCA), Argentina y Centro de Estudios de la Estructura Económica (CENES), Instituto de Investigaciones Económicas, Consejo Nacional de Investigaciones Científicas y Técnicas de Argentina (CONICET), Facultado de Ciencias Económicas, Universidad de Buenos Aires, Argentina. nachocarballo4@hotmail.com / ignaciocarballo@uca.edu.ar

${ }^{2}$ Facultad de Ciencias Económicas, Universidad de Buenos Aires, Argentina. mateobartolini@gmail.com
} 


\section{Introducción}

La estabilidad e integridad financiera son objetivos que se encuentran en el centro de la política económica de los principales reguladores y supervisores financieros, como mínimo, desde finales del siglo XX (Crochet, 1997; Marston, 2001; Rudd, 2009). Más recientemente, la contribución teórica de la inclusión financiera (que pretende llevar servicios financieros formales a las personas que no tienen acceso a estos) al logro de un crecimiento económico inclusivo y de los objetivos de desarrollo sostenible ha obtenido reconocimiento mundial, incorporándola al mencionado mapa de objetivos (De Sousa, 2015, Dema, 2015).

La inclusión financiera es un concepto amplio, polisémico y multidimensional que pareciera se encuentra en constante evolución, construcción y debate. De manera general, hace referencia al acceso y uso a un conjunto de productos y servicios financieros, ofrecidos a un costo razonable y a través de instituciones financieras formales. A nivel global, los sectores con bajos ingresos, los sectores rurales y los agentes más vulnerables encuentran mayores dificultades para disponer de dichos servicios de manera asequible y con igualdad de condiciones (Demirgüç-Kunt et. al., 2015; Carballo, 2018).

Mediante este nuevo objetivo de promoción a la inclusión financiera se han fomentado reformas y políticas críticas buscando ayudar a establecer un entorno financiero propicio en distintas economías. Por ejemplo, a través de alianzas público-privadas o compromisos específicos por parte de los Estados para asegurar que los recursos y las acciones necesarias se pongan en marcha para promover la inclusión financiera. Por ejemplo, las Estrategias Nacionales de Inclusión Financiera ${ }^{3}$, hoy implementadas en más de 60 economías de todo el mundo inclusive Argentina desde el mes de agosto 2019 (Trivelli y Caballero, 2018).

Junto con la puesta en escena de la inclusión financiera hacia adentro de los Estados, se ha creado un ecosistema global de fomento a una inclusión financiera de índole digital. Esta comunidad global de inclusión financiera incluye grupos tan relevantes como la Fundación Bill \& Melinda Gates, la Red Omidyar, Consultative Group to Assist the Poor, la Alianza Better Than Cash, y una serie de otros actores que presentan el dinero digital como más seguro o más conveniente para los clientes, y más eficiente para los proveedores financieros que potencialmente pueden procesar más transacciones digitales de manera más segura (Scott, 2013).

En términos generales, estos grupos apuntan a un mundo en el que los pagos digitales superan las limitaciones del efectivo para permitir una expansión de las oportunidades comerciales. La tendencia ha sido la de considerar a las nuevas tecnologías financieras (en adelante Fintech) como una fuerza para la inclusión financiera y el crecimiento económico, ya sea en términos de proporcionar a las personas que se encuentran en la "base de la pirámide" alguna herramienta básica para evitar dificultades asociadas con el dinero en efectivo, o para darles acceso a los beneficios de una economía digital de la que, a su vez demás, también están excluidos.

En este contexto de auge y asentamiento del fenómeno de índole global de inclusión financiera que se asocia a la revolución digital en las finanzas que promueven las Fintech, es donde los nuevos instrumentos de pagos digitales se esgrimen prominentes. Los instrumentos de pago son el tejido conectivo de todo sistema económico. Permiten a la población comprar bienes y servicios, así como a los gobiernos recaudar impuestos y desembolsar pagos sociales. Cuando estas transacciones son costosas e inconvenientes, la actividad económica se ve obstaculizada.

\footnotetext{
${ }^{3}$ Véase http://www.worldbank.org/en/topic/financialinclusion/brief/financial-inclusion-strategies-resource-center
} 
De este modo, los hogares de mayor poder adquisitivo viven su vida financiera incluidos en un sistema financiero que facilita su actividad económica al hacer que sea barato y sencillo para ellos realizar y recibir pagos. De igual modo, su dinero se encuentra salvaguardado en una cuenta bancaria virtual, donde puede ser transferido con el clic de un botón mediante cualquier dispositivo con conexión a internet. Por el contrario, los hogares excluidos de ese sistema financiero ahorran y transfieren valor a través de activos físicos, como dinero en efectivo o bienes.

Para dimensionar, la base de datos Global Findex del Banco Mundial ${ }^{4}$ encontró para 2017 que la cantidad de adultos del planeta que tenía una cuenta bancaria en una institución financiera o por medio de algún proveedor de dinero móvil ascendió al 69\% de la población global. Esto es, que todavía hay unos 1.700 millones de adultos no poseen acceso alguno a las bondades de las instituciones financieras. Para más, como viene demostrando este estudio trienal desde el año 2011, los excluidos de las finanzas formales son en su amplia mayoría los agentes en situación de pobreza (Demirgüç-Kunt et. al., 2018)

Esta brecha digital del efectivo crea dos desigualdades que se refuerzan mutuamente en la vida financiera de los hogares pobres. En primer lugar, hace que sea más costoso y arriesgado para los hogares más pobres realizar actividades financieras básicas, desde enviar dinero a familiares o socios hasta financiar una inversión o un emprendimiento. En segundo lugar, perpetúa la exclusión de los pobres de la economía formal al hacer que sea prohibitivamente costoso para las compañías de servicios públicos, bancos, compañías de seguros y otras instituciones realizar transacciones con ellos. En esta línea, cada vez más más se asume que conectar a los pobres a un sistema financiero digital generará importantes beneficios sociales y económicos (Radcliffe y Voorhies, 2012; Gabor y Brooks, 2017)

Inmersa en este fenómeno global, en Argentina la inclusión financiera ha ingresado de manera explícita en la política pública y financiera. A partir del año 2016, entre la batería de medidas impulsadas, las más destacadas fueron de impulso a la digitalización financiera. Estas, a su vez, facilitaron el desarrollo de un sector Fintech local tan pujante que a la fecha de redactar este informe se esgrime como el cuarto más desarrollado de América Latina (Berkmen et. al., 2019). Como se mencionó párrafos atrás, más recientemente desde el Gobierno Nacional se concretó con fuerza de Ley la implementación de nuestra primera Estrategia Nacional de Inclusión Financiera (en adelante ENIF). La ENIF fue publicada el 30 de agosto de 2019 por el Boletín Oficial (Resolución 17/2019, MH) buscando promover el acceso y uso responsable y sostenible de servicios financieros por parte de todas las personas y empresas en el territorio argentino, a la vez de contribuir al desarrollo social y al crecimiento económico del país y reducir la vulnerabilidad económica de los individuos y las empresas a través de la inclusión financiera ${ }^{5}$.

Confiando en que para diagramar una política de intervención efectiva de impulso a la inclusión financiera se torna fundamental conocer las urgencias, prioridades y necesidades específicas segregadas por tipo población, especialmente la más vulnerable, en este trabajo nos proponemos realizar dos aportes. Por un lado, se presenta un instrumento de creación propia y

\footnotetext{
${ }^{4}$ Actualmente el Global Findex es considerado el instrumento más exhaustivo de calibración del progreso en materia de inclusión financiera y la única fuente de datos recabados desde la demanda que permite realizar análisis comparativos entre países a nivel internacional y regional. El 19 de abril de 2018 se publicaron los datos del último Global Findex implementado durante 2017 actualizando el estado de conocimiento cuantitativo sobre inclusión financiera en el mundo.
}

${ }^{5}$ El Documento oficial puede obtenerse en el siguiente enlace: https://www.argentina.gob.ar/inclusion-financiera 
fácilmente replicable (que amplía y ajusta reconocidos cuestionarios globales) para analizar el rol de los pagos digitales en comercios radicados en asentamientos urbanos. En segundo lugar, se exponen los resultados de un primer relevamiento realizado con dicho instrumento a 104 comercios de esta población. Específicamente, se presenta aquí un estudio inédito para nuestro país al analizar, por primera vez, el rol y estado de los pagos digitales en los comercios de uno de los asentamientos urbanos más emblemáticos de Argentina: el Barrio Padre Carlos Mujica (ex Villa 31-31 bis, en adelante Barrio 31), ubicado en la Ciudad Autónoma de Buenos Aires.

Es importante mencionar que los sectores vulnerables de la población poseen diversas barreras al uso de los servicios financieros y los medios digitales. Estas son tanto estructurales como conductuales que limitan el uso de este tipo de medios. Consecuentemente, esta investigación expone un análisis de índole descriptivo y exploratorio en base a una recolección de datos inédita, sin pretender ser representativa a la totalidad de barreras ni tampoco extrapolable a todas las poblaciones vulnerables de Argentina. Nuestro objetivo es brindar una mayor comprensión a las barreras y bondades (efectivas y percibidas) que enfrentan los pagos digitales en esta población inexplorada como medio para mejorar el diseño de futuras políticas públicas de inclusión financiera mediante instrumentos de pago digital en barrios vulnerables.

De cara a futuras investigaciones, se podrían aplicar metodologías de análisis estadísticos/econométricos a la información recolectada para lograr mayores conclusiones. Se destaca también la posibilidad de replicar este ejercicio y cuestionario de manera centralizada por los hacedores de políticas en el marco de la ENIF o bien por instituciones privadas con interés en fomentar la inclusión financiera mediante pagos digitales en poblaciones vulnerables.

\section{Marco teórico y antecedentes.}

\section{II.1. Inclusión financiera y tecnologías financiera (Fintech)}

Como se adelantó, el concepto de inclusión financiera como herramienta para el desarrollo se consolida a nivel internacional con la Asamblea General de las Naciones Unidas celebrada a fines de 2015. Específicamente, cuando la Agenda 2030 posiciona en un lugar prioritario a la inclusión financiera mencionando la necesidad de un acceso ampliado o universal a los servicios financieros en cinco de sus 17 Objetivos de Desarrollo Sostenible (United Nations, 2015; Klapper, El-Zoghbi y Hess, 2016).

A su vez y con una mayor antelación histórica, ya las microfinanzas (que tienen sus raíces en iniciativas de microcrédito en Bangladesh y partes de América Latina a mediados de la década de 1970) habían sabido constituirse como una herramienta en busca de reducir las disparidades en el acceso a servicios financieros de los excluidos del sistema financiero tradicional, específicamente los más vulnerables. Las microfinanzas nacen entonces como una innovación metodológica para ofrecer distintos servicios financieros a la población en situación de pobreza o sin colateral. Casi medio siglo de evolución, estudio y desarrollo ha llevado a que las microfinanzas dejaran importantes lecciones respecto de cómo generar una efectiva inclusión financiera con foco en los más vulnerables (Lacalle Calderon y Rico Garrido, 2008; Armendáriz y Morduch, 2010).

Por estos motivos algunas posturas entienden a la inclusión financiera como un proceso evolutivo o superador del fenómeno de las microfinanzas. Básicamente porque sostienen que sus fines son más amplios que la reducción de la pobreza, contemplando también la reducción de riesgos y costos bancarios, el incremento de la economía formal, la creación de empleo, la mayor 
eficacia de las políticas monetarias, la estabilidad del sistema financiero, entre otros (Carballo, 2018).

La definición de inclusión financiera ha evolucionado a lo largo de los años y a veces es definida de distinto modo por diferentes países, organismos o actores (Alliance for Financial Inclusion, 2017). En términos generales, existe bastante consenso en definir a la inclusión financiera como el proceso que asegura el acceso, uso y disponibilidad del sistema financiero formal a todos los miembros de una economía (Allen, et. al., 2016; Demirgüç-Kunt y Singer, 2017).

Por su parte, la palabra "Fintech" apareció por primera vez en los buscadores hacia 2005, recién logrando diseminarse a gran escala en el año 2012 con casos prácticos de empresas innovadoras que mediante la tecnología mostraron una manera distinta de acercar servicios financieros (Bosch-Liarte \& Bosch-Liarte, 2016). Del mismo modo, "empresas Fintech" son aquellas encargadas de ofrecer, mediante plataformas tecnológicas, una variada gama de productos o servicios financieros a los consumidores de forma efectiva y accesible pero también a las propias instituciones financieras (Silvia y Ramos, 2017).

Si bien las empresas Fintech no son nuevas (Bloomberg fue creada en 1981 y Paypal a fines de la década de 1990), la cantidad de emprendimientos en este segmento aumentó exponencialmente luego de la crisis mundial del año 2008 tras el férreo replanteo hacia dentro de las instituciones tradicionales (Palacio Garcés, 2017). Aunque es naturalmente difícil definir categorías en un fenómeno tan dinámico y reciente, siguiendo a Torres Blázquez (2017), dentro de las grandes tendencias que se esgrimen como disruptivas para las finanzas podríamos diferenciar cuatro grandes grupos o corrientes (no taxativas): a) Fintech de financiación; b) Fintech de transferencia de fondos; c) Fintech de asesoramiento; d) Fintech de cobros y pagos a través de nuevos dispositivos móviles (Torres Blázquez, 2017)

Actualmente, las nuevas tecnologías financieras ya son una afamada rama dentro de la innovación que propone oportunidades y desafíos a la oferta, demanda y regulación de los servicios financieros (Rojas, 2016).

Como dijimos, las Fintech's cobraron un papel significativo en la inclusión financiera, que está siendo apoyado por estándares globales y organismos clave de inclusión financiera. De igual modo, cada vez más los gobiernos nacionales y las instituciones se comprometen a digitalizar sus entidades financieras y los grandes flujos de pagos ${ }^{6}$. De igual modo, podemos observar como las mencionadas ENIF de todo el mundo hacen mención explícita al rol de las nuevas tecnologías (Trivelli y Caballero, 2018).

Todo esto refleja cómo las Fintech's cobraron un papel significativo en la inclusión financiera, que está siendo apoyado por Estados, estándares globales y organismos multilaterales clave de inclusión financiera.

\footnotetext{
${ }^{6}$ A modo de ejemplo, la Alianza internacional 'Better Than Cash' ya posee más de 50 miembros que se han comprometido con los principios de pago digital de BTCA https://www.betterthancash.org/
} 


\section{II.2. Efectivo, pagos digitales y pobreza}

En este fenómeno global de auge y asentamiento de la inclusión financiera que se apalanca en la revolución digital de las finanzas, es donde los nuevos instrumentos de pagos digitales se esgrimen prominentes.

Como se mencionó, los pagos son el tejido conectivo de un sistema financiero. Enlazan a los compradores con los vendedores y permiten a los gobiernos realizar transacciones con sus ciudadanos. De hecho, los pagos son el componente básico de los demás servicios financieros. El ahorro, si bien es un concepto amplio, podría concebirse como una secuencia de pagos de depósito del cliente al banco y pagos de retiro del banco al cliente. De igual modo, a los fines de comprender el rol de los pagos digitales, el crédito podría entenderse como pagos de préstamos al cliente seguidos de reembolsos al banco. Lo mismo con los seguros, si es demasiado costoso para los bancos y las compañías de seguros realizar (o aceptar) estos pagos, no ofrecerán el servicio financiero subyacente.

De este modo, los hogares de mayor poder adquisitivo viven su vida financiera incluidos en un sistema financiero que facilita su actividad económica al hacer que sea barato y sencillo para ellos enviar y recibir pagos. De igual modo, su dinero se encuentra salvaguardado en una cuenta bancaria virtual, donde puede ser transferido de manera sencilla mediante cualquier dispositivo con conexión a internet.

Por el contrario, los hogares excluidos de ese sistema financiero ahorran y transfieren valor a través de activos físicos, como dinero en efectivo o bienes. A la vez de incrementar la inseguridad propia y delictiva relacionada al uso del efectivo, la pobreza no se beneficia de las bondades de las finanzas para suavizar su consumo mediante el ahorro, aminorar el impacto de los avatares de la vida mediante los seguros, y por supuesto de ver realizados sus proyectos económicos de vida mediante el crédito.

Esta brecha financiera y digital que crea la carencia de instrumentos seguros de pago (relacionada consecuentemente al uso del efectivo) promueve al menos dos canales de desigualdad y exclusión social que se refuerzan mutuamente en la vida financiera de los hogares pobres.

Un primer canal hace que sea más costoso y arriesgado para los hogares pobres realizar actividades financieras básicas en efectivo. Como se dijo, esto va desde enviar dinero a familiares o socios, hasta financiar una inversión en un emprendimiento o bien sostener un hábito de ahorro para contingencias o un proyecto económico:

i) Los hogares pobres dependientes del efectivo tienen múltiples opciones de ahorro. Pueden almacenar dinero debajo del colchón, acumular joyas o bienes, o confiar su dinero a proveedores informales, como guardias de dinero o grupos informales de ahorro. Desafortunadamente, estos mecanismos de almacenamiento informal están expuestos a un riesgo por inseguridad y falta de contratos considerablemente mayor en comparación al sistema financiero formal (Wright and Mutesasira, 2001).

ii) De igual modo, pensando en las remesas y transferencias, el efectivo agrega costo económico a cualquier transacción a distancia. Los agentes dependientes del efectivo se ven obligados a utilizar mecanismos informales más costosos como redes de autobuses y mensajeros, que tienden a ser lentos, caros y también más riesgosos (Gopinath et al, 2010)

iii) Por último, el uso de efectivo en la pobreza limita el hábito de ahorro. Cuando el dinero nace digitalmente a través de depósitos directos de salarios, pensiones u otros pagos digitales, 
esto ayuda a superar la tentación de gastar dinero en efectivo porque los fondos pasan por fuera de nuestras manos y van directamente a una cuenta. Numerosos estudios sobre el comportamiento del ahorro en los países desarrollados revelan que las tasas de ahorro son considerablemente más altas cuando se facilitan servicios financieros de ahorro (Madrian y Shea, 2002; Bernartzi y Thaler, 2004) $)^{7}$.

Por el contrario, el dinero de los pobres nace físico, lo que significa que tienen que tomar medidas más activas cada vez que quieren ahorrar (guardando dinero en efectivo debajo de su colchón, dándoselo a un guarda dinero o contribuyendo a un grupo de ahorro informal). Esto obliga a los hogares pobres a superar los retos de autocontrol una y otra vez en medio de demandas de consumo apremiantes (de alimentos, de vivienda, enfermedad, salud) y de peticiones de amigos y vecinos que también son pobres y víctimas de estos avatares. Hay evidencia de que a los pobres les resulta más difícil ahorrar, en parte, porque deben superar los desafíos del autocontrol una y otra vez (Vohs y Faber, 2007; Vohs et al, 2008),

En segundo lugar, el uso del efectivo en las poblaciones más vulnerables no sólo hace más difícil administrar sus finanzas, sino también perpetúa la exclusión y la marginación de los pobres de la economía formal:

i) Cualquier proveedor que desee servir a un cliente en efectivo debe primero establecer una infraestructura física para interactuar con este efectivo. Por lo tanto, la brecha digital generada por el uso del efectivo abre una brecha entre los hogares pobres y la economía formal al obligar a los bancos, los proveedores de servicios públicos y otras instituciones a desplegar una costosa infraestructura para almacenar, transportar y procesar su efectivo. Este costo a la oferta refuerza los motivos de exclusión en los excluidos.

ii) El otro motivo que refuerza la exclusión es que el manejo de efectivo implica que los proveedores sepan muy poco sobre sus clientes. Esto se debe a que las transacciones en efectivo no dejan ningún registro digital. Un proveedor encontrará mayor dificultad para si un agente en situación de pobreza y/o excluido financieramente paga regularmente y a término sus préstamos al prestamista informal o si envía dinero a su familia al final de cada mes. Esta asimetría de información hace que los proveedores agrupen a los clientes de bajo y alto riesgo en el mismo grupo de riesgo, aumentando así el costo que los clientes de bajo riesgo deben pagar para acceder a los servicios financieros e impidiendo que algunos proveedores atiendan a este segmento de clientes en su totalidad.

Esta deficiencia del mercado que encarece al proveedor servir al agente en situación de pobreza es clara con los seguros y los créditos, pero también aplica a los productos de ahorro y pago que plantean riesgos de fraude y blanqueo de dinero a los proveedores que no tienen visibilidad de los historiales financieros de sus clientes.

\footnotetext{
${ }^{7}$ Vale mencionar que existe también literatura que despierta alguna alerta sobre el uso de pagos digitales enfatizando la necesidad de promover educación financiera digital. Por ejemplo: a) Mayor probabilidad de tomar una decisión menos conveniente usando teléfonos inteligentes (Benartzi y Lehrer, 2015; Benartzi, 2015; Mirsch, Lehrer y Jung, 2017); b) Mayor cantidad de opciones financieras y mayor confusión a la hora de tomar la mejor elección. En suma, mayor probabilidad de tomar la alternativa financiera bastante más cara (Madrian et al., 2017; Bhargava, Conell-Price, Mason y Benartzi, 2018); c) Las pantallas táctiles tienden a sobrevalorar el producto a adquirir (Brasel y Gips, 2014); d) El procesamiento y retención de información escrita es menos efectiva en un dispositivo digital que en papel (Mangen, Walgermo y Brønnick, 2013); e) Mayor probabilidad de elegir un producto ofrecido en una publicidad digital que otra alternativa mejor cercana (Benartzi y Lehrer, 2015); f) mayor incentivo al gasto con tarjetas (Khan, 2011; Runnemark, Hedman,y Xiao, 2015)
} 
En esta línea, es cierto que conectar a los pobres con un sistema financiero digital no resolverá todas las barreras de costo para llegar con servicios financieros, servicios públicos o de cualquier otro tipo. Sin embargo, eliminará costos sustanciales del sistema, allanando el camino para esfuerzos comerciales más robustos a la hora de servir a los pobres. Por estos motivos es que cada vez más se asume que conectar a los pobres a un sistema financiero digital mediante instrumentos de pagos generará importantes beneficios sociales y económicos (Radcliffe y Voorhies, 2012; Gabor y Brooks, 2017)

En resumen, la inclusión financiera y los pagos digitales están en la agenda pública a nivel nacional desde los últimos años y, con igual énfasis, en el proceso de urbanización del Barrio 31 más recientemente. Es en este sentido que el aporte de esta investigación cobra total relevancia a la luz de los procesos de fomento e integración social mencionados. A continuación, se presentará nuestro análisis empírico.

\section{II.3. Antecedentes en Argentina}

Desde el año 2016, el Banco Central de la República Argentina (BCRA) viene impulsando un conjunto de medidas orientadas a promover el uso de Medios de Pago Electrónicos como un pilar fundamental para lograr una mayor inclusión financiera. Sucede que, como se adelantó, la inclusión financiera se posicionó como objetivo de política financiera de la entidad a la par de la estabilidad, desarrollo y eficiencia del sistema financiero nacional ${ }^{8}$.

Así, durante los años 2016 y 2017, se realizaron muchos avances en la normativa que promueve la inclusión financiera. Por ejemplo, se aumentó el monto máximo de acreditaciones y el saldo máximo de la Cuenta Gratuita Universal; se amplió el carácter gratuito de las transferencias bancarias inmediatas; se implementó una política de localización de sucursales bancarias en zonas desfavorables; se suprimieron costos por extracciones en todos los cajeros para los clientes de cuentas destinadas a la acreditación de haberes, jubilaciones y planes sociales; el BCRA realizó convenios para promover la Educación Financiera, entre muchas otras iniciativas.

No obstante, las medidas más destacadas fueron aquellas de impulso a la digitalización financiera. Específicamente, la institución considera que consolidar una red de pagos electrónicos moderna es condición necesaria para una política efectiva de inclusión financiera, ya que la ampliación de la red de aceptación de estos pagos es fundamental para potenciar su acceso de los excluidos y el uso por quienes se encuentran bancarizados de manera precaria (es decir, sin hacer uso de sus cuentas bancarias o de sus medios de pago asociados). De igual modo, el Banco Central considera que promover los medios de pago electrónicos ayuda también a obstaculizar el crimen organizado, el narcotráfico y el lavado de dinero, formalizar la economía y emparejar y moderar la carga tributaria, entre otras bondades 9 .

De esta manera, durante 2016 y 2017 se destacan iniciativas como la posibilidad de debitar de cajas de ahorro originadas para el pago de planes o programas de ayuda social el pago de impuestos, servicios y otros conceptos por canales electrónicos o débito automático; la apertura

\footnotetext{
${ }^{8}$ Véase sección de "Política Financiera" del BCRA

https://www.bcra.gob.ar/SistemasFinancierosYdePagos/Politica_Financiera.asp\#c

${ }^{9}$ Véase sección "Medios de Pagos Electrónicos" del BCRA

https://www.bcra.gob.ar/SistemasFinancierosYdePagos/Sistema_de_Pagos_medios_de_pago_electronicos.asp
} 
de cajas de ahorro a través de medios electrónicos y flexibilización de requisitos; la creación del ALIAS asociados al CBU para realizar transferencias y pagos; del medio de pago Débito Inmediato (DEBIN); la habilitación de una Plataforma de Pagos Móviles (PPM) para que las entidades financieras ofrezcan servicios de transferencias inmediatas de fondos y/o pago de bienes y servicios a cuentas de terceros adheridos al PPM; la implementación del POS-Móvil, el Botón de Pago y la Billetera Electrónica; entre otros.

Por su parte, durante el año 2018 se continuó en esta línea destacando el lanzamiento de los códigos QR interoperables permitiendo pagos electrónicos con cualquier Smartphone y cualquier billetera digital, a la vez de la creación de la Clave Virtual Uniforme (CVU) que habilita transferencias de dinero entre cuentas bancarias y virtuales de empresas no bancarias (Proveedores de Servicios de Pago). Como puede observarse, la batería de medidas para la digitalización de los pagos para la inclusión financiera se destaca en iniciativas de fomento a la competencia en la industria financiera, así como en el mercado de tarjetas de crédito y débito.

A pesar de este impresionante avance normativo de fomento a la inclusión financiera digital, la bancarización y el uso de pagos digitales en Argentina todavía es bajo en relación a otras economías. Por ejemplo, según los resultados del mencionado informe Global Findex 2017 del Banco Mundial.

Lo primero a señalar es que en Argentina sólo el 48.7\% de los adultos declaró tener una cuenta en institución financiera o por medio de algún proveedor móvil al 2017. También que, entre aquellos que estos, un $19.2 \%$ reportó no realizar movimiento alguno durante el último año (electrónicos o retiros en efectivo). En términos de tarjetas, sólo el $41.4 \%$ reportó tener de débito y un $24 \%$ de crédito, pero al indagar sobre su uso durante el último año los guarismos caen al $21.6 \%$ y $21 \%$ respectivamente.

Con ratios de acceso y uso tan reducidos, es lógico que el abordaje digital se esgrima como la gran promesa. Entre los encuestados con cuenta en institución financiera, el porcentaje que reportó haber usado un teléfono móvil o Internet para acceder a su cuenta en los últimos 12 meses ascendió al 21\%. Si bien el promedio en América Latina es del 19\%, este guarismo posiciona a Argentina como la sexta economía con mayor acceso a servicios financieros digitalmente.

Por otro lado, al indagar sobre el uso de Internet para pagar cuentas o comprar artículos online, encontramos que durante el periodo 2014-17 el guarismo se incrementó más de un 120\%. Este importante aumento implicó saltar del $8.4 \%$ al $18.6 \%$ de la población adulta. En términos comparativos también posiciona a Argentina como el sexto país con mayor uso de Internet para compra de productos o pago de cuentas en línea en América Latina.

Otro aspecto a destacar de los resultados del Global Findex 2017, es el ratio de adultos encuestados que declaran haber utilizado personalmente un servicio de dinero móvil en los últimos 12 meses. Este guarismo creció del $0.4 \%$ al 2.4\%. Si bien es un incremento relativo importante, Argentina queda aún muy rezagada en términos comparativos a otras economías de la región, encontrándose anteúltima en uso de dinero móvil frente a sus pares latinoamericanos.

En esta línea, en agosto del 2019 el Instituto Nacional de Estadísticas y Censos (INDEC) presento los resultados preliminares de la Encuesta Nacional de Gastos de los Hogares 20172018 con información inédita sobre qué medios de pago utilizan los argentinos para consumir ${ }^{10}$. A partir de los resultados preliminares se observa que el $69 \%$ del consumo que se realiza en el territorio nacional se paga con dinero en efectivo. Con mucho menos uso el pago con tarjeta de

${ }^{10}$ Ver "Gastos de los hogares" de INDEC https://www.indec.gob.ar/indec/web/Nivel4-Tema-4-45-151 
crédito que representa el 11\%, tarjeta de débito el 8\%, el 5\% con transferencia electrónica, el 4\% utilizando libreta (comúnmente denominado "fiado"), y un 3\% otros métodos de pagos que el informe no especifica.

Por último, el viernes 27 de septiembre de 2019 el Banco Central presentó un informe inédito de pagos minoristas para el primer semestre del $2019^{11}$. Este trabajo revela que el uso de medios de pagos electrónico a nivel nacional presentó un crecimiento agregado del $16 \%$. Específicamente, creció un 49\% la cantidad de transferencias de acreditación en línea respecto al mismo semestre del año anterior, $74 \%$ la cantidad de transacciones con tarjetas prepagas, los pagos inter billeteras digitales entre cuentas crecieron un $279 \%$, y un $146 \%$ como iniciadoras de transacciones de pago con tarjeta.

Por su parte, vale mencionar que la Estrategia Nacional de Inclusión Financiera hace un fuerte énfasis en el rol de la tecnología y las Fintech como motor. En este contexto, siguiendo declaraciones oficiales de la Cámara Fintech Argentina, en noviembre 2018 había 133 empresas en nuestro país, lo cual implicó un crecimiento del 110\% respecto a 2017. Argentina, representaría el cuarto ecosistema Fintech más importante de América Latina. Según la Cámara Argentina de Fintech, en el año 2018 el ecosistema local estaba conformado por 133 empresas, de las cuales, el $81 \%$ se radicaban en la ciudad capital y en la provincia de Buenos Aires. Mientras que otro $10 \%$ se repartía en partes iguales entre las provincias de Córdoba y Mendoza ( 7 empresas en cada una). Estas firmas se distribuían en un $24 \%$ bajo la categoría préstamos, un $20 \%$ bajo la categoría Pagos y Transferencias, un 20\% en Servicios Fintech B2B y un $11 \%$ en Inversiones (BID y FINNOVISTA, 2018).

De acuerdo a declaraciones de prensa posteriores el sector no ha dejado de crecer, según la Cámara Fintech, para noviembre 2019 el número de empresas ya era de 223 compañías. Recientemente, adelantos de la investigación que está llevando la Cámara junto al BID informan que para julio 2020 ya habría más de 260 compañías en nuestro país, habiéndose multiplicado por dos desde el relevamiento del 2018. Actualmente, según estimaciones privadas realizadas por la Cámara Fintech Argentina, se cree que las billeteras virtuales (que ofrecen cuentas con $\mathrm{CVU}$ ) atenderían a 7 millones de usuarios ${ }^{12}$.

Efectivamente y en base a los datos relevados, más allá del contundente ingreso del objetivo de promover la inclusión financiera digital en Argentina y todas las iniciativas subsiguientes, todavía queda mucho margen para incluir financieramente a la población mediante medios de pago electrónicos. Más aún en las poblaciones más vulnerables, las cuales están a su vez mayormente relegadas de los (pocos) diagnósticos existentes en nuestro país.

\section{Análisis empírico \\ III.1. Metodología}

Reconociendo la importancia de los pagos digitales para la inclusión financiera, y la necesidad de una medición robusta y profunda sobre los mismos en poblaciones vulnerables, es que se creó

\footnotetext{
11 Véase "Primer informe de Pagos Minoristas" del BCRA http://www.bcra.gov.ar/Noticias/Informe-pagosminoristas-012019.asp

${ }^{12}$ Véase "Radiografía de las billeteras virtuales, un boom en medio del aislamiento" publicado el 22 de abril del 2020 https://www.ambito.com/negocios/billetera-virtual/radiografia-las-billeteras-virtuales-un-boom-medio-delaislamiento-n5097541
} 
el Cuestionario de Pagos Digitales para el Barrio 31. El objeto de este instrumento es comprender en profundidad las barreras y bondades (efectivas y percibidas) que enfrentan los pagos digitales en esta población como medio para mejorar el diseño de futuras políticas públicas de inclusión financiera a través de instrumentos de pago digital en barrios vulnerables.

Nuestro cuestionario se creó combinando cuatro relevamientos: a) Pagos Digitales en India, Proyecto Goldberg N ${ }^{\circ} 171112324^{13}$; b) Reporte de Consumidores y Pagos Móviles del 2016 de la Reserva Federal de los Estados Unidos de América ${ }^{14}$; c) Global Payments Systems Survey del Banco Mundial ${ }^{15}$; d) y el Global Findex $2017^{16}$ de la misma institución. A su vez, se incorporaron distintas variables de creación propia en base a la experiencia práctica de los autores en este asentamiento en específico y el piloto de prueba realizado sobre una selección reducida de comercios.

Nuestra encuesta amplía y ajusta los cuatro cuestionarios mencionados transformándolo así en un instrumento inédito. En términos generales, nos permitió estudiar las siguientes dimensiones divididas en cinco módulos, sumando 85 preguntas en total:

1. Primer Módulo: Análisis socio demográfico (12 preguntas)

2. Segundo Módulo: Análisis de la actividad económica (13 preguntas)

3. Tercer Módulo: Análisis del acceso a servicios financieros (22 preguntas)

4. Cuarto Módulo: Análisis del uso de la telefonía móvil e internet (12 preguntas)

5. Quinto Módulo: Análisis del uso de los medios de pago digitales (26 preguntas)

El relevamiento de información se realizó entre las fechas 6 de julio y 11 de agosto del 2019. Como dijimos, semanas previas a dicha fecha, se realizó un piloto a cinco comercios con el propósito explorar nuevas variables a incorporar, evaluar la comprensión de las preguntas, e identificar términos que podrían generar confusión en la población específica del Barrio 31.

Para nuestra muestra se relevaron 104 comercios. Si bien no es una muestra estadísticamente representativa del Barrio 31, la misma se realizó en todos los sectores del barrio teniendo en cuenta su distribución entre feriantes, locales y manteros, así como su ubicación entre los distintos sectores del Barrio. La población relevada se distribuyó del siguiente modo:

\footnotetext{
13 Véase "India Digital Payments Merchant Survey Questionnaire" https://static.globalinnovationexchange.org/s3fspublic/asset/document/7.\%20USAID\%20India\%20Digital\%20Paym ents\%20Merchant\%20Survey\%20Questionnaire.pdf?eh41Mw.UCUETgSSmh_3jLlcL6dAEHnza

${ }^{14}$ Véase "Consumers and mobile financial services report"

https://www.federalreserve.gov/econresdata/consumers-and-mobile-financial-services-report-201603.pdf

${ }^{15}$ Véase "Global Payment System Survey Questionnarie"

http://pubdocs.worldbank.org/en/340581458138663080/payment-systems-GPSS-2012-questionnaire.pdf

16 Véase "2017 Global Findex Questionnarie"

https://globalfindex.worldbank.org/sites/globalfindex/files/databank/2017\%20Findex\%20questionnaire.pdf
} 
Tabla 1. \% por sector y espacio económico

\begin{tabular}{|c|c|c|c|c|c|c|c|c|}
\hline \multirow{3}{*}{$\begin{array}{l}\text { Sector } \\
\text { Comunicaciones }\end{array}$} & \multirow[b]{2}{*}{$\begin{array}{c}\% \text { de total de } \\
\text { comercios }^{17}\end{array}$} & \multirow[b]{2}{*}{$\begin{array}{c}\% \text { de total } \\
\text { encuestados }\end{array}$} & \multicolumn{6}{|c|}{ Espacio de la actividad económica \% por sector } \\
\hline & & & $\begin{array}{l}\text { Comercio a la } \\
\text { calle: }\end{array}$ & \multicolumn{2}{|c|}{$\begin{array}{l}\text { Puesto en la } \\
\text { Feria }\end{array}$} & \multicolumn{2}{|c|}{ Vía publica } & A domicilio \\
\hline & $1,6 \% \quad(n=13)$ & $2,9 \% \quad(n=3)$ & $66,6 \% \quad(\mathrm{n}=2)$ & $0,00 \%$ & $(n=0)$ & $33,3 \%$ & $(\mathrm{n}=1)$ & $0,00 \% \quad(\mathrm{n}=0)$ \\
\hline Cristo Obrero & $8,1 \% \quad(\mathrm{n}=67)$ & $13,5 \% \quad(\mathrm{n}=14)$ & $100,0 \% \quad(n=14)$ & $0,00 \%$ & $(\mathrm{n}=0)$ & $0,0 \%$ & $(\mathrm{n}=0)$ & $0,00 \% \quad(\mathrm{n}=0)$ \\
\hline Ferroviario & $4,3 \% \quad(\mathrm{n}=36)$ & $8,7 \% \quad(\mathrm{n}=9)$ & $77,7 \% \quad(\mathrm{n}=7)$ & $0,00 \%$ & $(n=0)$ & $22,2 \%$ & $(\mathrm{n}=2)$ & $0,00 \% \quad(\mathrm{n}=0)$ \\
\hline Güemes $^{18}$ & $55,4 \% \quad(\mathrm{n}=459)$ & $23,1 \% \quad(\mathrm{n}=24)$ & $50,0 \% \quad(\mathrm{n}=12)$ & $45,8 \%$ & $(\mathrm{n}=11)$ & $4,2 \%$ & $(\mathrm{n}=1)$ & $0,00 \% \quad(\mathrm{n}=0)$ \\
\hline Inmigrantes & $1,6 \% \quad(\mathrm{n}=13)$ & $4,8 \% \quad(\mathrm{n}=5)$ & $100,0 \% \quad(\mathrm{n}=5)$ & $0,0 \%$ & $(\mathrm{n}=0)$ & $0,0 \%$ & $(\mathrm{n}=0)$ & $0,0 \% \quad(\mathrm{n}=0)$ \\
\hline Playón Este & $9,5 \% \quad(\mathrm{n}=79)$ & $12,5 \% \quad(n=13)$ & $92,3 \% \quad(n=12)$ & $0,0 \%$ & $(n=0)$ & $7,70 \%$ & $(\mathrm{n}=1)$ & $0,0 \% \quad(\mathrm{n}=0)$ \\
\hline Playón Oeste & $7,1 \% \quad(\mathrm{n}=59)$ & $4,8 \% \quad(\mathrm{n}=5)$ & $100,0 \% \quad(\mathrm{n}=5)$ & $0,0 \%$ & $(n=0)$ & $0,0 \%$ & $(\mathrm{n}=0)$ & $0,0 \% \quad(\mathrm{n}=0)$ \\
\hline San Martin & $5,2 \% \quad(\mathrm{n}=43)$ & $21,2 \% \quad(n=22)$ & $95,5 \% \quad(\mathrm{n}=21)$ & $0,0 \%$ & $(\mathrm{n}=0)$ & $4,50 \%$ & $(\mathrm{n}=1)$ & $0,0 \% \quad(\mathrm{n}=0)$ \\
\hline YPF & $4,2 \% \quad(\mathrm{n}=35)$ & $8,7 \% \quad(\mathrm{n}=9)$ & $66,7 \% \quad(\mathrm{n}=6)$ & $0,0 \%$ & $(\mathrm{n}=0)$ & $0,0 \%$ & $(\mathrm{n}=0)$ & $33,3 \% \quad(n=3)$ \\
\hline Total & $100 \% \quad(=804)$ & $100 \% \quad(n=104)$ & $81,0 \% \quad(n=84)$ & $11 \%$ & $(\mathrm{n}=11)$ & $6 \%$ & $(\mathrm{n}=6)$ & $3 \% \quad(n=3)$ \\
\hline
\end{tabular}

Fuente: Elaboración propia en base al Cuestionario de Pagos Digitales del Barrio 31

\section{III.2. Hipótesis}

Se buscó contrastar seis hipótesis que se dividen en tres categorías de análisis.

En esta línea, las primeras dos hipótesis nos brindan información sobre el contexto y las características que son determinantes en cuanto inclusión financiera y digitalización de la población relevada. La tercera y cuarta hipótesis sobre el efecto multiplicador de que los comercios acepten pagos digitales en relación a otras dimensiones de la inclusión financiera. Esto es, tanto incrementando su acceso y uso de otros servicios financieros formales como también la utilización del dinero electrónico para realizar transacciones cotidianas por parte del comerciante. Finalmente, las últimas dos hipótesis nos brindan información sobre cuáles son los principales incentivos que perciben los comerciantes para adoptar o estar interesados en comenzar a aceptar pagos digitales en sus comercios.

A continuación, se listan las seis hipótesis de trabajo que, a su vez, dividirán las secciones en la presentación de resultados:

○ Hipótesis 1: Teléfono Móvil y Acceso al Mundo Digital: "El teléfono celular es el principal acceso al mundo digital de los comerciantes. La mayoría no tiene algún otro dispositivo con acceso a internet"

\footnotetext{
${ }^{17}$ Datos en base a los comercios relevados en el Informe, previamente citado, "Actividad Económica en el Barrio 31" realizado por el Centro de Investigación de Política Urbana y Vivienda de la Universidad Torcuato Di Tella. Nota de prensa aquí https://www.utdt.edu/ver_nota_prensa.php?id_nota_prensa=15452\&id_item_menu=6

${ }^{18}$ En el sector Güemes funciona la feria del barrio denominada "Feria Latina" que tiene 347 puestos habilitados, estos son contabilizados como comercios en el sector en el informe citado.
} 
○ Hipótesis 2: Pagos Digitales y Educación Digital: "Los comercios que no aceptan ni les interesa aceptar medios de pago digitales, a su vez, no se auto perciben suficientemente capacitados a nivel tecnológico"

○ Hipótesis 3: Pagos Digitales y Servicios Financieros: "Los comerciantes que aceptan medios de pago digitales luego hacen y demandan un uso mayor de otros servicios que ofrecen las entidades financieras formales"

- Hipótesis 4: Pagos Digitales y uso del dinero digital para Ventas y Compras: "Los comerciantes que aceptan medios de pago digitales, luego tienen mayor propensión a utilizar dinero electrónico en otros ámbitos, generando un efecto multiplicador"

○ Hipótesis 5: Pagos Digitales, Uso de Efectivo y Seguridad: "El efectivo es el medio de pago más utilizado por los comerciantes a pesar de que la mayor parte sufrió algún inconveniente y/o delito que le generó pérdidas (robos, billetes falsos, pérdidas, etc.). Los comerciantes valoran los medios de pagos digitales principalmente porque pueden ser una herramienta para mejorar la seguridad"

- Hipótesis 6: Pagos Digitales y Ventas Esperadas: "La percepción sobre la posibilidad de tener un crecimiento en las ventas es una de las principales motivaciones que encuentran los comerciantes que no aceptan pagos digitales, pero quisieran adoptar nuevos medios de pago digitales"

Vale destacar que, a la vez de contrastar nuestras hipótesis de investigación, este estudio generó el primer diagnóstico sobre el rol de los pagos digitales en un universo de comerciantes de algún asentamiento urbano del país. Por este motivo, aunque no representativa, la caracterización de nuestra muestra cobra valor en sí misma como diagnóstico inédito sobre la penetración y el uso de los pagos digitales en comerciantes de barrios vulnerables. Esto a su vez destaca el aporte de valor que tendría replicar este estudio en poblaciones de comerciantes más amplias en otros asentamientos urbanos.

\section{I.V. Resultados}

\section{IV.1. Características de la Muestra}

Se encuestaron 104 comerciantes del Barrio 31. Sólo el 24\% en total respondió que acepta pagos digitales. Este $24 \%$ se compone por usuarios de posnets inalámbricos $94 \%$ (21,2\% del total de la muestra), usuarios de mPos para el celular $20 \%$ (4,8\% del total de la muestra) y usuarios de Código QR 8\% (1,9\% de la muestra total). (Ver tabla A.1 Apéndice A)

Del total de encuestados, el 59\% fueron mujeres y el $41 \%$ hombres. En cuanto al nivel educativo, el $32,2 \%$ tiene sus estudios hasta primarios completos, el $88 \%$ hasta nivel secundario terminado, el $11,6 \%$ realizo o está realizando estudios universitarios y el $4 \%$ no inicio ni completo ningún nivel de estudios. (Ver tabla A.2, y A.3 Apéndice A).

El rango etario se distribuye principalmente entre los mayores de 25 y menores de 45 años de edad, que representan al $51 \%$ de la muestra. Luego, el $21 \%$ tiene entre 45 y 54 años y el $16 \%$ entre 55 y 64 . En los extremos se ubican el $7 \%$ entre 18 y 24 y el $5 \%$ entre 65 y 74 años de edad. (Ver tabla A.4, Apéndice A)

En cuanto al nivel de ingreso declarado, si bien hubo un $18 \%$ que no sabía o prefirió no responder, el $82 \%$ restante se distribuye entre un $35 \%$ que declaro tener un ingreso mayor a los $\$ 12.500$ pesos mensuales, un $18 \%$ un ingreso que va entre los $\$ 10.000$ y $\$ 12.500$, un $11 \%$ entre 
$\$ 7.500$ y $\$ 10.000$, un $7 \%$ entre $\$ 5.000$ y $\$ 7.500$, un $7 \%$ entre $\$ 2.500$ y $\$ 5.000$ y un 5\% entre $\$ 0$ y $\$ 2500$. Del total encuestado el $22 \%$ declaro recibir algún tipo de apoyo económico del gobierno, excluyendo jubilaciones o pagos relacionados a un trabajo. (Ver tabla A.5 y A.6, Apéndice A)

Para describir los rubros de actividad, en la Figura 1 podemos observar el porcentaje de comercios encuestados por categoría. Los trece cuadrados que representan un $1 \%$ que no tienen descripción son los trece rubros que solo se repitieron una vez entre los comerciantes ${ }^{19}$.

\section{Figura 1. \% de rubros comerciales}

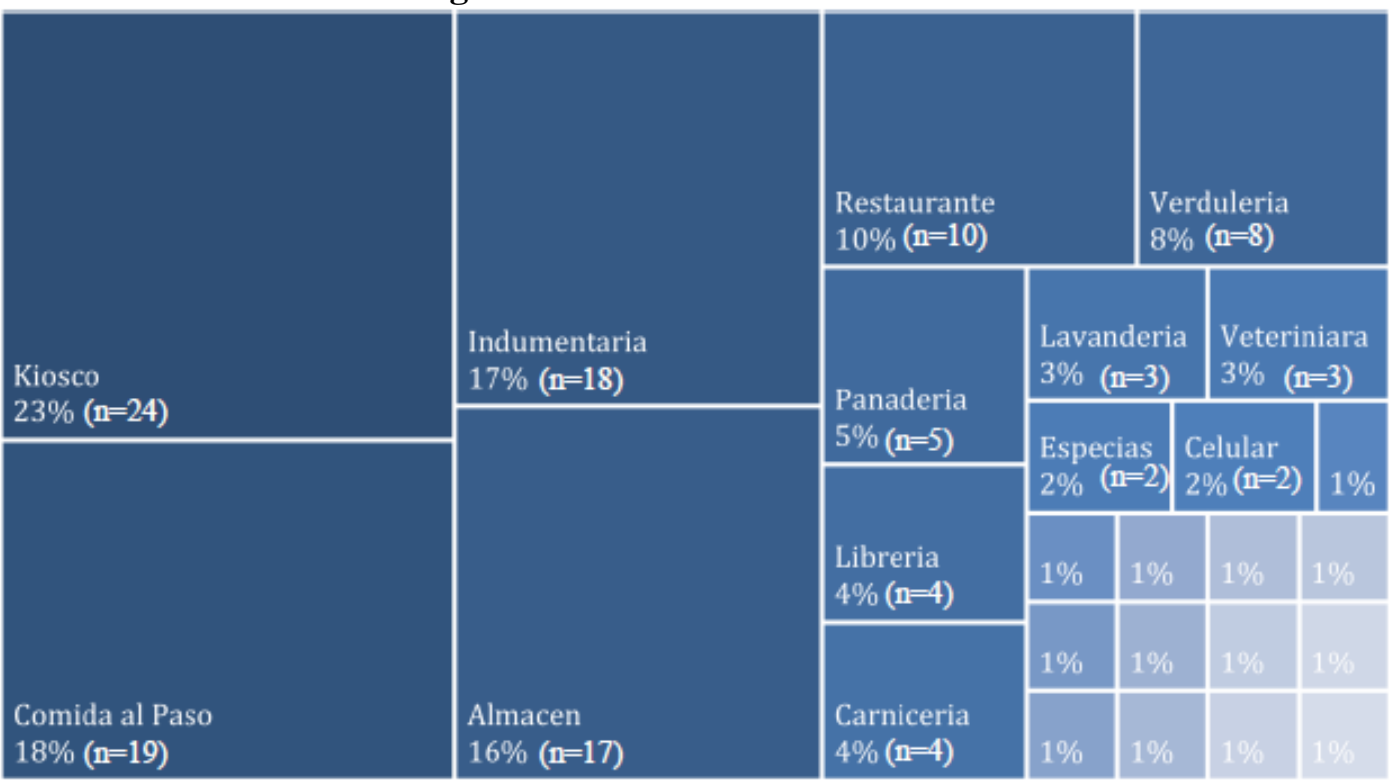

Fuente: Elaboración propia en base al Cuestionario de Pagos Digitales del Barrio 31

En cuanto a la formalidad de las actividades comerciales, el 55\% declara no estar formalizadas ante la AFIP, el 25\% está registrado como Monotributista tradicional, el $13 \%$ como Monotributista Social, y el $7 \%$ no brindo respuesta. Es importante agregar que el $96 \%$ de los comerciantes tenían DNI. Y únicamente el $11 \%$ de los comerciantes declaro tener empleados. (Ver Tabla A.8 y A.9, Apéndice A).

Sobre el espacio en donde se lleva adelante la actividad, el $81 \%$ se desarrollan desde un establecimiento comercial, el $11 \%$ desde un puesto en la feria del barrio, el $6 \%$ en la vía pública, y el $3 \%$ en el domicilio del cliente.

En cuanto a la ganancia declarada, el $27 \%$ respondió que obtiene una ganancia mayor a los $\$ 10.000$, el $9 \%$ entre $\$ 7.500$ y $\$ 10.000$, el $10 \%$ entre $\$ 5000$ y $\$ 7500$, el $6 \%$ entre $\$ 2.500$ y $\$ 5.000$, el $13 \%$ menor a $\$ 2.500$ y el $36 \%$ dijo que no sabía cuál era su ganancia o prefería no responder. Respecto al volumen de atención, el $21 \%$ dijo que recibe más de 40 personas por día. El $7 \%$ entre

\footnotetext{
${ }^{19}$ A saber, Cerámica, Cotillón, Cyber, Farmacia, Ferretería, Juguetería, Mueblería, Pastelería, Peluquería, Perfumería, Limpieza, Lavandería Repostería, y Heladería.
} 
30 y 40. El $23 \%$ entre 20 y 30. El 27\% e entre 10 y 20 Y el 22\% menos de diez. (Ver Tabla A.10 y A.12, Apéndice A)

\section{IV.2. Hipótesis 1: Teléfono Móvil y Acceso al Mundo Digital: "El teléfono celular es el principal acceso al mundo digital de los comerciantes. La mayoría no tiene algún otro dispositivo con acceso a internet"}

Para estudiar los pagos digitales en cualquier población, es fundamental primero conocer con que herramientas digitales se cuenta. Como se extrae de la Figura 2, un primer dato sumamente relevante a destacar es que el $87 \%$ de los comercios encuestados tiene un teléfono inteligente, mientras que sólo el $43 \%$ posee una computadora, el $19 \%$ una Netbook ${ }^{20}$, el $11 \%$ una Tablet, y el 7\% no posee ningún dispositivo. Cuando se pregunta si los dispositivos están disponibles en donde realizan su actividad económica (en el establecimiento comercial), la disponibilidad de teléfono celular se mantiene en $87 \%$, pero la de una computadora decrece al $13 \%$, la de una netbook al $0 \%$ y la de una Tablet al $1 \%$.

\section{Figura 2. \% de tenencia de dispositivos tecnológicos}

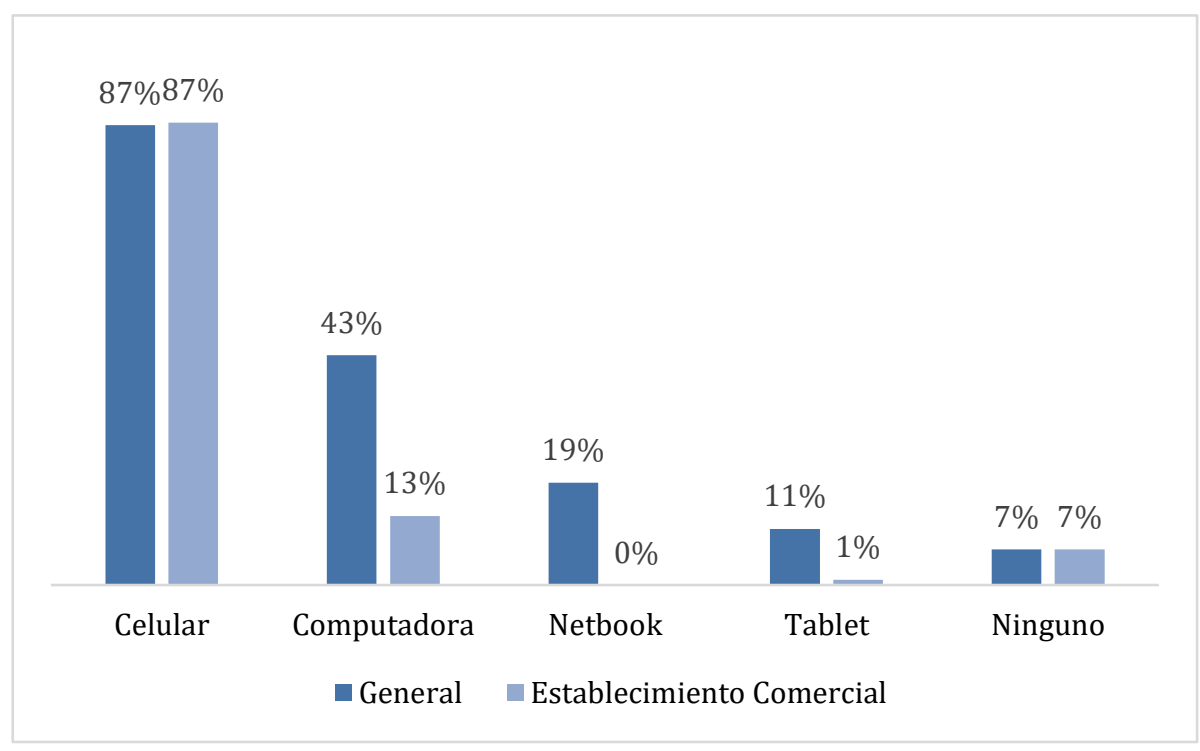

Fuente: Elaboración propia en base al Cuestionario de Pagos Digitales del Barrio 31

Es muy importante denotar que el 50\% de los comercios encuestados no tienen ni una computadora, ni una netbook, ni una Tablet, pero (de esa mitad sin otro tipo de dispositivo) el

\footnotetext{
${ }^{20}$ Se diferenció "Netbook" de computadora, porque tanto el plan de educación digital del Gobierno Nacional "Conectar Igualdad" como el del Gobierno de la Ciudad de Buenos Aires "Sarmiento" incluyen la entrega de una computadora estilo netbook a cada estudiante secundario de las Escuelas Públicas. Así, de acuerdo al piloto de prueba de nuestro instrumento, se notó que muchos vecinos identifican al computador con el nombre "Netbook" y se decidió diferenciar de este modo para evitar que algunos respondan que no tenían una computadora cuando en realidad si poseen las Netbook que entregan los respectivos planes de gobierno.
} 
$85 \%$ sí tienen un teléfono inteligente. En otras palabras, esto implica que el $40 \%$ de los comercios relevados tiene como único dispositivo digital con acceso a internet el celular.

\section{Figura 3. con acceso a internet únicamente a través del celular}

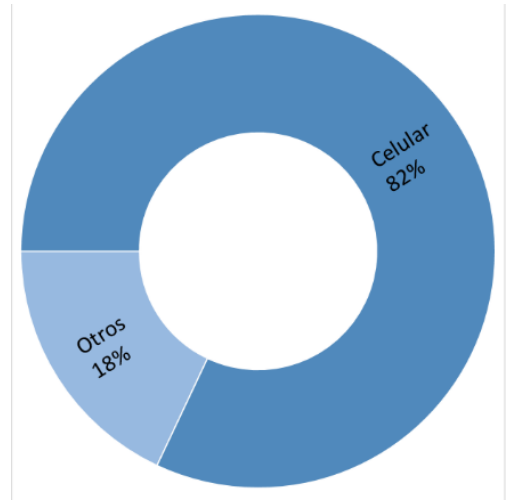

Fuente: Elaboración propia en base a encuesta Pagos Digitales del Barrio 31

Hacia adentro de este $40 \%$, cuando les preguntamos si tenían una cantidad suficientes de datos móviles, el 38\% respondió que no tenía la cantidad necesaria, el 33\% que llegaba con lo justo a fin de mes y el $29 \%$ que le sobraban. Si se suman los que sólo tiene un teléfono celular pero no llegan con los datos a fin de mes a los que no tienen celular ni ningún otro dispositivo, encontramos que un tercio, o el $29 \%$ de los comercios encuestados, no tiene acceso certero a internet.

Por otro lado, al indagar si poseen internet o señal satelital en su comercio, el $49 \%$ de los comerciantes relevados afirma que sí tiene acceso a internet desde donde realiza su actividad económica. En esta población con acceso a internet, la tenencia de un teléfono celular alcanza el $96 \%$, y el $82 \%$ depende únicamente del celular para acceder a internet ya que es el único dispositivo que les permite utilizarlo. Sólo el $18 \%$ restante puede acceder a través de una computadora o una Tablet.

De los que tienen internet, el 90\% desarrolla su actividad en su comercio mientras que esta cifra desciende al $71 \%$ entre quienes no tienen internet. El 6\% en el domicilio del cliente, cifra que desaparece $(0 \%)$ entre los que no tienen internet y arroja un $4 \%$ en la feria del barrio, que sube al $17 \%$ entre los que no tienen internet. Además, entre los segundos, se suma un $12 \%$ que corresponde a quienes desarrollan su actividad en la vía pública.

Un paso subsiguiente de análisis sería analizar cuántos comercios utilizan internet como una plataforma de ventas. En esta línea, el uso de internet para complementar la actividad comercial alcanza a menos de un tercio de los comerciantes, sólo el 27\% hizo alguna operación ya sea una compra o una venta a través de internet. Específicamente a través del celular, sólo el $12 \%$ hizo al menos una venta y el $17 \%$ una compra. Vale la pena resaltar que apenas el $1 \%$ de los comercios declara que hizo al menos una venta con computadora y solo el $8 \%$ una compra.

Así, aunque el guarismo es bajo en términos absolutos, vale destacar que el 54\% de las personas que comerciaron por internet lo hicieron exclusivamente a través celular mientras que sólo el $18 \%$ exclusivamente a través la computadora, y el $29 \%$ combinando los dispositivos. 
Nuevamente se observa un impactante predominio del celular como puerta de entrada a las herramientas digitales, en este caso para realizar actividades comerciales de compra o venta.

Finalmente, es importante estudiar cómo aún la tenencia masiva de teléfonos celulares no tiene impacto suficiente en las esferas de los pagos digitales y acceso a los servicios financieros formales para los comerciantes relevados del Barrio 31 .

En la Figura 4 podemos observar para qué utilizan prioritariamente el teléfono móvil los comerciantes. Mientras que en el último mes el $64 \%$ se sacó al menos una foto con el celular, envió un video o bien habló por Whatsapp, sólo el 2\% cobro con códigos QR, el 5\% cobró con un mPos y el $7 \%$ utilizó una Billetera Digital. Los teléfonos móviles no están siendo utilizados en lo absoluto para realizar pagos en actividades comerciales del Barrio 31.

Figura 4. \% de usos del teléfono celular / población total

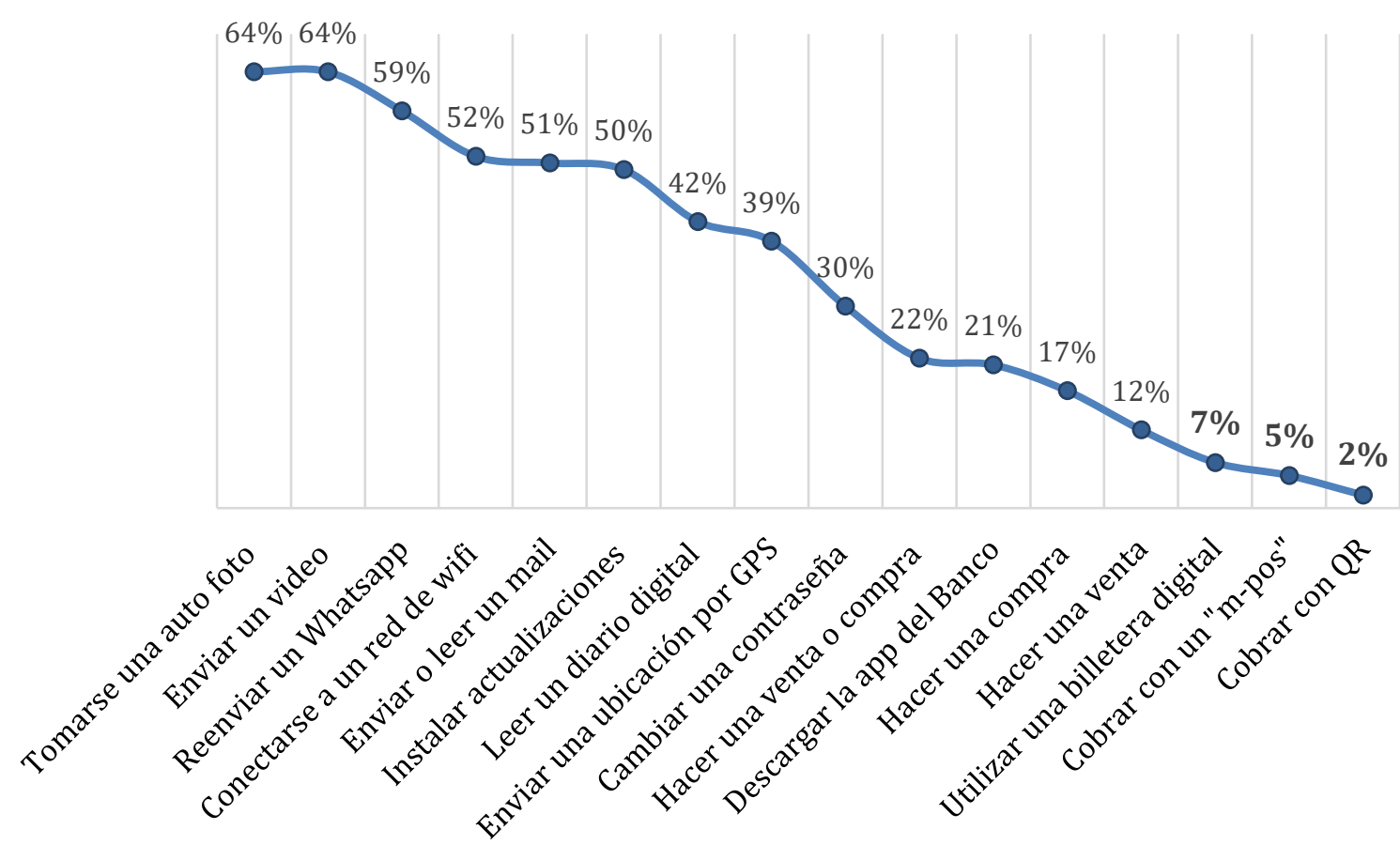

Fuente: Elaboración propia en base al Cuestionario Pagos Digitales del Barrio 31

Para resumir, en base al Cuestionario de Pagos Digitales del Barrio 31 podemos corroborar que el teléfono móvil es el gran acceso al mundo digital para los comerciantes. Incluso en muchos casos, es el único medio propio que tiene un comerciante para acceder a internet.

Sin embargo, esto no significa que porque haya más celulares hay o habrá más pagos digitales de forma espontánea. Al contrario, como vimos, los datos muestran una convivencia entre tenencia masiva de un teléfono móvil inteligente y un casi nulo uso del mismo para realizar compras, ventas, descargar una billetera digital, etc.

En conclusión, aunque sin lugar a dudas estos resultados muestran un inmenso potencial para impulsar pagos digitales a través de herramientas móviles, es importante denotar que al ser la única puerta de entrada al mundo digital de los comerciantes las iniciativas de fomento deberán 
contemplar y abordar adecuadamente el equilibrio entre uso personal y uso comercial del celular. Una estrategia coherente podría considerar la posibilidad de ampliar la cantidad de dispositivos móviles disponibles de los comerciantes para que tengan un dispositivo específicamente destinado al uso comercial, más allá de aquél de uso personal.

IV.3. Hipótesis 2. Pagos Digitales y Educación Digital: “Los comercios que no aceptan ni les interesa aceptar medios de pago digitales, a su vez, no se auto perciben suficientemente capacitados a nivel tecnológico"

Como se mencionó en la hipótesis anterior, la disponibilidad de herramientas digitales es el primer paso para la digitalización de los pagos. Además, producto de la alta penetración de teléfonos inteligentes, existe un potencial inmenso para incorporar pagos digitales en comerciantes del Barrio 31 mediante esta vía. En este sentido, la educación digital y la financiera se tornan factores fundamentales y obligadamente complementarios a la hora de impulsar un buen uso de los productos y servicios financieros.

En vísperas del fomentó público y privado a una inclusión financiera digital, además del acceso a nuevas herramientas digitales y/o móviles, el correcto entendimiento y la capacidad auto percibida (confianza) en torno al uso de los nuevos dispositivos digitales se torna una condición necesaria para acercar servicios financieros por este canal.

De nuestro relevamiento surge que el $90 \%$ de los comerciantes tiene un teléfono celular y el $87 \%$ un celular inteligente. De los que tenían un teléfono celular, sólo el $38 \%$ respondió que "se sentía muy seguro" para entender y utilizar la tecnología de su teléfono. El $62 \%$ restante se distribuye entre un $39 \%$ que informa sentirse "más o menos" seguro y un $22 \%$ que "no se sentía seguro".

Como se observó en la Figura 4, se indagó sobre cuántas veces aproximadamente en el último mes habían utilizado su teléfono para una serie seleccionada de acciones ${ }^{21}$. A partir de cómo habían respondido sobre su seguridad percibida con la tecnología del teléfono, analizamos las respuestas para poder estratificar cómo cambiaban los usos en relación a la confianza en las habilidades tecnológicas. Como podemos observar en las tablas del Apéndice B, a medida que aumenta la confianza en las habilidades también es mayor el ratio de frecuencia en cada una de las acciones evaluadas.

La segmentación en base a qué tan seguros se auto perciben los comerciantes con el teléfono celular y con qué frecuencia hacen determinados usos también nos permitió avanzar en observar cómo los tres segmentos (los que se sienten "muy seguros", "más o menos" o "no se sienten seguros") se comportan frente al interés de aceptar medios de pagos digitales y al uso de dinero en efectivo.

En esta línea, de los comerciantes que no tienen un teléfono celular, sólo el 10\% acepta pagos digitales. De los que tienen y no se sienten seguros con la tecnología del teléfono el $19 \%$ los acepta. De los que tienen celular y se sienten más o menos el $24 \%$. Y de los que sienten muy seguros el $31 \%$. Como podemos ver en la Figura 5 a medida que aumenta la confianza en el

\footnotetext{
${ }^{21}$ Específicamente: A) Instalar actualizaciones para su sistema o aplicaciones. B) Cambiar la contraseña de acceso a su teléfono o a aplicaciones. C) Enviar o leer un correo electrónico. D) Tomarse una auto foto (selfie). E) Enviar un video a otra persona. F) Reenviar a más de una persona al mismo tiempo un mensaje de WhatsApp. G) Enviar una ubicación de GPS. H) Conectarse a una red de wi-fi ingresando usuario y clave. I) Leer un diario digital.
} 
manejo de la tecnología del celular aumenta también la cantidad de comerciantes que aceptan pagos digitales. Entre los que se sienten muy seguros y entre los que no tienen un celular se triplica la cantidad de comerciantes que aceptan pagos digitales en sus comercios.

Figura 5. \% de comercios que aceptan pagos digitales según seguridad en el manejo de la tecnología del celular

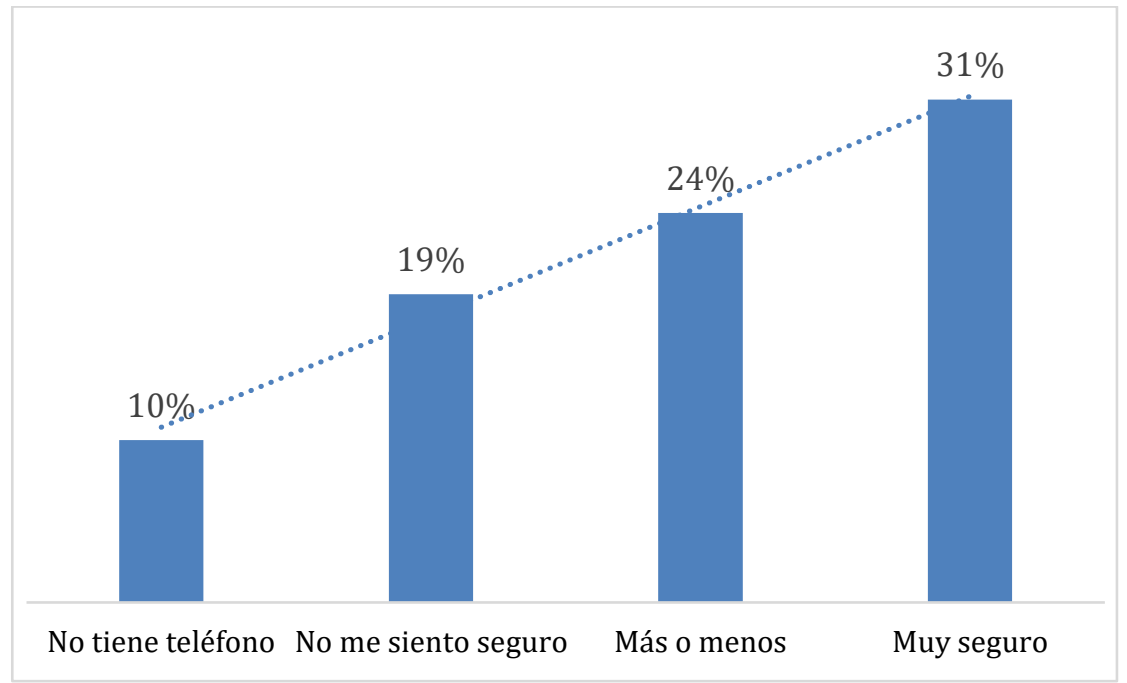

Fuente: Elaboración propia en base al Cuestionario de Pagos Digitales del Barrio 31

De manera similar, si analizamos al interior de los comercios que aceptan pagos digitales, en la Figura 6 podemos observar que el $44 \%$ de los comerciantes que venden con pagos digitales se siente muy seguro con la tecnología del teléfono. El 36\% "más o menos" seguro, el $16 \%$ no se siente seguro y el $4 \%$ no tiene teléfono. En cambio, en el caso de los que no aceptan pagos digitales el $32 \%$ se siente muy seguro, el 35\% "más o menos" seguro, el $22 \%$ no se siente seguro y el $11 \%$ no tiene celular. 
Figura 6. \% de nivel de confianza entre comerciantes que aceptan y no aceptan pagos digitales

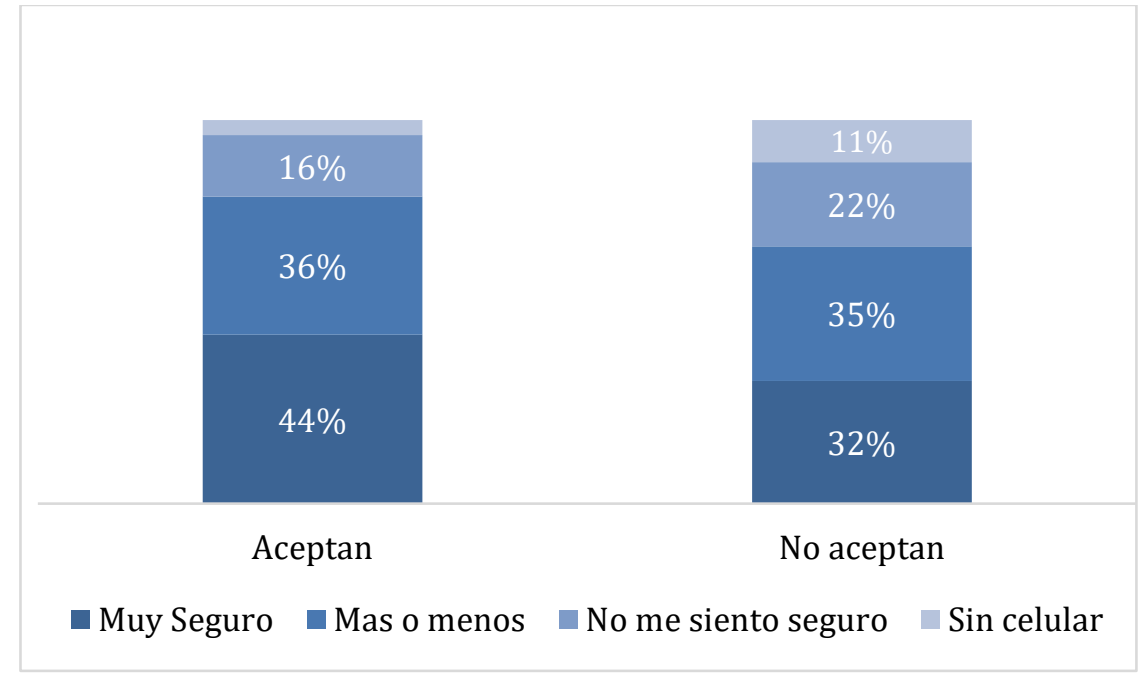

Fuente: Elaboración propia en base al Cuestionario de Pagos Digitales del Barrio 31

En la Figura 7 analizamos el nivel de confianza con la tecnología del celular de quienes no aceptan pagos digitales en sus comercios, pero afirman que sí están interesados en empezar a aceptar. Respecto a los comerciantes que no aceptan pagos digitales y no tienen un teléfono celular, sólo al 22\% le interesa adoptar pagos digitales. En los que tienen celular, pero no se sienten seguros, el interés crece al 41\%. En los que se sienten "Mas o menos" seguros al 57\%. Y alcanza un punto máximo en la población que se siente "Muy segura" donde al $60 \%$ le interesa digitalizar pagos. Resulta precisa la connotación sobre cómo a medida que más seguros se sienten los comerciantes del Barrio 31 con la tecnología se incrementa su interés por adoptar pagos digitales. 
Figura 7. \% de interesados en Pagos Digitales según el manejo del celular

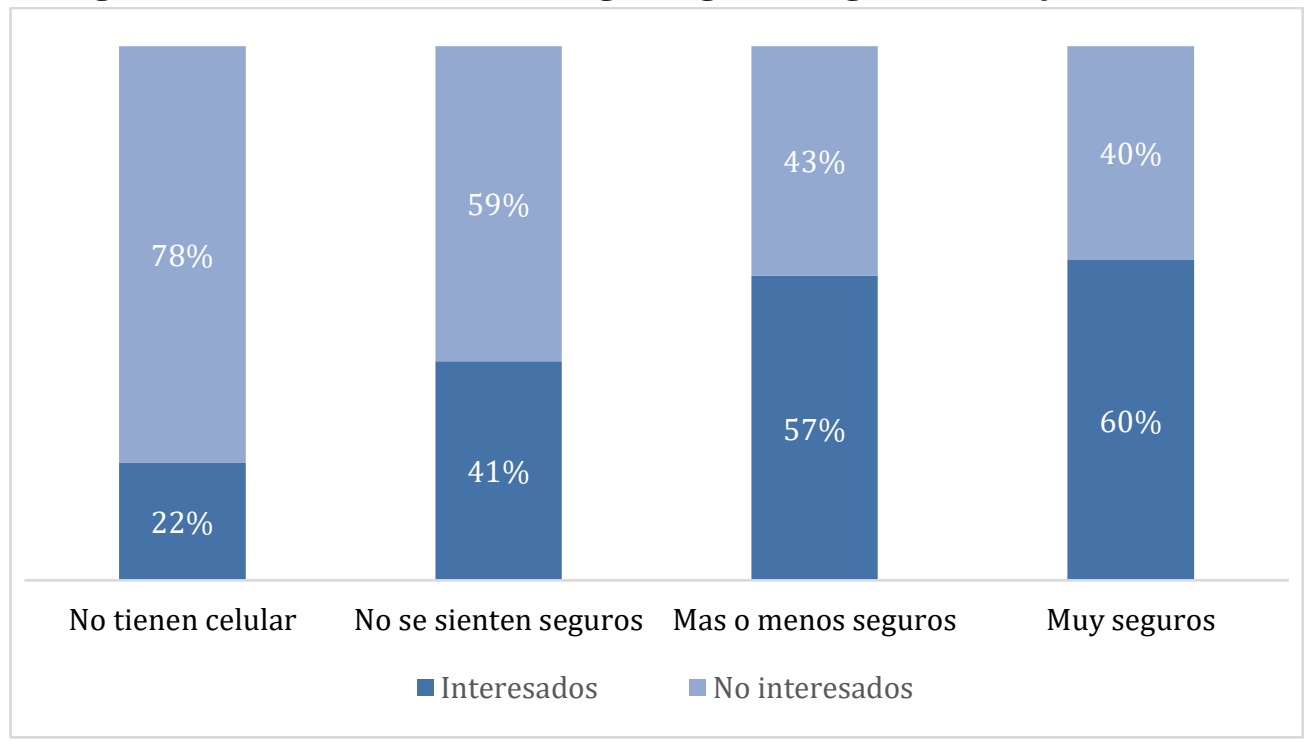

Fuente: Elaboración propia en base al Cuestionario de Pagos Digitales del Barrio 31

En un sentido similar, en el cuestionario también se indagó si los comerciantes tenían una cuenta en una Billetera Digital. Se encontró que sólo el $8 \%$ del total informó que utilizaba alguna de ellas. No obstante, aunque es un guarismo bajo, es importante señalar que el $75 \%$ de los que informaron que tienen billeteras digitales también aceptan un medio de pago digital en sus comercios y al $25 \%$ restante le interesaría empezar.

Por otro lado, entre los bancarizados indagamos quienes habían descargado la aplicación de banca móvil. Del 42\% que tiene una cuenta bancaria, el 50\% descargo la aplicación en el celular. El 64\% de los que descargo la aplicación acepta pagos digitales y al 27\% le interesaría. Sólo el $9 \%$ no acepta ni está interesado.

Por su parte, si bien por el tamaño de nuestra muestra no podemos afirmar que haya una relación directa entre nivel educativo y las habilidades tecnológicas, los datos reflejan que cuanto menos uso e interés hay en los pagos digitales, menor es el nivel educativo, denotando algún tipo de correlación entre educación y pagos digitales. Específicamente, el 64\% de los que aceptan medios de pago digitales terminaron la secundaria y el $96 \%$ la primaria, mientras que de los que no aceptan pagos digitales el $46 \%$ finalizo sus estudios secundarios y el $85 \%$ la primaria. $\mathrm{Si}$ filtramos por los que no tienen y no les interesa tener pagos digitales, el $41 \%$ termino la secundaria y el $79 \%$ la primaria. La proporción de personas sin estudios primarios se multiplica por cinco, pasando del $4 \%$ al 21\%, entre los que aceptan pagos y los que no aceptan ni les interesa.

Para finalizar, un último punto para analizar esta hipótesis es el rango etario. Consecuente con otros relevamientos, encontramos una mayor propensión y afinidad hacia los pagos digitales en comerciantes más jóvenes. Específicamente, el $74 \%$ de los que tienen entre 25 y 34 años dijo que le interesaría ser aceptar pagos digitales Esta cifra se reduce al 32\% entre los que tienen entre 45 y 54 años, y al $18 \%$ entre los que tienen entre 65 y 75 años.

Si suponemos que las poblaciones más jóvenes tienen más facilidad para acceder a las nuevas tecnologías, estos datos refuerzan la hipótesis de que cuando las personas se auto perciben poco 
capacitadas en tecnología son más adversas a incorporar nuevos medios de pago que prescindan del efectivo.

Figura 8. \% de interesados en Pagos Digítales en relación al rango etario

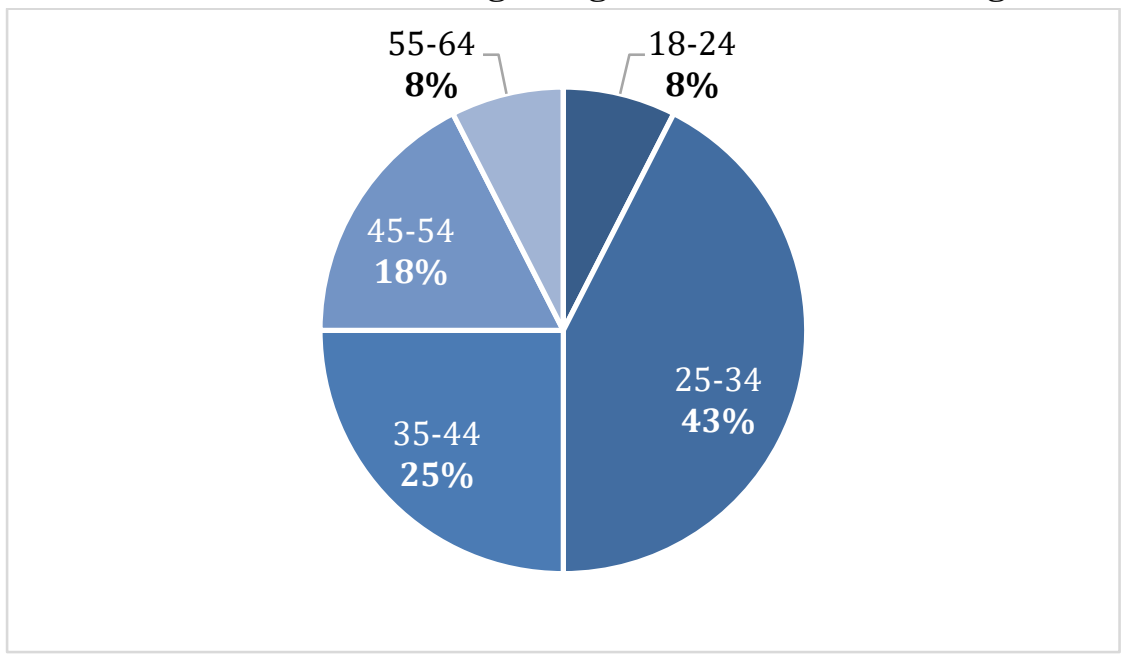

Fuente: Elaboración propia en base al Cuestionario de Pagos Digitales del Barrio 31

En resumen, la información relevada a partir del Cuestionario de Pagos Digitales del Barrio 31 nos permite observar que (de acuerdo a nuestra muestra) los comerciantes que no se sienten capacitados a nivel tecnológico, son menos propensos a ofrecer y también a verse interesados en ofrecer formas de pago digital en sus comercios. Mientras que las poblaciones que se sienten más seguras con las nuevas tecnológicas tienen mayores ratios de uso e interés en digitalizar sus ventas. Como dato a contemplar, estas poblaciones son las más jóvenes y con mayores estudios alcanzados.

Consecuentemente, una estrategia de fomento a la aceptación de pagos digitales en comercios de barrios vulnerables deberá estar acompañada no sólo de educación financiera, sino también de educación digital que promueva la confianza en la utilización de dispositivos móviles. De igual modo, comenzar acercando nuevas herramientas de pago digitales a poblaciones jóvenes para que sean referentes en sus círculos sería una estrategia coherente con estos resultados.

\section{IV.4. Hipótesis 3. Pagos Digitales y Servicios Financieros: “Los comerciantes que aceptan medios de pago digitales luego hacen y demandan un uso mayor de otros servicios que ofrecen las entidades financieras formales"}

Como señalamos en nuestro Marco Teórico, los medios de pagos son la columna vertebral de los otros servicios financieros (ahorros, préstamos y seguros). En esta línea, tras haber estudiado el acceso a la tecnología y sus dimensiones de confianza, así como la aceptación y propensión a la adopción de pagos digitales en los comercios relevados, en el desarrollo de esta hipótesis estudiaremos cómo estos medios de pago pueden ser una puerta para incrementar la inclusión financiera multidimensional. El objetivo aquí es observar cómo varía el uso de otros servicios financieros formales en relación a la aceptación de pagos digitales en los comerciantes relevados. 
El $42 \%$ del total de los comerciantes tiene una cuenta en una institución financiera formal. Como los instrumentos de pago mayoritariamente (aunque no excluyentemente) deben estar vinculados a una cuenta, encontramos que el $96 \%$ de los que aceptan pagos digitales son titulares de una cuenta. Apenas el $25 \%$ de los que no aceptan pagos digitales declara tener una cuenta. En otras palabras, en nuestra muestra, podemos suponer que el incentivo a aceptar un medio de pago se transforma podría transformarse así implícitamente en un incentivo a bancarizarse.

En cuanto al uso de las cuentas bancarias, el $18 \%$ del total bancarizado no las utiliza en absoluto. Entre los que no aceptan pagos digitales este guarismo crece al 30\%. Lógicamente, entre los que sí aceptan pagos digitales sólo un 8\% declara no utilizar su cuenta bancaria. Sobre la frecuencia de uso, el $60 \%$ de los que no tienen pagos digitales las utiliza entre 1 y 2 veces al mes, mientras que dicho ratio de poco uso cae al 54\% entre los que sí. Entre los comercios que usan su cuenta entre 3 y 5 veces por mes los porcentajes son $10 \%$ y $33 \%$ respectivamente. Por último, el $4 \%$ de los comercios que aceptan pagos digitales utiliza su cuenta "Más de 5 veces al mes", mientras que ningún comerciante que posea cuenta bancaria e informe no aceptar pagos digitales hace un uso tan frecuente por mes. En resumen, como se observa en la Figura 9, se encuentra que los comercios bancarizados que aceptan pagos digitales parecieran hacer un uso ampliamente más frecuente de las cuentas.

\section{Figura 9. \% frecuencia de uso de la cuenta / población bancarizada con y sin pagos digitales}

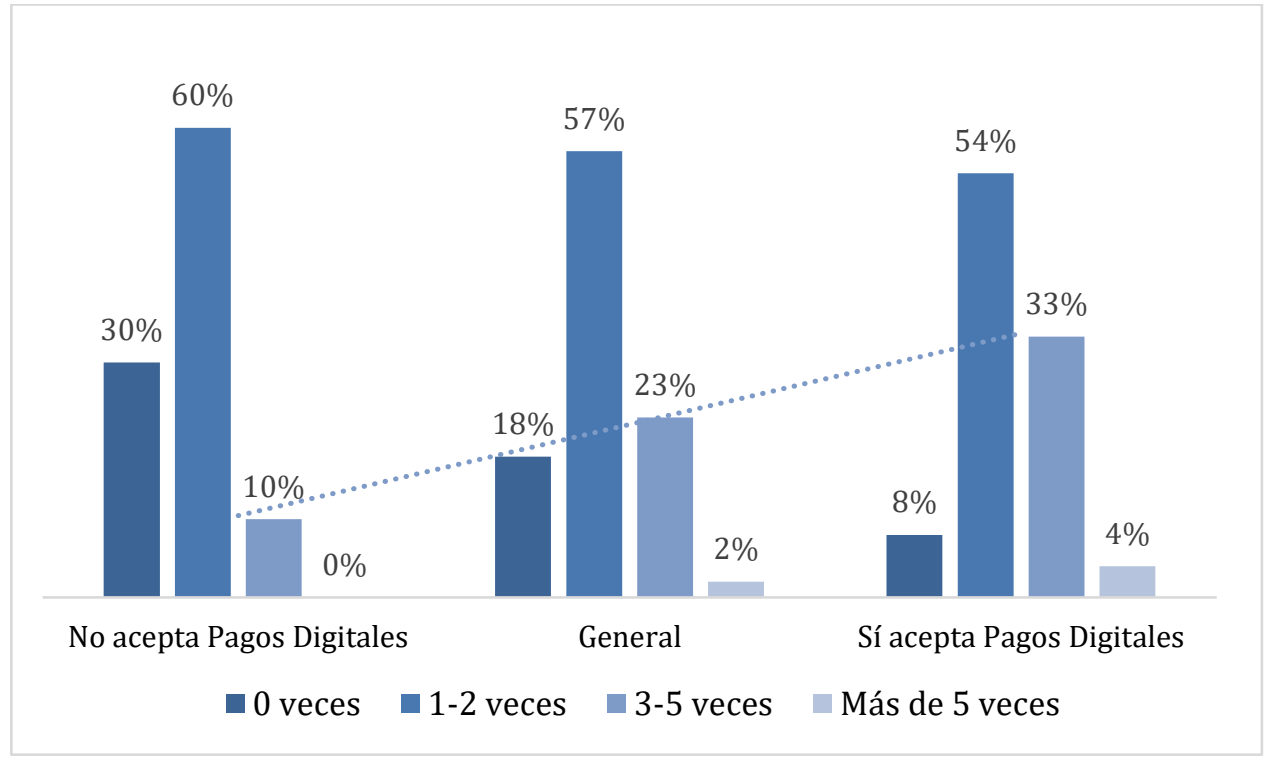

Fuente: Elaboración propia en base al Cuestionario de Pagos Digitales del Barrio 31

En cuanto al ahorro, el $49 \%$ del total de los comerciantes declara haber ahorrado en los últimos 12 meses (Ver Tabla A.14, Apéndice A). De los comerciantes que no aceptan pagos digitales en sus comercios el guarismo desciende al $42 \%$, y entre los que sí aceptan el mismo se incrementa al $72 \%$ que respondió haber ahorrado en los últimos 12 meses.

Cuando analizamos de qué modo lo habían hecho, únicamente el $12 \%$ de todos los que ahorraron (6\% de la muestra total) lo hicieron en una entidad financiera. Entre los que no aceptan 
pagos digitales únicamente el $6 \%$ de los que ahorraron dinero lo hizo en una cuenta formal, mientras que entre los que sí los aceptan el 22\%. Aceptar pagos digitales incrementaría la propensión a ahorrar en términos generales, y en una institución financieras en particular.

En cuanto al crédito, sólo el $24 \%$ del total sacó un crédito en los últimos doce meses. Los destinos de los mismos fueron, por una amplia mayoría, iniciar o mejorar un emprendimiento el $76 \%$, seguido por crédito para la vivienda con el $20 \%$, para consumo el $16 \%$, y para salud o educación el 8\% (Ver Tabla A.17, Apéndice A).

Dividimos a la población según si son comercios que aceptan o no pagos digitales. De los comerciantes que aceptan pagos digitales, el 32\% recibió un préstamo de una institución financiera formal en los últimos doce meses, y de los que no aceptan sólo el 22\%. Como podemos observar en la Figura 10, el porcentaje de prestatarios aumenta un $45 \%$ en los que tienen pagos digitales respecto a los que no. Este dato es sumamente relevante pues, como mencionamos en nuestro marco teórico, el uso de pagos digitales permite generar un registro de flujos que le abre las puertas al agente excluido al financiamiento formal y en este caso productivo.

Algo similar se esgrime al estudiar el acceso a una tarjeta de crédito que les permita suavizar los consumos en cuotas. Así, cuando analizamos quienes tenían tarjeta de crédito, el $60 \%$ de los comercios que aceptan pagos digitales declara tener una tarjeta de crédito, y entre los que no sólo el 6\%. Aceptar pagos digitales en comercios incrementa la propensión a solicitar una tener una tarjeta de crédito, con todo lo que ello implica.

En cuanto a la demanda potencial de crédito (propensión/interés a solicitar financiamiento), el $67 \%$ de los comerciantes relevados tomaría un préstamo en los próximos doce meses. Los destinos potenciales fueron aquí más diversos, aunque con un orden de prioridades similar. Para un emprendimiento el 87\%, para la vivienda el 63\%, para salud o educación el 49\%, para consumo el 39\% y para una celebración el 10\% (Ver Tabla A.17, Apéndice A). En línea con nuestra hipótesis, aunque con una diferencia no tan crítica, aquellos comerciantes que aceptan pagos digitales presentan mayores guarismos de demanda potencial $(72 \%)$ que aquellos que no aceptan pagos digitales (66\%).

Como se extrae de la Figura 10, el dato crítico a destacar aquí es la inmensa necesidad de financiamiento reflejada en la demanda potencial en general, y la enorme brecha entre los comerciantes que lograron acceder y los que quisieran acceder a crédito, fiel reflejo de la amplia exclusión a financiamiento que tienen los comerciantes del Barrio 31. 
Figura 10. Demanda efectiva y demanda potencial de crédito

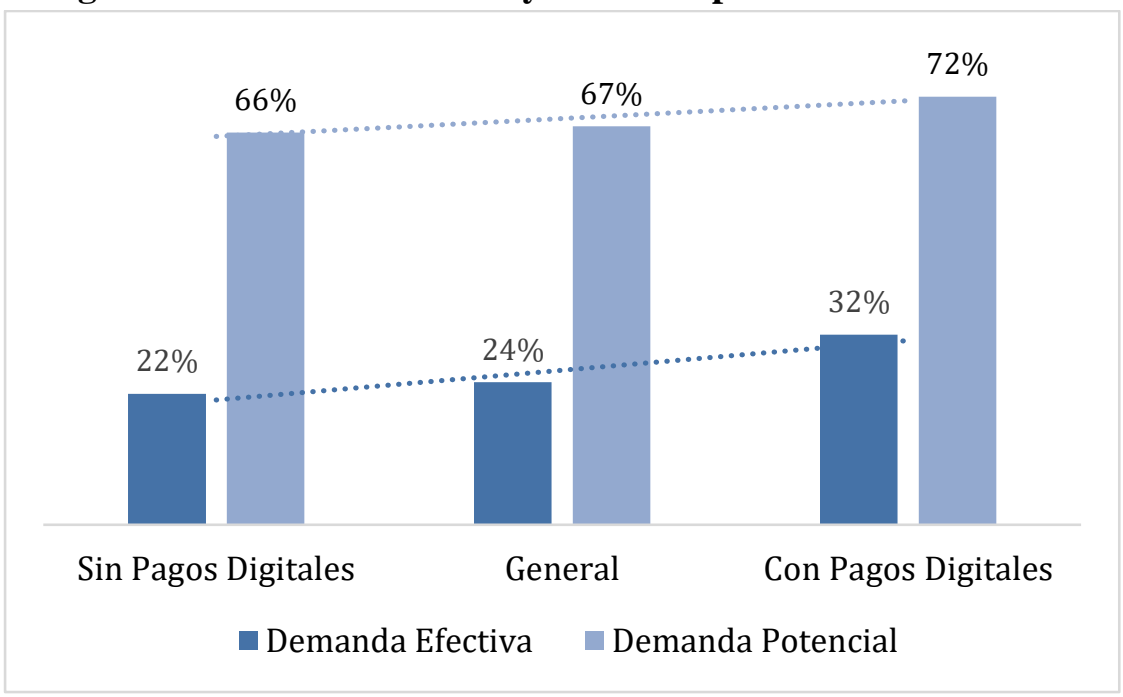

Fuente: Elaboración propia en base a encuesta Pagos Digitales del Barrio 31

Analizamos también la frecuencia en el uso de los cajeros automáticos, en la Figura 11 podemos observar que el $48 \%$ de los comercios que no aceptan pagos digitales y declaro ser titular de una cuenta nunca usa (cero veces) un cajero automático en un mes, mientras que entre los que sí aceptan dicho guarismo de no uso cae al 29\%. A medida que aumenta la frecuencia, el $24 \%$ de los que no aceptan pagos digitales usa un cajero entre 3 y 4 veces por semana y de los que sí el $21 \%$. Y entre los que los usan más de 5 veces por mes los porcentajes son $5 \%$ y $17 \%$ respectivamente. Efectivamente, en nuestra muestra, encontramos que los comerciantes que aceptan pagos digitales parecen hacer un uso mayor de los cajeros automáticos. 
Figura 11. Uso cajeros automáticos en relación al de pagos digitales

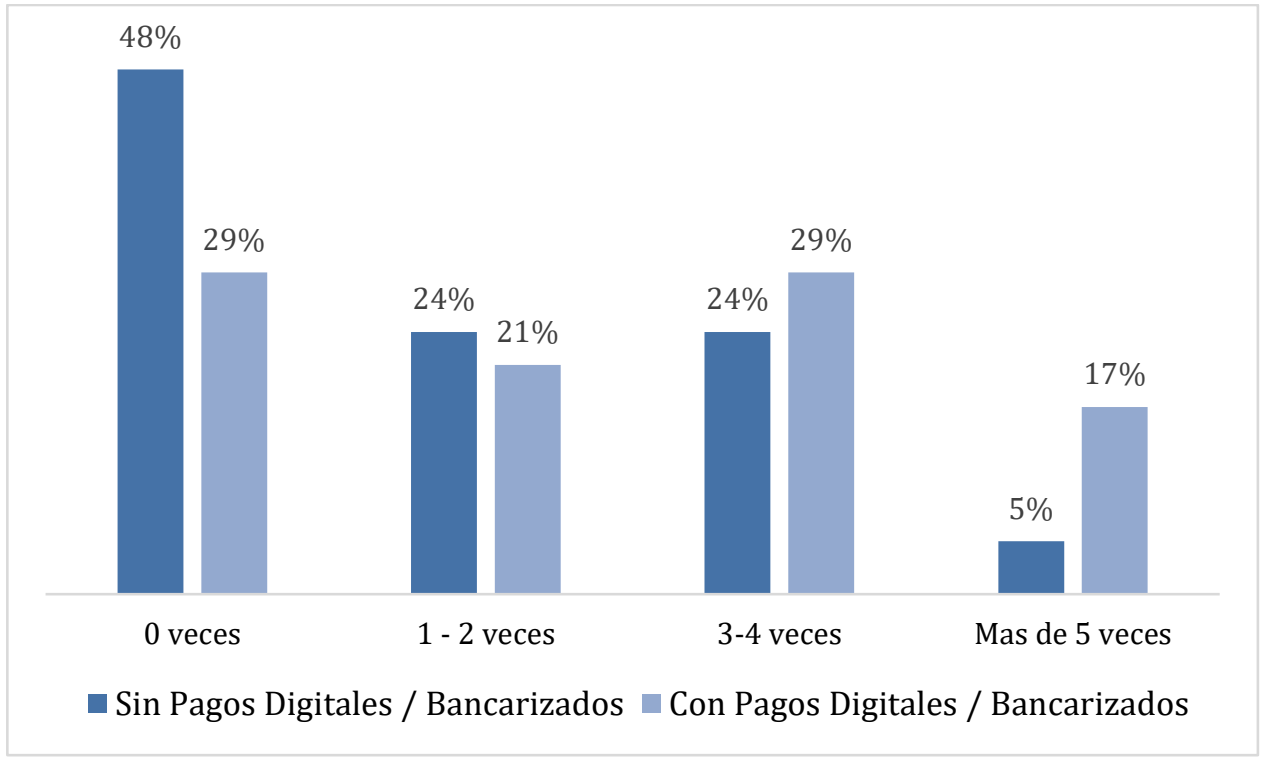

Fuente: Elaboración propia en base a encuesta Pagos Digitales del Barrio 31

Por último, analizamos qué comerciantes habían descargado y utilizado la aplicación de banca móvil. El 50\% de los comerciantes bancarizados utiliza el servicio móvil de su Banco. Esto equivale al $21 \%$ del total de los que respondieron el Cuestionario. Como podemos ver en la Figura 12, el 64\% de los comercios que usan la aplicación también ofrecen a sus clientes pagar con tarjeta de débito o crédito. Por otro lado, como podemos observar en el Apéndice A, de los que aceptan pagos digitales el 56\% informa que descargo la aplicación de banca móvil, mientras que de los que no tienen solo el $10 \%$ la descargo.

Figura 12. \% de usuarios de Banca Móvil con Pagos Digitales

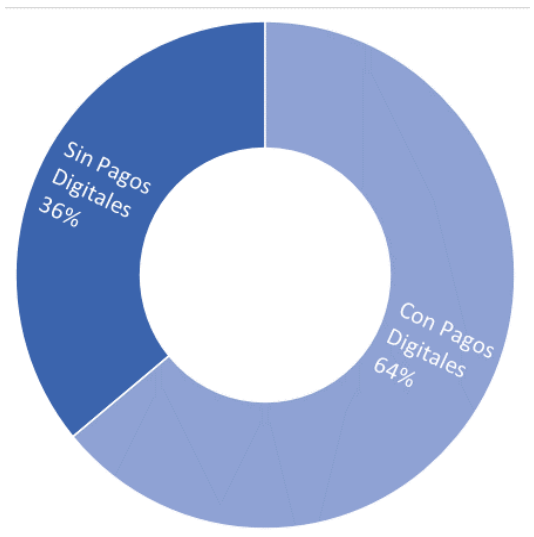

Fuente: Elaboración propia en base al Cuestionario de Pagos Digitales del Barrio 31 
En conclusión, el desarrollo de esta hipótesis permite observar el hecho de cómo aumenta no solo el acceso, sino también el uso de distintos servicios financieros en la población de comerciantes que aceptan pagos digitales. En línea con nuestro marco teórico, sería entonces destacable como la expansión de los pagos digitales tiene incentivos cruzados. Por un lado, para los comerciantes que tienen más acceso a nuevos servicios financieros y hacen más uso de ellos, pero también para las entidades financieras por los beneficios que todo ello implica. Esto podría ser un primer punto de partida para pensar los pagos digitales como una política de beneficios recíprocos tanto para las empresas de servicios financieros como para los usuarios, pero también como puerta de entrada a la inclusión financiera multidimensional.

IV.5. Hipótesis 4. Pagos Digitales y el uso del dinero digital para Ventas y Compras: "Los comerciantes que aceptan medios de pago digitales, luego tienen mayor propensión a utilizar dinero electrónico en otros ámbitos, generando un efecto multiplicador”

En la Hipótesis anterior pudimos observar cómo los comerciantes que aceptan pagos digitales también hacen un mayor uso de otros servicios que ofrecen las entidades financieras, con los beneficios que esto implica tanto para ellos como usuarios, como para las entidades, que en definitiva tienen más y mejores clientes.

En esta hipótesis el objetivo es analizar si además los comerciantes que aceptan pagos digitales en sus comercios tienen mayor propensión a utilizar dinero digital en su vida cotidiana o con sus proveedores, generando así un efecto multiplicador en la digitalización del dinero (e incrementando también los beneficios para las entidades financieras). En esta sección hablaremos de los comerciantes en su rol de consumidores de bienes y servicios no sólo financieros.

En primer lugar, analizamos las respuestas de porqué motivos aceptan pagos digitales los comerciantes. Agrupamos las opciones brindadas en cinco grupos y sumamos sin duplicar las personas que habían elegido alguna de las opciones incluidas. Las opciones de respuesta que componen cada categoría son las siguientes:

- Uso de dinero digital: I) Me interesa ser cliente de la institución financiera, O) Es mejor para ahorrar porque el dinero va directo a una cuenta, y $P$ ) Me conviene para luego comprar con la tarjeta de débito.

- Ventas: B) Me trae más ventas, G) Los consumidores gastan más, J) Quiero competir.

- Logística: A) Fue fácil de aprender y entender, E) Redujo la molestia de encontrar cambio, $F$ ) Es más rápido, $H$ ) La aplicación es fácil de utilizar, $L)$ Me permite evitar que fíen, N) Ahorro tiempo para hacer el registro de las ventas mensual.

- Seguridad: C) Seguridad y M) Es más seguro para cuando los empleados manejan la caja.

- $\quad$ Costos: K) Es gratis el mantenimiento y D) Redujo mi costo de manejo de efectivo.

Como podemos observar en la Figura 13, el 92\% de los comercios que aceptan medios de pago digital lo hacen por razones que se enmarcan en la categoría de un mayor uso del dinero digital. El $88 \%$ porque mejora sus ventas, el $84 \%$ por seguridad, el $72 \%$ para mejorar la logística y el $52 \%$ para reducir los costos. 
Figura 13. \% de motivos de comerciantes que aceptan pagos digitales

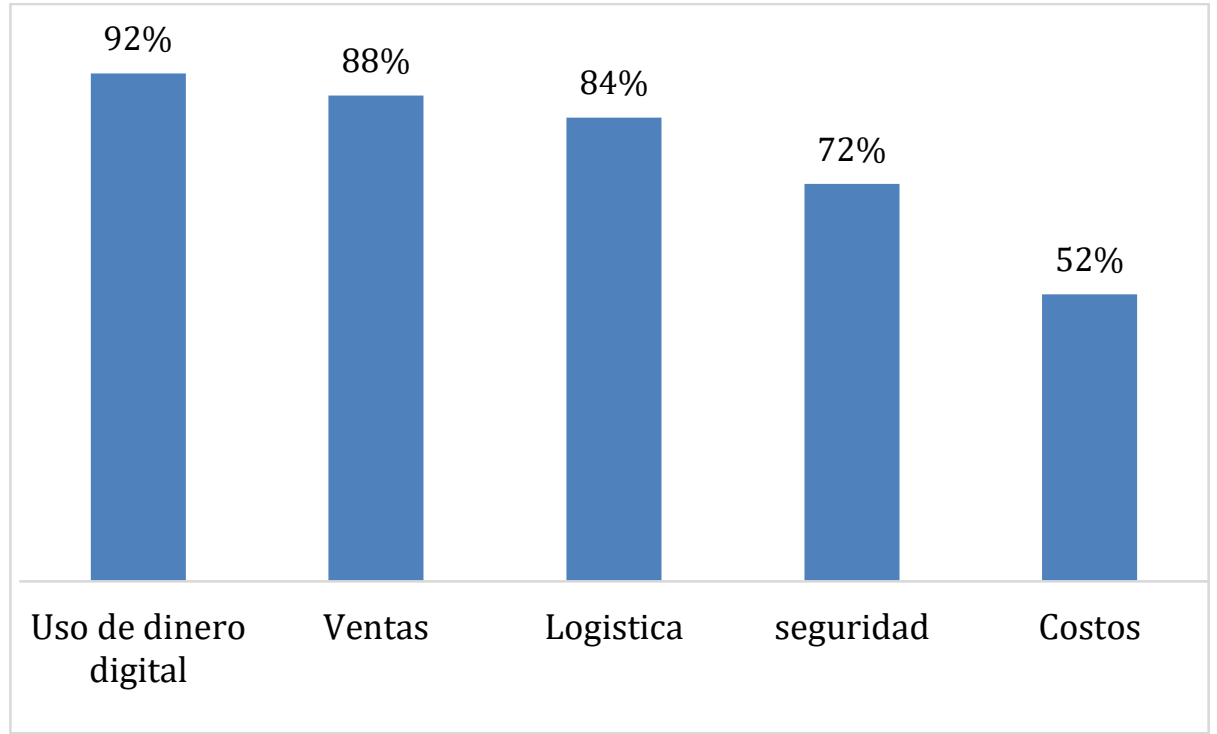

Fuente: Elaboración propia en base al Cuestionario de Pagos Digitales del Barrio 31

En segundo lugar analizamos qué tan de acuerdo estarían los comerciantes como consumidores a pagarle a sus proveedores sin utilizar efectivo. Del total, el 20\% dijo que estaria "muy de acuerdo" en pagarles de forma digital. En el caso de los comerciantes que aceptan pagos digitales el 48\%, y de los que no aceptan el 11\%. Si sumamos lo que estarian "Muy de acuerdo" y "De acuerdo", el 92\% de los comerciantes que aceptan medios de pago electronicos aprobaria que sus proveedores les cobren tambien de forma digital. Y si sumamos entre los que no aceptan pago electronico, sólo el 39\% aprobaria que sus proveedores les cobren tambien de forma digital.

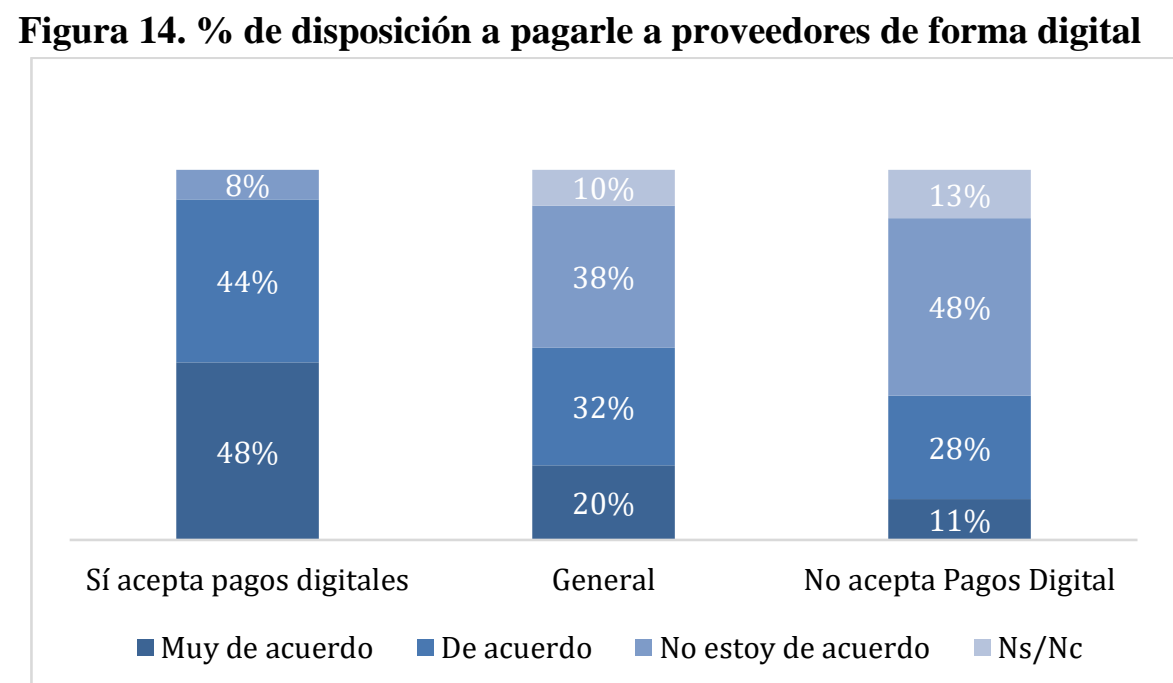

Fuente: Elaboración propia en base al Cuestionario de Pagos Digitales del Barrio 31 
Seguidamente, analizamos la frecuencia de uso de la tarjeta de débito por parte de los comerciantes en su rol de consumidores. De los que tienen la tarjeta y no aceptan pagos digitales el $18 \%$ nunca la utiliza, el $47 \%$ la usa entre 1 y 2 veces, el $18 \%$ entre 3 y 5 veces y el $12 \%$ más de cinco veces al mes. La tendencia se invierte con los comerciantes que sí aceptan pagos digitales. Sólo el $4 \%$ informa que nunca la utiliza, mientras que el $33 \%$ la usa entre 1 y 2 veces por mes, el $38 \%$ las usa entre 3 y 5 veces, y $21 \%$ la utiliza más de 5 veces al mes. En resumen, como se observa en la Figura 15, los comerciantes que aceptan pagos digitales parecen hacer un uso más frecuente de su tarjeta de débito a la hora de consumir.

\section{Figura 15. \% frecuencia de uso de la T. de débito / población con tarjeta con y sin pagos digitales}

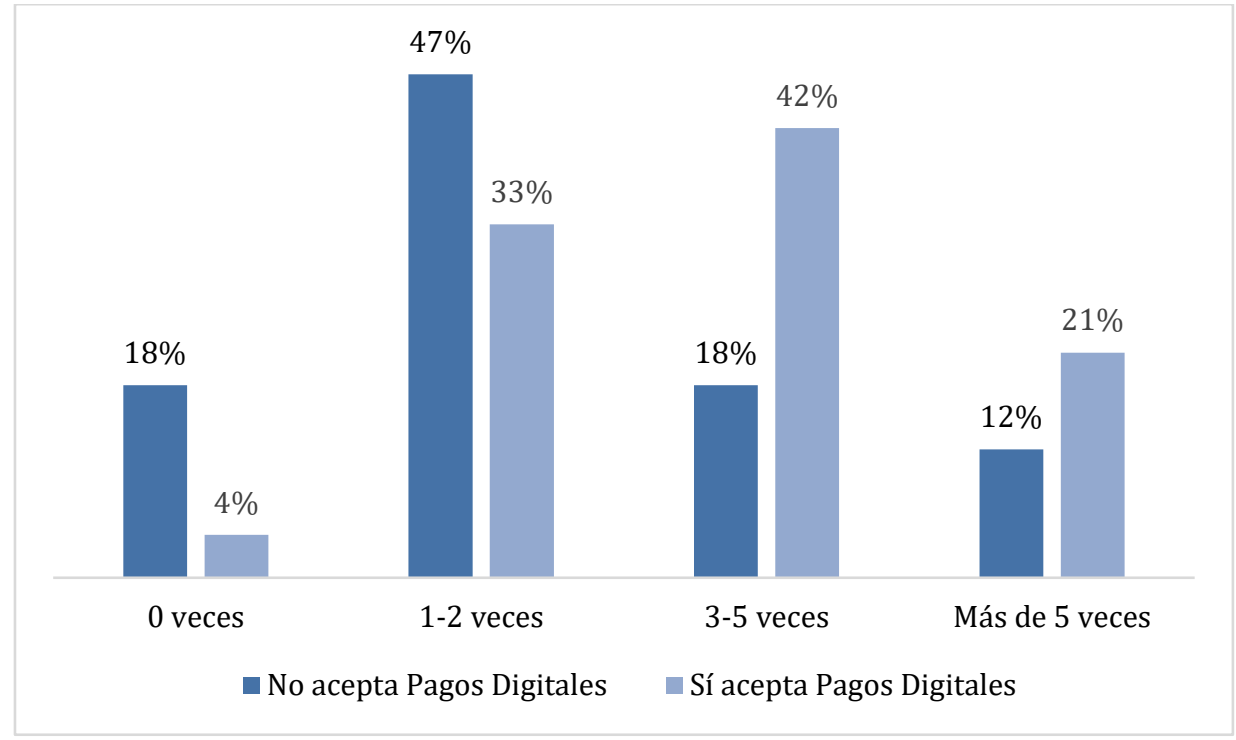

Fuente: Elaboración propia en base al Cuestionario de Pagos Digitales del Barrio 31

Por último, en la Figura 16 estudiamos cómo se componen los comerciantes que pagan de forma digital determinados bienes y servicios. Para eso clasificamos a los comercios que pagaron de forma digital cada bien o servicio entre: los comercios que aceptan pagos digitales, los que no, los que les interesaría empezar a aceptarlos para poder usar la tarjeta de débito con el dinero que recibirían de las ventas, y los que les interesa por alguna otra razón no relacionada estrictamente al uso del dinero digital.

Haciendo un promedio de los que pagan digitalmente las ocho categorías de bienes y servicios, el $56 \%$ de los comerciantes que ofrecen pagos digitales en sus comercios, también pagan de forma digital en su rol de consumidores. Si les sumamos los que todavía no cobran digitalmente pero si les interesaría empezar porque quieren utilizar más dinero digital, el promedio asciende al $82 \%$ de los que pagan de forma digital. Si a su vez agregamos los que aceptan pagos y les interesa por razones no estrictamente relacionadas al uso de dinero electrónico, podemos decir que en promedio el $92 \%$ de los comerciantes que consumen y pagan de forma digital ofrecen o les interesaría adoptar pagos digitales. 
La Figura 16 muestra cómo los comerciantes que aceptan o tienen interés por aceptar los pagos digitales son ampliamente la mayor parte de los que cuando consumen los utilizan.

Figura 16. Composición de la población que paga digitalmente

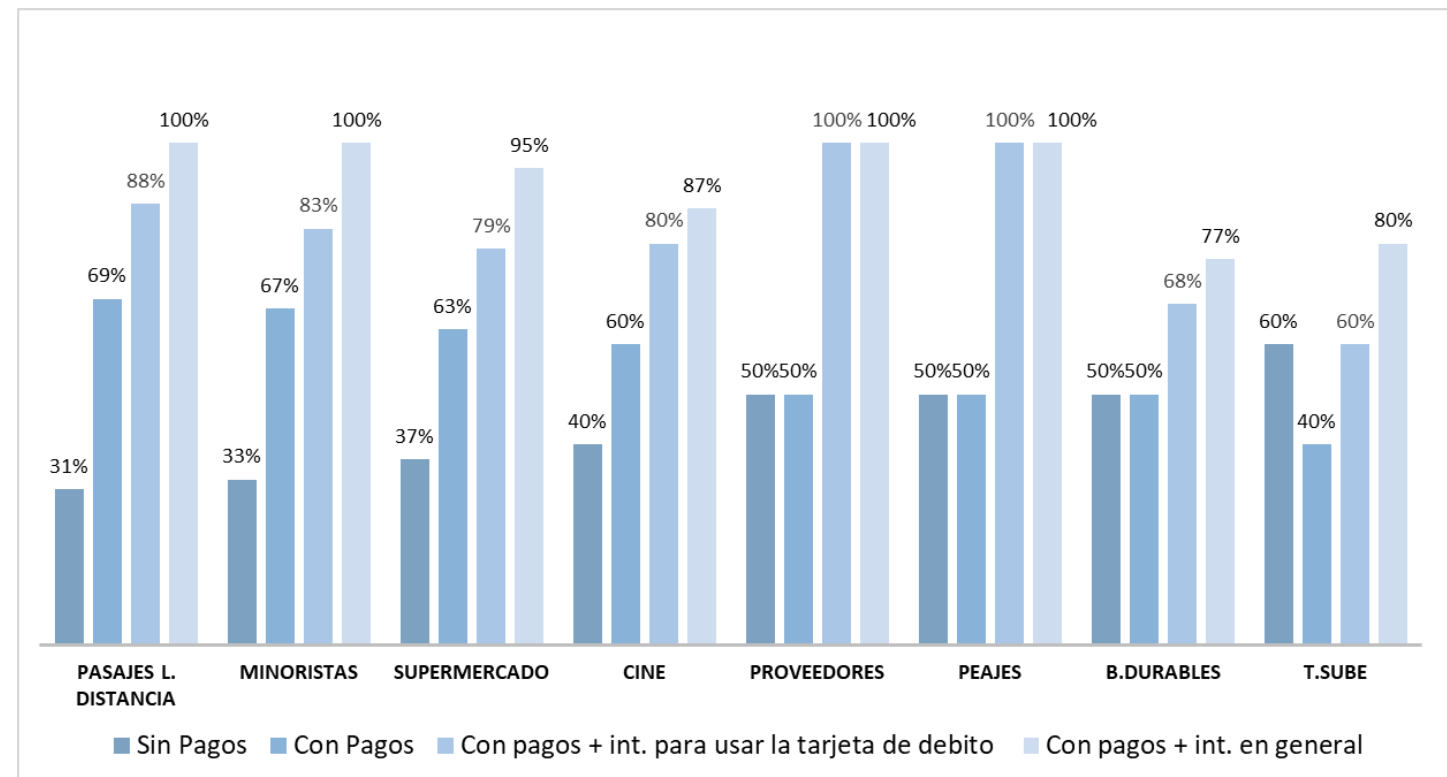

Fuente: Elaboración propia en base a encuesta Pagos Digitales del Barrio 31

Para concluir, como vimos en este apartado, la aceptación de pagos digitales en el comercio tiene un efecto multiplicador en la reducción del efectivo, al convertir a los comerciantes que aceptan estos medios de pagos en demandantes de los mismos cuando ocupan el rol de consumidores.

Los datos del Cuestionario de Pagos Digitales del Barrio 31 muestran que quienes ofrecen a sus clientes pagar digitalmente, son más propensos luego a consumir pagando de la misma manera en su rol de consumidores, generando así un círculo virtuoso en la cadena de pagos digitales multiplicando sus efectos inclusivos.

$\mathrm{Al}$ igual que en la hipótesis anterior, este escenario también invita a pensar el uso de los pagos digitales como una puerta para la inclusión financiera de manera amplia. Se convierte así en una política de múltiples beneficios tanto para los usuarios como para las entidades financieras que pueden acrecentar los beneficios logísticos y económicos del dinero digital generando menores costos de operación en comparación a los que implica la gestión de los billetes en efectivo (mantenimiento de cajeros, seguridad de caudales, horas hombre de atención por caja, etc.). 
IV.6. Hipótesis 5. Pagos Digitales, Uso de Efectivo y Seguridad: "El efectivo es el medio de pago más utilizado por los comerciantes a pesar de que la mayor parte sufrió algún inconveniente y/o delito que le generó pérdidas (robos, billetes falsos, pérdidas, etc.). Los comerciantes valoran los medios de pagos digitales principalmente porque puede ser una herramienta para mejorar la seguridad"

Como se dijo, en las últimas dos hipótesis sumaremos a nuestro análisis cuáles son los ejes sobre los que debe trabajar una política de pagos digitales para lograr mayor adhesión en los comerciantes. Para ello, un factor comúnmente mencionado a la hora de destacar o recomendar el uso de Pagos Digitales en comercios es aquel vinculado a la seguridad que implican estos mecanismos por sobre el dinero en efectivo, tanto para el comercio como para los clientes de estos. Así, estudiar el uso y las consecuencias del efectivo a la vez de la valoración por parte de los comercios de la dimensión vinculada a la seguridad se torna fundamental.

De acuerdo al Cuestionario de Pagos Digitales del Barrio 31, el 62\% de los comerciantes sufrió en los últimos tres años un siniestro delictivo en relación al dinero en efectivo. Dentro esa cifra, un 57\% recibió pagos con dinero falsificado entre otros delitos y un 5\% nunca recibió dinero falso, pero sí fue víctima de otro delito. Sólo el 38\% de los comercios relevados nunca sufrió un robo o un hecho de inseguridad. En la Figura 17 se pueden ver los delitos y el porcentaje de comercios relevados que fue víctima de los mismos.

Figura 17. \% de víctimas de inseguridad en relación al dinero en efectivo

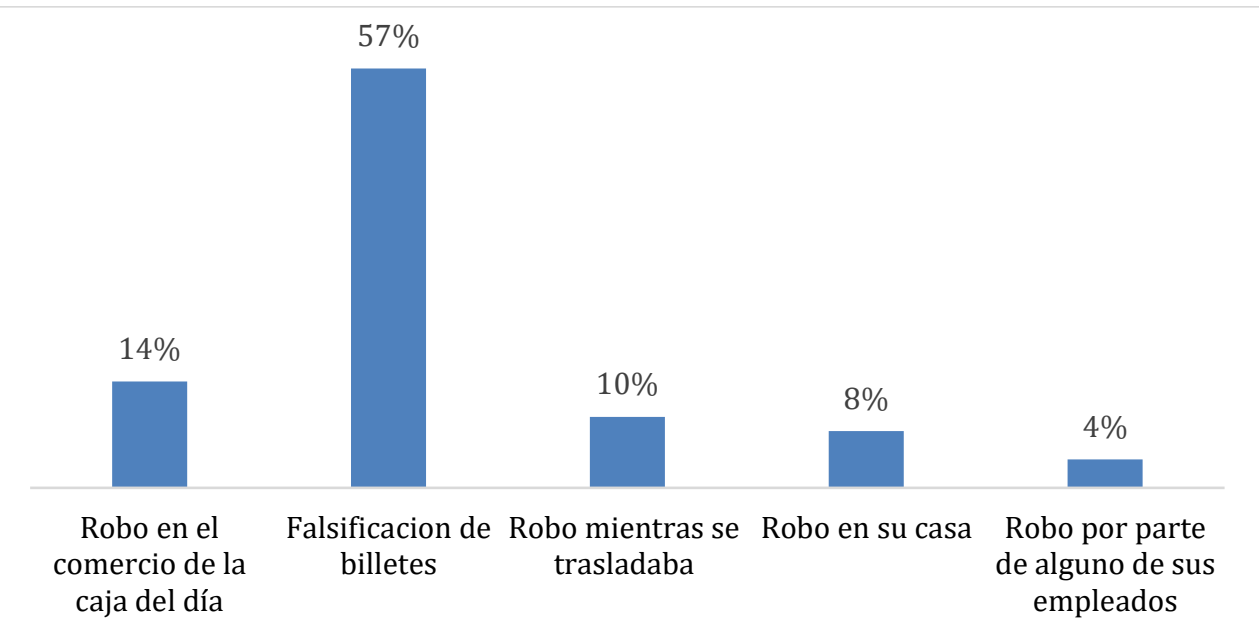

Fuente: Elaboración propia en base a encuesta Pagos Digitales del Barrio 31

En nuestra encuesta indagamos sobre las razones por las que les interesaría adoptar pagos digitales a los comercios que no los usan. Del total de comercios que no acepta pagos digitales, el 51\% está interesado en empezar a aceptar en el futuro y cómo podemos observar en la Figura 19 el 73\% del total de interesados eligió entre sus motivos mejorar la seguridad de su actividad económica.

Focalizando en los comercios que sufrieron un hecho delictivo, el 75\% declara estar interesado en adoptar pagos digitales. De estos, el 70\% dijo que es específicamente porque les 
parece más seguro que el efectivo. Por otro lado, como vimos en la Figura 13 de la Hipótesis 4, aunque el principal motivo de los que actualmente ya aceptan pagos digitales son las ventas, pudimos denotar que el $72 \%$ de los comercios los adoptan porque considera que es más seguro que el efectivo.

Cuando se indaga sobre cómo se sienten en relación a la seguridad cuando se manejan con efectivo, la mitad del total relevado (el 49\%) respondió que en general "no se sentía seguro", sólo el 30\% que "sí se sentía seguro" y el 16\% que "se sentía muy seguro" (Ver Tabla A.18, Apéndice A). Consecuentemente, cuando se analiza específicamente los que no se sienten seguros manejando efectivo y a su vez no aceptan pagos digitales (el 53\% del total que no acepta actualmente), encontramos que a más de la mitad (el 57\%) le interesaría adoptarlos. De estos, el $71 \%$ dijo que una de las razones era para mejorar la seguridad.

Como nos dice la teoría y los datos mencionados, puesto que la inseguridad del efectivo se relaciona de manera directa con la seguridad de los pagos digitales, comprender el manejo del efectivo por parte de los comerciantes en su rol de consumidores ${ }^{22}$ es valioso a la hora de pensar en una política de promoción de los pagos digitales.

En la Figura 18 se presenta en que proporciones los comerciantes consumen ciertos bienes y servicios, y que porcentaje pagan de forma digital. La línea azul denota el total de "comerciantes consumidores" que consume determinado bien o servicio. La línea naranja indica la cantidad de "comerciantes consumidores" que pagan digitalmente dicho consumo sobre el total encuestado y la línea roja sobre el total de "comerciantes consumidores" del respectivo bien o servicio. Como puede observarse, más allá de la alta tasa de hechos delictivos relacionados al dinero en efectivo, este medio continúa siendo por mucho el medio de pago más utilizado.

Figura 18. \% de consumidores por bien o servicio y forma de pago

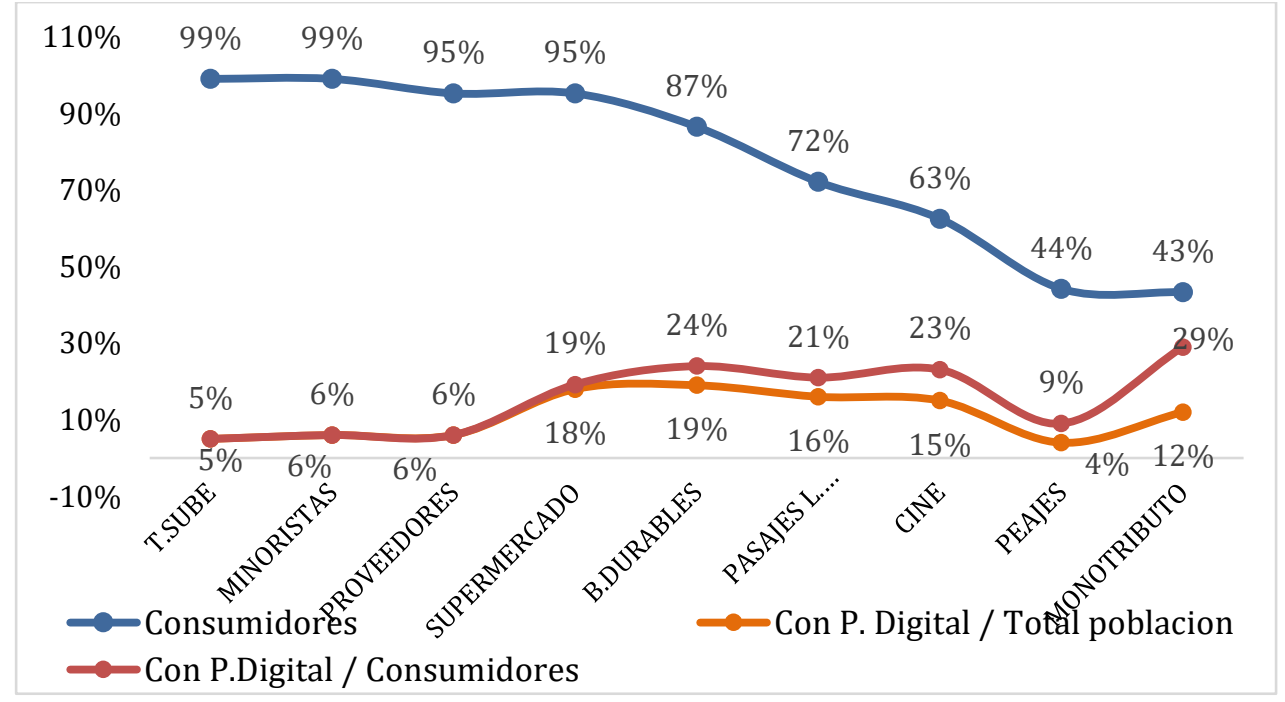

Fuente: Elaboración propia en base al Cuestionario de Pagos Digitales del Barrio 31

\footnotetext{
${ }^{22}$ En línea con la hipótesis anterior, recurriremos a la idea de "comerciante consumidor" para tratar el uso del efectivo por parte del dueño del comercio en su día a día. Esto es, en su rol de consumidor por fuera de su actividad comercial, salvo con sus proveedores, pero no referido a sus clientes.
} 
Como puede observarse, los servicios más consumidos son el transporte, representado en la carga de la tarjeta "SUBE", y las compras "minoristas" por el 99\% en ambos casos. En una proporción menor pero muy mayoritaria también se encuentra las compras a "proveedores" con el 95\%. Luego el 87\% consume "bienes durables", el 72\% "pasajes de larga distancia" en micro u avión, el 63\% entradas al "cine", el 44\% "peajes", y 43\% abona el régimen tributario simple de "Monotributo".

Si analizamos la proporción de comerciantes en su rol de consumidores que pagan de forma digital como porcentaje del total de "comerciantes consumidores" de cada bien y/o servicio particular, el máximo de pagos digitales se da en el caso del Monotributo donde un 29\% lo paga con tarjeta de débito o crédito ${ }^{23}$. Lo sigue el consumo de bienes durables donde el $24 \%$ lo paga de forma digital, luego al cine el 23\%, al supermercado el 19\%, los peajes el 9\%, el pago a proveedores el 6\%, las compras minoristas el 6\% y por último y para la tarjeta SUBE solo el 5\% la recarga de forma digital.

El pago para carga de la tarjeta de transporte SUBE requiere dos aclaraciones importantes que invitan reflexionar sobre el potencial que aún falta explotar desde la política pública en cuanto a vincular el pago electrónico del transporte con el uso del dinero digital. En primer lugar, la alta frecuencia con que se realiza esta recarga, siendo que el $67 \%$ hace más de 3 cargas de la tarjeta SUBE por mes y el 28\% incluso más de 5 cargas por mes (Ver Tabla A.13, Apéndice A) En segundo término, que cargarla en efectivo muchas veces tiene un costo fijo adicional que agregan en los puntos de carga (kioscos o almacenes) de manera informal. Su digitalización además de brindar seguridad y tiempo implicaría un ahorro económico.

Cabe aquí denotar otro aspecto relevante. Por un lado, que los bienes y servicios menos consumidos por los comerciantes son aquellos que están más digitalizados en cuanto a sus pagos, aunque todavía en proporciones ínfimas. Por el contrario, los bienes y servicios más consumidos por los comerciantes se manejan casi totalmente en efectivo.

Vale la pena agregar a esta información que, según se desprende de nuestro cuestionario, al $60 \%$ de los comerciantes que aceptan pagos digitales informa también que ningún cliente le pagó una compra con tarjeta de crédito y al $40 \%$ restante menos del $10 \%$. De igual modo, al $20 \%$ de los que aceptan pagos digitales nunca le pagaron con tarjeta débito, al $72 \%$ como máximo el 10\% de sus clientes le pagó con débito, y al $8 \%$ entre el 25\% y el 30\% de sus clientes (Ver Tabla A.16, Apéndice A). Es obligado trabajar en los incentivos a usar pagos digitales en la demanda además de en la oferta (los comerciantes).

Por último cuando analizamos cuánto es el circulante en efectivo que manejan los comercios diariamente, el $26 \%$ de los comerciantes respondió que lleva consigo más de $\$ 600$ por día, el $21 \%$ más de $\$ 800$, y el $37 \%$ deja en su casa más de $\$ 800$. Para más información véase el Tabla A.15, Apéndice A. Por supuesto este dato se vincula de manera directa con la inseguridad ya mencionada.

Para resumir, la mayor parte de los comerciantes son efectivamente víctimas de la inseguridad relacionada al uso del efectivo. El interés por adoptar pagos digitales en sus comercios tiene, justamente, una de sus motivaciones en representar una opción más segura de administrar el dinero y evitar robos u otro tipo de delitos. A su vez, encontramos que, aunque la mayoría de los

\footnotetext{
${ }^{23}$ Es importante aclarar que por la Resolución 4084-E de la AFIP es obligatorio pagarlo, exceptuando la categoría social, de forma electrónica
} 
comerciantes han sufrido un hecho delictivo en relación al efectivo, este medio de pago es el más utilizado en todas las categorías analizadas.

Podemos afirmar entonces que hay una convivencia que se retroalimenta entre hechos de inseguridad que tienen como protagonista el dinero en efectivo, y un escenario donde los pagos digitales aún son incipientes en su utilización por parte de los vecinos. La vacancia para mejorar este escenario es absoluta. Consecuentemente, un primer eje que debe considerar una política efectiva para la aceptación de pagos digitales en esta población deberá ser enfatizar en la seguridad de los comerciantes a la vez de abordar los consumos de bienes y servicios más frecuentes por parte de estos en su rol de consumidores.

IV.7. Hipótesis 6. Pagos Digitales y Ventas Esperadas: "La percepción sobre la posibilidad de tener un crecimiento en las ventas es una de las principales motivaciones que encuentran los comerciantes que no aceptan pagos digitales, pero quisieran adoptar nuevos medios de pago digitales"

Por último, otro causal teórico fundamental para aceptar pagos digitales en un comercio es, lógicamente, el impacto esperado en ventas y ganancias. A la hora de decidir si aceptar tarjetas o pagos móviles, todo comerciante ponderará (consciente o inconscientemente) el efecto que dicha decisión le implique en sus ventas. Ya analizamos los comerciantes que actualmente aceptan pagos, donde confirmaron dicho valor, se torna entonces relevante indagar sobre la percepción de los comerciantes que no los aceptan en torno al efecto esperado que tendría la aceptación de pagos digitales en sus ventas.

De los que no aceptan pagos digitales ( $76 \%$ del total), el $\mathbf{5 1 \%}$ dijo que le interesaría empezar a aceptar en el futuro. Para comprender porque les interesaría, con una lógica similar a la utilizada en la Hipótesis 4, se les dio a elegir de forma múltiple una serie de opciones ${ }^{24}$.

Agrupamos las opciones en cinco grupos y sumamos sin duplicar las personas que habían elegido alguna de las opciones incluidas. Las categorías y las respectivas opciones de respuesta que las componen son:

- Uso de dinero electrónico: I) Me interesa ser cliente de la institución financiera, O) Es mejor para ahorrar porque el dinero va directo a una cuenta, y $P$ ) Me conviene para comprar con la tarjeta de débito.

- Ventas: B) Me trae más ventas, G) Los consumidores gastan más, J) Quiero competir H) Ofrecer cuotas o/y promociones.

- Logística: A) Fue fácil de aprender y entender, E) Redujo la molestia de encontrar cambio, $F$ ) Es más rápido, $L)$ Me permite evitar que fíen, $N$ ) Ahorro tiempo para el registro de ventas.

- $\quad$ Seguridad: C) Seguridad y M) Es más seguro para cuando los empleados manejan la caja.

- $\quad$ Costos: K) Es gratis el mantenimiento y D) Redujo mi costo de manejo de efectivo.

\footnotetext{
${ }^{24}$ Vale señalar que para el caso de la Hipótesis 4 la pregunta rectora fue la 5.18, mientras que aquí lo fue la 5.24. Aunque similares, presentan diferencias sutiles en sus opciones de respuestas. Para más información véase Apéndice C.
} 
En la figura 19 podemos observar que la principal motivación declarada para empezar a aceptar pagos digitales en el futuro es efectivamente la posibilidad de mejorar las ventas. Específicamente, el 83\% de los interesados la escogió como una razón para empezar aceptar pagos digitales en su comercio. Seguida en segundo lugar por el potencial en mejorar la logística y la seguridad $(73 \%)$.

Figura 19. \% de interesados en aceptar Pagos Digítales según motivaciones

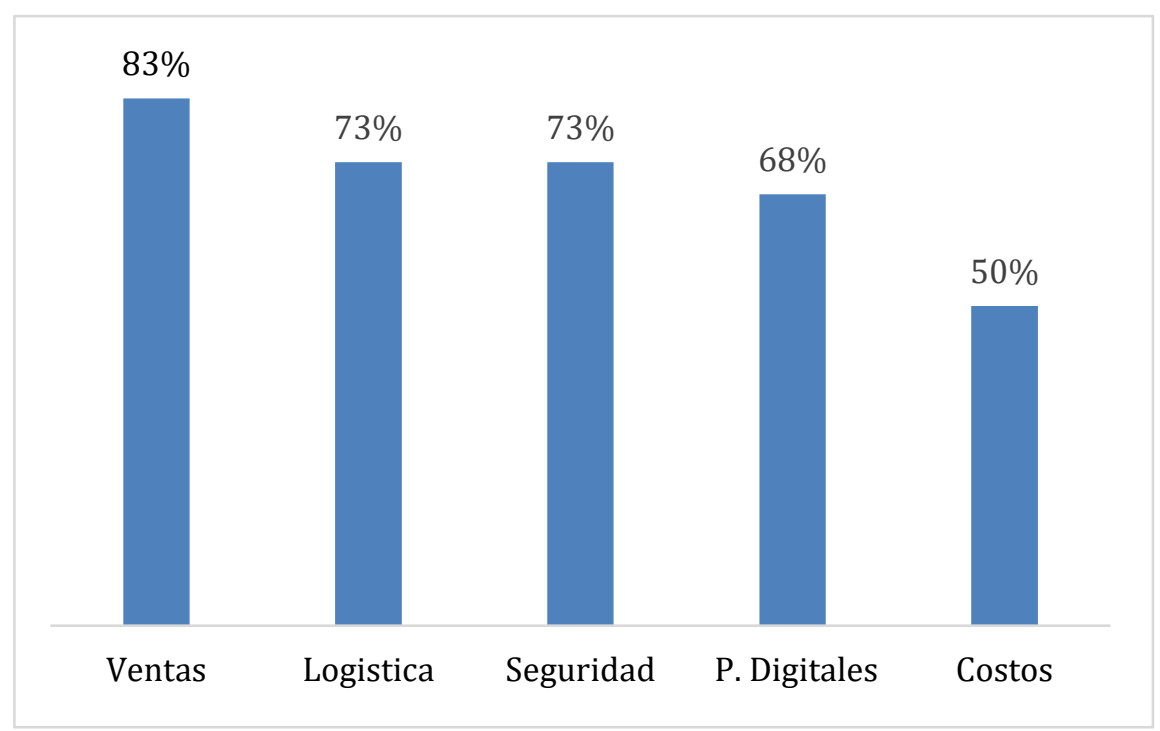

Fuente: Elaboración propia en base al Cuestionario de Pagos Digitales del Barrio 31

En la Hipótesis $\mathrm{N}^{\circ} 4$ indagamos sobre porque los comerciantes elegían aceptar pagos digitales. Si observamos la Figura 13 donde se analizan las razones por la que los comercios que aceptan pagos digitales actualmente deciden continuar, el $88 \%$ considero que ofrecer formas de pago digital es una oportunidad para mejorar las ventas.

En este sentido, a modo adicional, resulta interesante sumar al análisis la percepción de los comerciantes que aceptan pagos digitales en sus comercios acerca del futuro de las ventas con esta forma de pago en los próximos doce meses de su actividad comercial. Este análisis que excede los fines de esta hipótesis, se realiza con el objeto de aportar valor comparativo a la motivación principal de incrementar las ventas entre los interesados que no aceptan pagos.

Así, aunque como ya denotamos son pocos los comercios que actualmente aceptan y a su vez han recibido pagos con tarjetas, en la Tabla 2 podemos observar que el $92 \%$ de los comercios que aceptan pagos digitales cree que sus ventas van a aumentar más del $10 \%$ en los próximos doce meses con tarjeta de débito y el $8 \%$ restante que van a crecer, pero menos del $10 \%$. En el caso de las ventar con tarjeta de crédito el $68 \%$ cree que van a aumentar más del $10 \%$, el $4 \%$ menos del $10 \%$, el $12 \%$ que se van a mantener estables y apenas el $8 \%$ cree que van a bajar.

Estas respuestas se dan en un contexto donde el $77 \%$ respondió que sus ventas que habían bajado más del 10\% en el último año, y un 11\% que habían bajado menos del 10\% (Ver Apéndice A). 
Tabla 2. Variación esperada de ventas usuarios de Pagos Digitales

\begin{tabular}{|c|c|c|}
\hline Variación de ventas & $\%$ Con tarjeta de debito & $\%$ Con tarjeta de crédito \\
\hline Van a crecer más del $10 \%$ & $92,0 \% \quad(n=23)$ & $68,0 \% \quad(n=17)$ \\
\hline Van a crecer menos del $10 \%$ & $8,0 \% \quad(\mathrm{n}=2)$ & $4,0 \% \quad(\mathrm{n}=1)$ \\
\hline Se van a mantener igual & $0,0 \% \quad(\mathrm{n}=0)$ & $12,0 \% \quad(n=3)$ \\
\hline Van a bajar & $0,0 \% \quad(\mathrm{n}=0)$ & $8,0 \% \quad(\mathrm{n}=2)$ \\
\hline $\mathrm{Ns} / \mathrm{Nc}$ & $0,0 \% \quad(\mathrm{n}=0)$ & $8,0 \% \quad(\mathrm{n}=2)$ \\
\hline Total & $100,0 \% \quad(n=25)$ & $100,0 \% \quad(n=25)$ \\
\hline
\end{tabular}

Fuente: Elaboración propia en base al Cuestionario de Pagos Digitales del Barrio 31

En resumen, contemplar la mencionada importancia que tiene la motivación de vender más a la hora de decidir aceptar medios de pago electrónicos para los comerciantes del Barrio 31 es vital para planificar una buena estrategia de digitalización. Los datos de esta hipótesis nos muestran que la aceptación de pagos digitales no es sólo un tema de seguridad, sino también es una estrategia de negocios racional a la hora de mejorar la actividad económica.

Los comercios manifiestan que mejorar la seguridad y la logística, sumada a la expectativa de tener mejores resultados en las ventas son los grandes motores para impulsar la digitalización de sus pagos. Consecuentemente, el segundo eje que una política de promoción a los pagos digitales en el Barrio 31 debe considerar es transmitir de manera sencilla y clara cómo el comerciante se beneficiará en términos económicos incrementando sus ventas o atrayendo nuevos clientes.

\section{Conclusiones y reflexiones finales}

A lo largo de este trabajo hemos buscado comprender con mayor profundidad el estado actual de los pagos digitales en comercios del Barrio 31. Para ello, además de caracterizar y diagnosticar el estado actual, se han analizado las barreras y bondades (efectivas y percibidas) que enfrentan los pagos digitales en esta población. Nuestro objetivo ha sido presentar un primer relevamiento como medio para mejorar el diseño de futuras políticas de inclusión financiera mediante instrumentos de pago digital en barrios vulnerables.

Hemos puesto en manifiesto que los pagos digitales son un elemento fundamental para la inclusión financiera y sus causales, principalmente en poblaciones más vulnerables. En nuestro Marco Teórico analizamos en profundidad los motivos de esta afirmación, posteriormente describimos el contexto nacional de fomento a la inclusión financiera en nuestro país para luego introducir el caso del Barrio 31 en torno a esta temática.

Reconociendo la importancia de los pagos digitales para la inclusión financiera, y la necesidad de una medición robusta y profunda para el buen diseño de intervenciones efectivas, avanzamos en nuestro ejercicio empírico. Para ello creamos una encuesta inédita que nos permitió contrastar seis hipótesis de investigación.

En las Hipótesis 1 y 2 hemos demostrado que los comerciantes del Barrio 31 a pesar de tener una alta penetración de teléfonos celulares, tienen percepciones diversas acerca de sus capacidades para manejar la tecnología. Los datos sobre el uso del celular, acceso a internet y la tenencia de otros dispositivos tecnológicos, invitan a entender que la inclusión financiera 
mediante herramientas digitales tiene un potencial inmenso. Pero, a su vez, que se requiere previamente mejorar la confianza en la tecnología con educación digital para posicionar al teléfono móvil como un instrumento factible para realizar pagos digitales.

En las Hipótesis 3 y 4 hemos presentado las externalidades propias y el efecto multiplicador de los pagos digitales para la inclusión financiera. Vimos que los comerciantes que aceptan pagos digitales tienen mayor acceso y hacen mayor uso de otros servicios y productos financieros. Además de esto, los comerciantes que aceptan pagos digitales también hacen mayor uso del dinero electrónico en sus consumos diarios y pagos a proveedores. Este círculo virtuoso es positivo para el comerciante porque consume más servicios financieros y utiliza menos efectivo, como para las instituciones financieras que ven multiplicada su demanda de servicios.

Por último, en las Hipótesis 5 y 6 demostramos que mejorar la seguridad del dinero y enfatizar en el incremento de las ventas del comercio son los incentivos más importantes que los comerciantes que aún no aceptan pagos digitales encuentran para empezar a aceptar en un futuro.

Definitivamente una política pública de pagos digitales en comercios de barrios vulnerables deberá atender con especial atención a un conjunto de fortalezas, oportunidades, debilidades, y amenazas que se desprenden de la lectura de este trabajo de investigación.

Entre los factores que resultan positivos y favorables en el entorno del Barrio 31 para la adopción de medios de pagos digitales, podemos mencionar como oportunidades la alta tenencia de teléfonos celulares inteligentes $(87 \%)$ y el alto interés por comenzar a digitalizar pagos en comercios $(51 \%)$. De manera similar, los comerciantes tienen en claro porque quieren pagos digitales: seguridad y ventas. Esto refleja una fortaleza pues quienes realizan transacciones vía medios de pago digitales presentan una menor probabilidad de ser víctimas de actos delictivos en general, y de entrega de dinero 'falso", en especial, que quienes recurren al efectivo. Ambos resultados facilitan la planificación de una estrategia a medida ya que contamos con información sobre qué aspectos hay que resaltar y perfeccionar para que el interés en digitalizar las ventas se transforme en una realidad efectiva.

Sobre los factores que podrían provocar una posición desfavorable del dinero digital frente al efectivo como debilidad, se esgrime la escaza educación y confianza digital, la baja penetración de las billeteras digitales (8\%) y el uso que se le da al celular actualmente que está muy alejado todavía de los aspectos comerciales (transferencias, compras por internet, pagos con QR, etc.). Por su parte, una amenaza destacada es que el uso del efectivo está muy arraigado en toda la población del Barrio 31, tanto para realizar ventas en los comercios relevados como también para realizar compras por parte de los comerciantes en su rol de consumidores. Este contexto hace más difícil la diseminación de los beneficios destacados en la aceptación de pagos digitales.

Consecuentemente, una estrategia de digitalización deberá ser lo suficientemente potente y llamativa como para contrarrestar una situación en la cual las personas ya están acostumbradas a utilizar efectivo. Generar confianza y entusiasmo en los cambios de hábitos y herramientas será sustancial para poder sustentar un escenario donde los comerciantes avancen en cambiar la manera en que cobraron y pagaron históricamente. Sólo así se podrá promover una inclusión financiera de mediante pagos digitales efectiva.

Finalmente, vale mencionar nuevamente, que los sectores vulnerables de la población poseen diversas barreras al uso de los servicios financieros y los medios digitales. Estas son tanto estructurales como conductuales que limitan el uso de este tipo de medios. Consecuentemente, esta investigación expuso un análisis descriptivo y exploratorio en base a una recolección de datos inédita, sin pretender ser representativa a la totalidad de barreras ni tampoco extrapolable 
a todas las poblaciones vulnerables de Argentina. Nuestro objetivo fue brindar mayor comprensión a las barreras y bondades (efectivas y percibidas) que enfrentan los pagos digitales en esta población como medio para mejorar el diseño de futuras políticas públicas de inclusión financiera mediante instrumentos de pago digital en barrios vulnerables.

De cara a futuras investigaciones, se podrían aplicar metodologías de análisis estadísticos/econométricos a la información recolectada para lograr conclusiones más limpias. Se destaca también la posibilidad de replicar este ejercicio y cuestionario de manera centralizada por los hacedores de políticas en el marco de la ENIF o bien por instituciones privadas con interés en fomentar la inclusión financiera mediante pagos digitales en comercios radicados en poblaciones vulnerables. Nuestro país no posee información precisa sobre el acceso y uso de las finanzas digitales segmentada hacia dentro de esta población, nuestro trabajo es un primer paso en ese sentido.

\section{Referencias}

Allen F., Demirguc-Kunt A., Klapper L. \& Peria, M. S. M. (2016). The foundations of financial inclusion: understanding ownership and use of formal accounts. Journal Financial Intermediation, 27, 1-30.

Alliance for Financial Inclusion (2016). 2016 Maya declaration report: Celebrating five years of advancing global financial inclusion. Kuala Lumpur, Malaysia. Retrieved from: https://www.afi-global.org/publications/2359/The-2016-Maya-Declaration-Report

Alliance for Financial Inclusion (2017). Guideline Note No.28, 'Defining Financial Inclusion', July 2017 https://www.afi-global.org/sites/default/files/publications/2017-

07/FIS_GN_28_AW_digital.pdf

Armendáriz, B., \& Morduch, J. (2010). The economics of microfinance. Estados Unidos: MIT Press.

Arner, D. W., Barberis, J., \& Buckey, R. P. (2017). FinTech, RegTech, and the reconceptualization of financial regulation. Northwestern Journal of International Law \& Business, 37(3), 371-413.

Banartzi, Shlomo and Richard Thaler (2004). Save more tomorrow: Using behavioral economics to increase employee saving. Journal of Political Economy, 112(S1), S164-S187

Benartzi, S., \& Lehrer, J. (2017). The smarter screen: Surprising ways to influence and improve online behavior. Penguin.

Berkmen, P., Beaton, M. K., Gershenson, M. D., del Granado, M. J. A., Ishi, K., Kim, M., ... \& Rousset, M. M. V. (2019). Fintech in Latin America and the Caribbean: Stocktaking. International Monetary Fund.

Bhargava, S., Conell-Price, L., Mason, R. \& Benartzi, S. (2018). Save(d) by Design. Recuperado de https://doi.org/10.2139/ssrn.3237820 
BID y Finnovista (2018). Fintech: América Latina 2018: Crecimiento y consolidación. Banco Interamericano de Desarrollo.

Bosch-Liarte, J., \& Bosch-Liarte, J. (2016). Radiografía del Fintech: clasificación, recopilación y análisis de las principales startups (Tesis de maestría). Recuperado de https://upcommons.upc.edu/handle/2117/97361

Brasel, S. \& Gips, J. (2014). Tablets, touchscreens, and touchpads: How varying touch interfaces trigger psychological ownership and endowment. Journal of Consumer Psychology, 24(2), 226-233. https://doi.org/10.1016/j.jcps.2013.10.003

Carballo I.E, Schvarztein D.E (2019, en prensa). Inclusión Financiera en el Barrio 31: nueva evidencia empírica mediante encuesta multidimensional. Nota de prensa aquí https://www.lanacion.com.ar/economia/radiografia-excluidos-del-sector-financiero-nid2174548

Carballo I.E. (2018) Financial Inclusion in Latin America. In: Farazmand A. (eds) Global Encyclopedia of Public Administration, Public Policy, and Governance. Springer, Cham

Crockett, A. (1997). Why is financial stability a goal of public policy?. Economic ReviewFederal Reserve Bank of Kansas City, 82(4), 5.

De Sousa, M. M. (2015). Financial inclusion and global regulatory standards: An empirical study across developing economies.

Dema, E. (2015). Managing the twin responsibilities of financial inclusion and financial stability. Applied Financial Economics, 12, 159-70.

Demirgüç-Kunt, A., Klapper, L. F., Singer, D., \& Van Oudheusden, P. (2015). The global findex database 2014: Measuring financial inclusion around the world. The Wolrd Bank

Demirguc-Kunt, A., Klapper, L., Singer, D., Ansar, S., y Hess, J. (2018). The Global Findex Database 2017: measuring financial inclusion and the Fintech revolution. The World Bank.

Demirguc-Kunt, A., Klapper, L., y Singer, D. (2017). Financial inclusion and inclusive growth: A review of recent empirical evidence. The World Bank.

Gabor, D., \& Brooks, S. (2017). The digital revolution in financial inclusion: international development in the fintech era. New Political Economy, 22(4), 423-436.

Gopinath, Shreyas, Justin Oliver, Supriyo Bhattacharya, R.R. Kulkarni (2010), "Putting Money in Motion: How Much Do Migrants Pay for Domestic Transfers?" IFMR and Reserve Bank of India College for Agricultural Banking Working Paper.

GPFI (2010). Principles for Innovative Financial Inclusion

GPFI (2016). Global Standard-Setting Bodies and Financial Inclusion: The Evolving Landscape.

Khan, J. (2011). Cash or card: Consumer perceptions of payment modes (Doctoral dissertation, Auckland University of Technology).

Klapper, L., El-Zoghbi , M., \& Hess, J. (2016). Achieving the Sustainable Development Goals: The Role of Financial Inclusion. Washington, DC: CGAP. 
Lacalle Calderon, M., y Rico Garrido, S. (2008). Microcreditos y pobreza: De un sueño al nobel de la paz.

Madrian, B., Hershfield, H., Sussman, A., Bhargava, S., Burke, J., Huettel, S., Jamison, J., Johnson, E., Lynch, J., Meier, S., Rick, S. \& Shu, S. (2017). Behaviorally informed policies for household financial decisionmaking. Behavioral Science \& Policy, 3(1), 26-40.

https://doi.org/10.1353/bsp.2017.0003

Madrian, B. C. and Shea, D. F. (2001). The power of suggestion: Inertia in 401(k) participation and savings behavior. The Quarterly Journal of Economics. 116(4), 1149-1525.

Mangen, A., Walgermo, B. \& Brønnick, K. (2013). Reading linear texts on paper versus computer screen: Effects on reading comprehension. International journal of educational research, 58, 61-68. Recuperado de https://shlyahta.com.ua/wpcontent/uploads/mangen_a_2013_reading_linear_texts_on_paper_ve_14552.pdf

Marston, M. D. (2001). Financial System Standards and Financial Stability: The Case of Basel Core Principles (No. 1-62). International Monetary Fund.

Mirsch, T., Lehrer, C. \& Jung, R. (2017). Digital Nudging: Altering User Behavior in Digital Environments. In Proceedings of the 13th International Conference on Wirtschaftsinformatik (WI) 2017 (pp. 634-648). Atlanta, GA: Association for Information Systems. AIS Electronic Library (AISeL).

Palacio Garcés, R. A., (2017). La convergencia del FinTech, LawTech \& RegTech: Panorama global de aprendizaje para Ameríca Latina. Felaban

Radcliffe, D., \& Voorhies, R. (2012). A Digital Pathway to Financial Inclusion. Available at SSRN 2186926.

Rojas, L. (2016). La Revolución de las empresas FinTech y el futuro de la Banca. Disrupción tecnológica en el sector financiero. Serie Políticas Públicas y Transformación Productiva, Banco de Desarrollo de América Latina.

Rudd, K. (2009). The global financial crisis. Monthly, The, (Feb 2009), 20.

Runnemark, E., Hedman, J., \& Xiao, X. (2015). Do consumers pay more using debit cards than cash?. Electronic Commerce Research and Applications, 14(5), 285-291.

Scott, B. (2013). The heretic's guide to global finance: hacking the future of money. London: Pluto Press.

Sehtman, A. (2009). La reproducción política de la precariedad urbana. El caso de la Villa 31 (1996-2007). Tesis de Maestría en Políticas Públicas y Gerenciamiento del Desarrollo, Georgetown University.

Silva, A., \& Ramos, M. (2017). La evolución del Sector Fintech, modelos de negocio, regulación y retos. Documento de coyuntura 2017-02. Recuperado de https://bit.ly/2IUjHYY

Torres Blázquez, R. (2017). Incorporación de las Nuevas Tecnologías al negocio bancario en España: impacto de las" Fintech".

Trivelli Ávila, C., \& Caballero Calle, E. (2018). ¿Cerrando brechas?: Las estrategias 
nacionales de inclusión financiera en América Latina y el Caribe. Lima: Instituto de Estudios Peruanos, IEP.

United Nations. (2015). Transforming our world: The 2030 Agenda for Sustainable Development https://sustainabledevelopment.un.org/post2015/transformingourworld

Vohs, K. D. and Faber, R. J. (2007). Spent Resources: Self-Regulatory Resource Availability Affects Impulse Buying. Journal of Consumer Research, 33(4), 537-548.

Vohs, K. D., Baumeiste, R. F., Schmeichel, B. J., Twenge, J. M., Nelson, N. M., and Tice, D. M. (2008). Making Choices Impairs Subsequent Self-Control: A Limited-Resource Account of Decision Making, Self-Regulation, and Active Initiative. Journal of Personality and Social Psychology, 94(5), 883-898.

Wright, G. and Mutesasira, L. (2001). The Relative Risks of Informal Savings. MicroSave Research Paper. 


\section{Apéndice A. Descripción de la Muestra}

Tabla A.1. Medios de pago digitales en el Barrio 31

\begin{tabular}{cr}
\hline & $\begin{array}{r}\text { \% que lo acepta como medio } \\
\text { de pago sobre población total }\end{array}$ \\
\hline Posnet inalámbrico & $21,2 \% \quad(\mathrm{n}=22)$ \\
\hline m-pos & $4,8 \% \quad(\mathrm{n}=5)$ \\
\hline Código QR & $1,9 \% \quad(\mathrm{n}=2)$ \\
\hline Otro & $0,0 \% \quad(\mathrm{n}=0)$ \\
\hline Total (Rtas. Únicas - excluyendo repeticiones) & $24,0 \% \quad(\mathrm{n}=25)$ \\
\hline
\end{tabular}

Fuente: Elaboración propia

Tabla A.2. Género

\begin{tabular}{|c|c|}
\hline Genero & $\%$ total población \\
\hline Femenino & $59,0 \% \quad(\mathrm{n}=61)$ \\
\hline Masculino & $41,0 \% \quad(n=43)$ \\
\hline Total & $100,0 \% \quad(n=104)$ \\
\hline
\end{tabular}

Fuente: Elaboración propia

Tabla A.3. Nivel educativo de los comerciantes

\begin{tabular}{crc}
\hline Nivel & \% total población \\
\hline Sin estudios & $3,80 \%$ & $(\mathrm{n}=4)$ \\
\hline Primario Incompleto & $8,70 \%$ & $(\mathrm{n}=9)$ \\
\hline Primario Completo & $20,20 \%$ & $(\mathrm{n}=21)$ \\
\hline Secundario Incompleto & $17,30 \%$ & $(\mathrm{n}=18)$ \\
\hline Secundario Completo & $38,50 \%$ & $(\mathrm{n}=40)$ \\
\hline Universitario Incompleto & $5,80 \%$ & $(\mathrm{n}=6)$ \\
\hline Universitario Completo & $5,80 \%$ & $(\mathrm{n}=6)$ \\
\hline Total & $\mathbf{1 0 0 , 0 0 \%}$ & $(\mathbf{n}=\mathbf{1 0 4})$
\end{tabular}

Fuente: Elaboración propia 
Tabla A.4. Rango etario de los comerciantes

\begin{tabular}{cc}
\hline Rango etario & \% total población \\
\hline $18-24$ & $6,7 \% \quad(\mathrm{n}=7)$ \\
\hline $25-34$ & $22,1 \% \quad(\mathrm{n}=23)$ \\
\hline $35-44$ & $28,8 \% \quad(\mathrm{n}=30)$ \\
\hline $45-54$ & $21,2 \% \quad(\mathrm{n}=22)$ \\
\hline $55-64$ & $16,3 \% \quad(\mathrm{n}=17)$ \\
\hline $65-74$ & $4,8 \% \quad(\mathrm{n}=5)$ \\
\hline Total & $\mathbf{1 0 0 , 0 \%}(\mathrm{n}=\mathbf{1 0 4})$ \\
\hline
\end{tabular}

Fuente: Elaboración propia

Tabla A.5. Nivel de ingreso de los comerciantes

\begin{tabular}{cc}
\hline Nivel de ingreso & \% total población \\
\hline$\$ 0-\$ 2.500$ & $4,8 \% \quad(\mathrm{n}=5)$ \\
\hline$\$ 2.500-\$ 5000$ & $6,7 \% \quad(\mathrm{n}=7)$ \\
\hline$\$ 5000-\$ 7.500$ & $6,7 \% \quad(\mathrm{n}=7)$ \\
\hline$\$ 7.500-\$ 10.000$ & $10,6 \% \quad(\mathrm{n}=11)$ \\
\hline$\$ 10.000-\$ 12.500$ & $18,3 \% \quad(\mathrm{n}=19)$ \\
\hline Mayor a $\$ 12.500$ & $34,6 \% \quad(\mathrm{n}=36)$ \\
\hline $\mathrm{Ns} / \mathrm{Nc}$ & $18,3 \% \quad(\mathrm{n}=19)$ \\
\hline Total & $\mathbf{1 0 0 , 0 \%} \quad(\mathrm{n}=\mathbf{1 0 4})$ \\
\hline
\end{tabular}

Fuente: Elaboración propia

Tabla A.6. Beneficiarios de programas sociales

\begin{tabular}{crl}
\hline & \multicolumn{2}{c}{ \% total población } \\
\hline No recibió apoyo económico del gobierno & $77,8 \%$ & $(\mathrm{n}=81)$ \\
\hline Recibió apoyo económico del gobierno & $22,1 \%$ & $(\mathrm{n}=23)$ \\
\hline Total & $\mathbf{1 0 0 , 0 \%}$ & $(\mathrm{n}=\mathbf{1 0 4})$ \\
\hline
\end{tabular}

Fuente: Elaboración propia 
Tabla A.7. Forma de acreditación de programas sociales

\begin{tabular}{crc}
\hline Recibió en depósito bancario & $10,6 \% \quad(\mathrm{n}=11)$ \\
\hline Recibió en cheque & $1,0 \% \quad(\mathrm{n}=1)$ \\
\hline Recibió en efectivo & $2,9 \% \quad(\mathrm{n}=3)$ \\
\hline Recibió con una tarjeta prepaga & $6,7 \% \quad(\mathrm{n}=7)$ \\
\hline Recibió con otra alternativa & $4,3 \% \quad(\mathrm{n}=1)$ \\
\hline Total & $\mathbf{1 0 0 , 0 \%} \quad(\mathbf{n}=\mathbf{1 0 4})$
\end{tabular}

Fuente: Elaboración propia

Tabla A.8. Nivel de formalización

\begin{tabular}{crr}
\hline & \% total población \\
\hline Monotributo tradicional & $25,00 \%$ & $(\mathrm{n}=26)$ \\
\hline Monotributo Social & $13,00 \%$ & $(\mathrm{n}=14)$ \\
\hline Ns/Nc & $7,00 \%$ & $(\mathrm{n}=7)$ \\
\hline No está inscripto & $55,00 \%$ & $(\mathrm{n}=57)$ \\
\hline Total & $\mathbf{1 0 0 , 0 0 \%}$ & $(\mathbf{n}=\mathbf{1 0 4})$ \\
\hline
\end{tabular}

Fuente: Elaboración propia

Tabla A.9. Tiene DNI / Tiene Empleados

\begin{tabular}{crll}
\hline Tiene empleados & $11,40 \%$ & $(\mathrm{n}=11)$ \\
\hline Tiene DNI & $96,20 \%$ & $(\mathrm{n}=100)$ \\
\hline Total & $\mathbf{1 0 0 , 0 0 \%}$ & $(\mathbf{n}=\mathbf{1 0 4})$ \\
\hline
\end{tabular}

Fuente: Elaboración propia

Tabla A.10. Ganancias de las actividades

\begin{tabular}{crl}
\hline Nivel de ganancia & \% total población \\
\hline$\$ 0-\$ 2.500$ & $13,50 \%$ & $(\mathrm{n}=14)$ \\
\hline$\$ 2.500-\$ 5000$ & $5,80 \%$ & $(\mathrm{n}=6)$ \\
\hline$\$ 5000-\$ 7.500$ & $9,60 \%$ & $(\mathrm{n}=10)$ \\
\hline$\$ 7.500-\$ 10.000$ & $8,70 \%$ & $(\mathrm{n}=9)$ \\
\hline Más de $\$ 10.000$ & $26,90 \%$ & $(\mathrm{n}=28)$ \\
\hline Ns/Nc & $35,60 \%$ & $(\mathrm{n}=37)$ \\
\hline Total & $\mathbf{1 0 0 , 0 0 \%} \quad(\mathbf{n}=\mathbf{1 0 4})$ \\
\hline
\end{tabular}

Fuente: Elaboración propia 
Tabla A.11. Variación de ventas en los últimos 12 meses

\begin{tabular}{cr}
\hline Variación & \% total población \\
\hline Subieron más del 10\% & $2,90 \% \quad(\mathrm{n}=3)$ \\
\hline Subieron entre el 3\% y 10\% & $1,90 \% \quad(\mathrm{n}=2)$ \\
\hline Se mantuvieron igual & $3,80 \% \quad(\mathrm{n}=4)$ \\
\hline Bajaron entre un 3\% y 10\% & $10,60 \% \quad(\mathrm{n}=11)$ \\
\hline Bajaron más del 10\% & $76,90 \% \quad(\mathrm{n}=80)$ \\
\hline Ns/Nc & $3,80 \% \quad(\mathrm{n}=4)$ \\
\hline Total & $\mathbf{1 0 0 , 0 0 \%} \quad(\mathbf{n}=\mathbf{1 0 4})$ \\
\hline
\end{tabular}

Fuente: Elaboración propia

Tabla A.12. Volumen diario de clientes

\begin{tabular}{crl}
\hline & \% total población \\
\hline $0-10$ personas & $22,10 \%$ & $(\mathrm{n}=23)$ \\
\hline $10-20$ personas & $26,90 \%$ & $(\mathrm{n}=28)$ \\
\hline $20-30$ personas & $23,10 \%$ & $(\mathrm{n}=24)$ \\
\hline $30-40$ personas & $6,70 \%$ & $(\mathrm{n}=7)$ \\
\hline Más de 40 personas & $21,20 \%$ & $(\mathrm{n}=22)$ \\
\hline Total & $\mathbf{1 0 0 , 0 0 \%}$ & $(\mathbf{n}=\mathbf{1 0 4})$ \\
\hline
\end{tabular}

Fuente: Elaboración propia

Tabla A.13. Frecuencia carga de la tarjeta SUBE

\begin{tabular}{cr}
\hline Frecuencia mensual & \% de la población \\
\hline 0 veces & $5,7 \% \quad(\mathrm{n}=6)$ \\
\hline $1-2$ veces & $26,9 \% \quad(\mathrm{n}=28)$ \\
\hline $3-5$ veces & $39,4 \% \quad(\mathrm{n}=41)$ \\
\hline $5-10$ veces & $19,2 \% \quad(\mathrm{n}=20)$ \\
\hline Más de 10 veces & $8,6 \% \quad(\mathrm{n}=9)$ \\
\hline Total & $\mathbf{1 0 0 , 0 \%} \quad(\mathbf{n}=\mathbf{1 0 4})$ \\
\hline
\end{tabular}

Fuente: Elaboración propia 
Tabla A.14. Ahorro

\begin{tabular}{ccc}
\hline & $\begin{array}{c}\text { \% ahorro en los últimos } \\
\text { doce }\end{array}$ & $\begin{array}{c}\text { \% } \\
\text { ahorro en una cuenta } \\
\text { formal / ahorraron }\end{array}$ \\
\hline total / total & $49,0 \% \quad(\mathrm{n}=51)$ & $11,8 \% \quad(\mathrm{n}=6)$ \\
\hline usuarios / usuarios & $72,0 \% \quad(\mathrm{n}=18)$ & $22,2 \% \quad(\mathrm{n}=4)$ \\
\hline no usuarios / no usuarios & $41,8 \% \quad(\mathrm{n}=33)$ & $6,1 \% \quad(\mathrm{n}=2)$ \\
\hline
\end{tabular}

Fuente: Elaboración propia

Tabla A.15. Dinero en efectivo en un día ordinario

\begin{tabular}{crlrl}
\hline $\begin{array}{c}\text { Cantidad de } \\
\text { dinero }\end{array}$ & $\begin{array}{c}\text { \% de la población que lleva este } \\
\text { dinero consigo misma }\end{array}$ & $\begin{array}{r}\text { \% de la población que deja } \\
\text { en su casa este dinero }\end{array}$ \\
\hline$\$ 0$ & $2,9 \%$ & $(\mathrm{n}=3)$ & $9,6 \%$ & $(\mathrm{n}=10)$ \\
\hline$\$ 1-\$ 200$ & $17,3 \%$ & $(\mathrm{n}=18)$ & $2,9 \%$ & $(\mathrm{n}=3)$ \\
\hline$\$ 200-\$ 400$ & $31,7 \%$ & $(\mathrm{n}=33)$ & $6,7 \%$ & $(\mathrm{n}=7)$ \\
\hline$\$ 400-\$ 600$ & $14,4 \%$ & $(\mathrm{n}=15)$ & $8,7 \%$ & $(\mathrm{n}=9)$ \\
\hline$\$ 600-\$ 800$ & $4,8 \%$ & $(\mathrm{n}=5)$ & $9,6 \%$ & $(\mathrm{n}=10)$ \\
\hline Más de $\$ 800$ & $21,2 \%$ & $(\mathrm{n}=22)$ & $36,5 \%$ & $(\mathrm{n}=38)$ \\
\hline Ns/Nc & $7,7 \%$ & $(\mathrm{n}=8)$ & $26,0 \%$ & $(\mathrm{n}=27)$ \\
\hline Total & $\mathbf{1 0 0 , 0 \%}$ & $(\mathrm{n}=104)$ & $100,0 \%$ & $(\mathrm{n}=104)$ \\
\hline
\end{tabular}

Fuente: Elaboración propia

Tabla A.16. Ventas con Debito

\begin{tabular}{crl}
\hline $\begin{array}{c}\text { \% de clientes que les pagan con } \\
\text { Tarjeta de Debito }\end{array}$ & \% de comerciantes que aceptan pagos digitales \\
\hline $0,0 \%$ & $20,0 \%$ & $(\mathrm{n}=5)$ \\
\hline $1,0 \%$ & $4,0 \%$ & $(\mathrm{n}=1)$ \\
\hline $5,0 \%$ & $4,0 \%$ & $(\mathrm{n}=1)$ \\
\hline $10,0 \%$ & $64,0 \%$ & $(\mathrm{n}=16)$ \\
\hline $25,0 \%$ & $4,0 \%$ & $(\mathrm{n}=1)$ \\
\hline $30,0 \%$ & $4,0 \%$ & $(\mathrm{n}=1)$ \\
\hline Total & $\mathbf{1 0 0 , 0} \%$ & $(\mathrm{n}=25)$ \\
\hline
\end{tabular}

Fuente: Elaboración propia 
Tabla A.17. Demanda de créditos

\begin{tabular}{lrlll}
\hline & \% Demandantes efectivos & \% Demandantes potenciales \\
\hline $\begin{array}{l}\text { Total demandantes / } \\
\text { población }\end{array}$ & $\mathbf{2 4 \%}$ & $(\mathbf{n}=\mathbf{2 5})$ & $\mathbf{6 7 \%}$ & $(\mathbf{n}=\mathbf{7 0})$ \\
\hline Emprendimientos & $76,0 \%$ & $(\mathrm{n}=19)$ & $87,1 \%$ & $(\mathrm{n}=61)$ \\
\hline Vivienda & $20,0 \%$ & $(\mathrm{n}=5)$ & $62,9 \%$ & $(\mathrm{n}=44)$ \\
\hline Salud y Educación & $16,0 \%$ & $(\mathrm{n}=4)$ & $48,6 \%$ & $(\mathrm{n}=34)$ \\
\hline Consumo & $8,0 \%$ & $(\mathrm{n}=2)$ & $38,6 \%$ & $(\mathrm{n}=27)$ \\
\hline Celebraciones & $0,0 \%$ & $(\mathrm{n}=0)$ & $10,0 \%$ & $(\mathrm{n}=7)$ \\
\hline
\end{tabular}

Fuente: Elaboración propia

Tabla A.18. Percepción de seguridad

\begin{tabular}{|c|c|c|c|}
\hline & \% no acepta pagos digitales & $\%$ acepta pagos digitales & $\%$ total \\
\hline De acuerdo & $29,1 \% \quad(n=23)$ & $32,0 \% \quad(\mathrm{n}=8)$ & $29,8 \% \quad(n=31)$ \\
\hline $\begin{array}{l}\text { Muy de } \\
\text { acuerdo }\end{array}$ & $15,2 \% \quad(n=12)$ & $20,0 \% \quad(n=5)$ & $16,3 \% \quad(\mathrm{n}=17)$ \\
\hline $\begin{array}{l}\text { No estoy de } \\
\text { acuerdo }\end{array}$ & $50,6 \% \quad(\mathrm{n}=40)$ & $44,0 \% \quad(\mathrm{n}=11)$ & $49,0 \% \quad(\mathrm{n}=51)$ \\
\hline $\mathrm{Ns} / \mathrm{Nc}$ & $5,1 \% \quad(\mathrm{n}=4)$ & $4,0 \% \quad(\mathrm{n}=1)$ & $4,8 \% \quad(n=5)$ \\
\hline Total & $100,0 \% \quad(n=79)$ & $100 \% \quad(n=25)$ & $100,0 \% \quad(n=104)$ \\
\hline
\end{tabular}

Fuente: Elaboración propia 
Apéndice B. Usos del teléfono y confianza autopercibida de los comerciantes del Barrio 31.

Tabla B.1. Instalar actualizaciones

\begin{tabular}{|c|c|c|c|c|c|c|c|c|}
\hline \multirow{2}{*}{$\begin{array}{l}\text { ¿En el último mes cuantas veces aproximadamente } \\
\text { utilizo su celular para instalar actualizaciones del } \\
\text { sistema o aplicaciones? }\end{array}$} & \multicolumn{2}{|c|}{ Muy Seguro } & \multicolumn{2}{|c|}{ Más o menos } & \multicolumn{2}{|c|}{ No me siento seguro } & \multicolumn{2}{|c|}{ Suma total } \\
\hline & $\mathbf{N}$ & $\%$ & $\mathbf{n}$ & $\%$ & $\mathbf{n}$ & $\%$ & $\mathbf{n}$ & $\%$ \\
\hline $1-2$ & 11 & $30.6 \%$ & 11 & $29.7 \%$ & 0 & $0 \%$ & 22 & $23.4 \%$ \\
\hline $3-5$ & 10 & $27.8 \%$ & 4 & $10.8 \%$ & 2 & $9.5 \%$ & 16 & $17.0 \%$ \\
\hline $6-10$ & 2 & $5.5 \%$ & 0 & $0 \%$ & 0 & 0 & 2 & $2.1 \%$ \\
\hline Más que 10 & 1 & $2.8 \%$ & 1 & $2.7 \%$ & 0 & 0 & 2 & $2.1 \%$ \\
\hline Suma total & 36 & $100 \%$ & 37 & $100 \%$ & 21 & $100 \%$ & 94 & $100 \%$ \\
\hline
\end{tabular}

Fuente: Elaboración propia 
Tabla B.2. Cambiar contraseña

¿En el último mes cuantas veces aproximadamente utilizo su celular para cambiar la contraseña de acceso a su teléfono o aplicaciones?

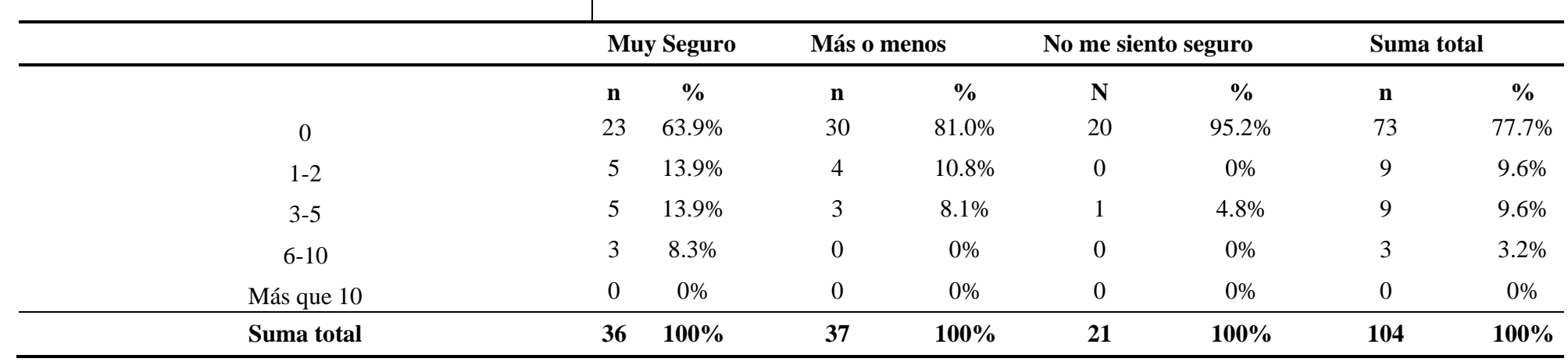

¿Qué tan seguro se siente con sus capacidades para entender y utilizar la tecnología de un teléfono?

Fuente: Elaboración propia 
Tabla B.3. Enviar un mail

¿En el último mes cuantas veces aproximadamente utilizo su celular para enviar o leer un correo electrónico (mail)?

¿Qué tan seguro se siente con sus capacidades para entender y utilizar la tecnología de un teléfono?

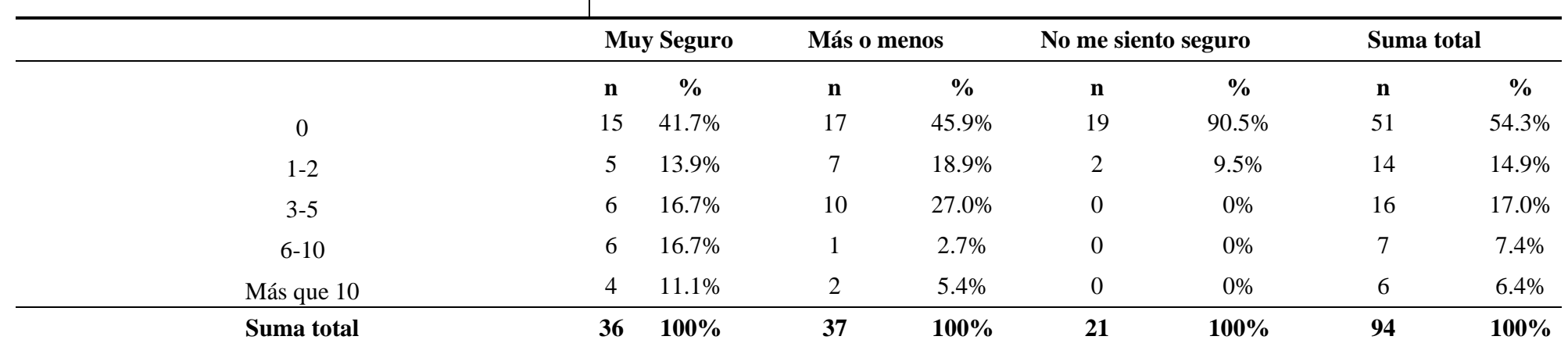

Fuente: Elaboración propia 
Tabla B.4. Tomarse una selfie

\begin{tabular}{|c|c|c|c|c|c|c|c|c|}
\hline \multirow[t]{2}{*}{$\begin{array}{l}\text { ¿En el último mes cuantas veces aproximadamente } \\
\text { utilizo su celular para tomarse una auto foto (selfie)? }\end{array}$} & \multicolumn{8}{|c|}{$\begin{array}{l}\text { ¿Qué tan seguro se siente con sus capacidades para entender y utilizar la tecnología de un } \\
\text { teléfono? }\end{array}$} \\
\hline & \multicolumn{2}{|c|}{ Muy Seguro } & \multicolumn{2}{|c|}{ Más o menos } & \multicolumn{2}{|c|}{ No me siento seguro } & \multicolumn{2}{|c|}{ Suma total } \\
\hline 0 & 11 & $30.6 \%$ & 11 & $29.7 \%$ & 15 & $71.4 \%$ & 37 & $39.4 \%$ \\
\hline $1-2$ & 3 & $8.3 \%$ & 3 & $8.1 \%$ & 2 & $9.5 \%$ & 8 & $8.5 \%$ \\
\hline $3-5$ & 7 & $19.4 \%$ & 10 & $27.0 \%$ & 3 & $14.3 \%$ & 20 & $21.3 \%$ \\
\hline $6-10$ & 4 & $11.1 \%$ & 4 & $10.8 \%$ & 0 & $0 \%$ & 8 & $8.5 \%$ \\
\hline Más que 10 & 11 & $30.6 \%$ & 9 & $24.3 \%$ & 1 & $4.8 \%$ & 21 & $22.3 \%$ \\
\hline Suma total & 36 & $100 \%$ & 37 & $100 \%$ & 21 & $100 \%$ & 94 & $100 \%$ \\
\hline
\end{tabular}

Fuente: Elaboración propia 
Tabla B.5. Enviar un video

\begin{tabular}{|c|c|c|c|c|c|c|c|c|}
\hline \multirow[t]{2}{*}{$\begin{array}{l}\text { ¿En el último mes cuantas veces aproximadamente } \\
\text { utilizo su celular para enviar un video a otra persona? }\end{array}$} & \multicolumn{8}{|c|}{$\begin{array}{c}\text { ¿Qué tan seguro se siente con sus capacidades para entender y utilizar la tecnología de un } \\
\text { teléfono? }\end{array}$} \\
\hline & $\mathbf{N}$ & $\%$ & $\mathbf{n}$ & $\%$ & $\mathbf{n}$ & $\%$ & $\mathbf{n}$ & $\%$ \\
\hline 0 & 12 & $33.3 \%$ & 12 & $32.4 \%$ & 13 & $61.9 \%$ & 37 & $39.4 \%$ \\
\hline $3-5$ & 8 & $22.2 \%$ & 12 & $32.4 \%$ & 5 & $23.8 \%$ & 25 & $26.6 \%$ \\
\hline $6-10$ & 8 & $22.2 \%$ & 3 & $8.1 \%$ & 0 & $0 \%$ & 11 & $11.7 \%$ \\
\hline Más que 10 & 6 & $16.7 \%$ & 4 & $10.8 \%$ & 0 & $0 \%$ & 10 & $10.6 \%$ \\
\hline Suma total & 36 & $100 \%$ & 37 & 1000 & 21 & $100 \%$ & 94 & $100 \%$ \\
\hline
\end{tabular}

Fuente: Elaboración propia 


\section{Tabla B.6. Reenviar mensajes de whatsapp}

¿En el último mes cuantas veces aproximadamente utilizo su celular para reenviar a más de una persona al mismo tiempo un mensaje de WhatsApp?

¿Qué tan seguro se siente con sus capacidades para entender y utilizar la tecnología de un teléfono?

\begin{tabular}{|c|c|c|c|c|c|c|c|c|}
\hline & \multicolumn{2}{|c|}{ Muy Seguro } & \multicolumn{2}{|c|}{ Más o menos } & \multicolumn{2}{|c|}{ No me siento seguro } & \multicolumn{2}{|c|}{ Suma total } \\
\hline & $\mathbf{n}$ & $\%$ & $\mathbf{n}$ & $\%$ & $\mathbf{n}$ & $\%$ & $\mathbf{n}$ & $\%$ \\
\hline 0 & 10 & $27.8 \%$ & 17 & $45.9 \%$ & 16 & $76.2 \%$ & 43 & $45.7 \%$ \\
\hline $3-5$ & 9 & $25.0 \%$ & 9 & $24.3 \%$ & 3 & $14.3 \%$ & 21 & $22.3 \%$ \\
\hline $6-10$ & 7 & $19.4 \%$ & 3 & $8.1 \%$ & 1 & $4.8 \%$ & 11 & $11.7 \%$ \\
\hline
\end{tabular}

Fuente: Elaboración propia 


\section{Tabla B.7. Enviar una ubicación de GPS}

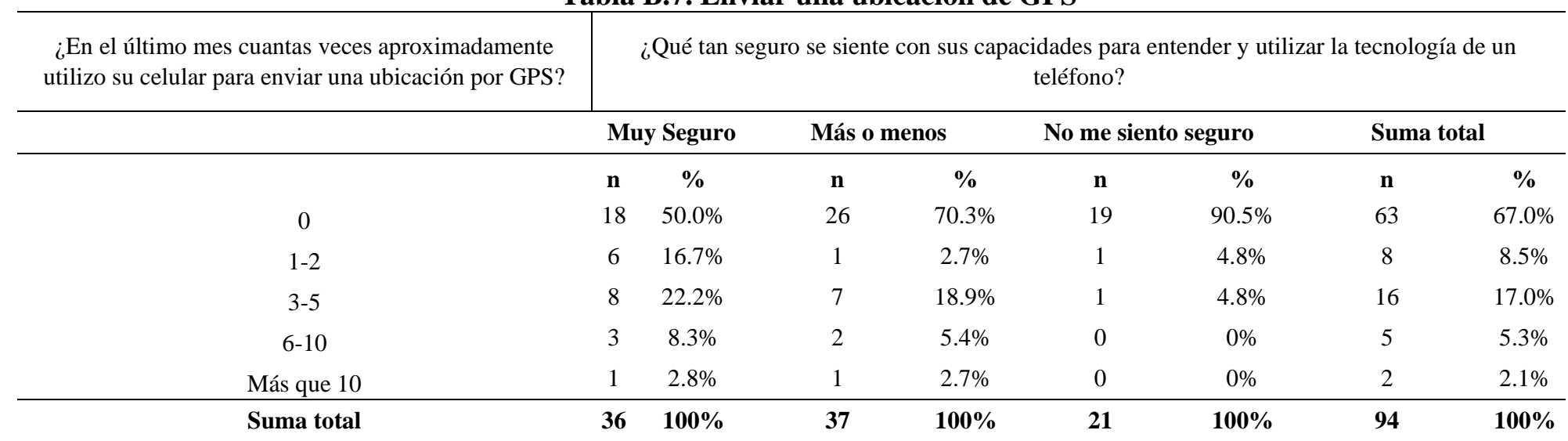

Fuente: Elaboración propia

\section{Tabla B.8. Uso de red wifi}

\begin{tabular}{|c|c|c|c|c|c|c|c|c|}
\hline \multirow[t]{3}{*}{$\begin{array}{c}\text { ¿En el último mes cuantas veces aproximadamente } \\
\text { utilizo su celular para conectarse a una red wifi } \\
\text { ingresando usuario y clave? }\end{array}$} & \multicolumn{8}{|c|}{$\begin{array}{c}\text { ¿Qué tan seguro se siente con sus capacidades para entender y utilizar la tecnología de un } \\
\text { teléfono? }\end{array}$} \\
\hline & \multicolumn{2}{|c|}{ Muy Seguro } & \multicolumn{2}{|c|}{ Más o menos } & \multicolumn{2}{|c|}{ No me siento seguro } & \multicolumn{2}{|c|}{ Suma total } \\
\hline & $\mathbf{n}$ & $\%$ & $\mathbf{n}$ & $\%$ & $\mathbf{n}$ & $\%$ & $\mathbf{n}$ & $\%$ \\
\hline 0 & 12 & $33.3 \%$ & 20 & $54.0 \%$ & 19 & $85.7 \%$ & 50 & $54.2 \%$ \\
\hline $1-2$ & 2 & $5.6 \%$ & 3 & $8.1 \%$ & 1 & $4.8 \%$ & 6 & $6.4 \%$ \\
\hline $3-5$ & 7 & $19.4 \%$ & 6 & $16.2 \%$ & 1 & $4.8 \%$ & 14 & $14.9 \%$ \\
\hline $6-10$ & 6 & $16.7 \%$ & 5 & $13.5 \%$ & 0 & $0 \%$ & 11 & $11.7 \%$ \\
\hline Más que 10 & 9 & $25.0 \%$ & 3 & $8.1 \%$ & 1 & $4.8 \%$ & 13 & $13.8 \%$ \\
\hline Suma total & 36 & $100 \%$ & 37 & $100 \%$ & 21 & $100 \%$ & 94 & $100 \%$ \\
\hline
\end{tabular}

Fuente: Elaboración propia 
Tabla B.9. Diarios digitales

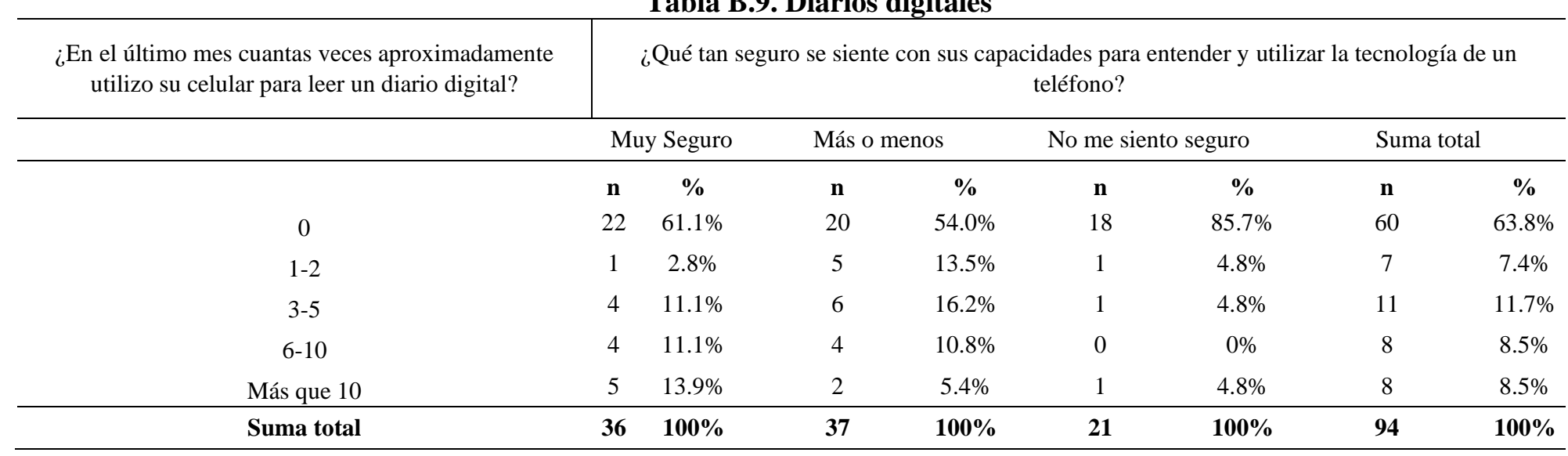

Fuente: Elaboración propia 


\section{Apéndice C}

\section{Cuestionario de Pagos Digitales en el Barrio 31.}

Introducción al encuestado: Esta encuesta forma parte de un trabajo de investigación sobre las barreras y los incentivos para utilizar medios de pago de digitales en el Barrio 31. La idea de hoy es completar un cuestionario anónimo para tener más información sobre los medios de pago que predominan en el barrio en general. Esa información nos va a permitir comprobar ciertas hipótesis y elaborar propuestas de políticas públicas para mejorar la inclusión financiera a través de los pagos digitales.

*Obligatorio

\section{Del entrevistado (sociodemográfico)}

\section{1) ¿Tiene Documento Nacional de Identidad? *}

Marca solo un óvalo.

○ Sí.

$\circ \quad$ No

1.2) ¿En qué sector del Barrio se encuentra el encuestado? *

Marca solo un óvalo.

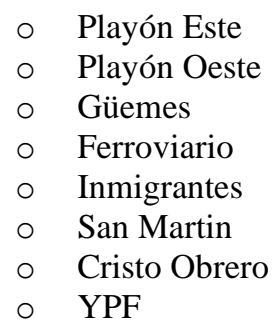

1.3) ¿Cuál es su edad? Indique el número exacto

1.4) ¿Cuál es su género?

Marca solo un óvalo.

○ Masculino

○ Femenino 
1.5) ¿Cuál es su nivel de estudios máximo alcanzado?

Marca solo un óvalo.

- Sin estudios

- Primario incompleto

- Primario completo

- Secundario incompleto

- Secundario completo

- Universitario incompleto

- Universitario completo

○ Post universitario

1.6) ¿Cuántas personas viven en su hogar?

Indique con un numero

○

1.7) ¿Todas las personas que viven en esta vivienda comparten un mismo gasto para alimentarse? Marca solo un óvalo.
○ Sí
$\circ \quad$ No

1.8) ¿Entonces cuantos hogares o grupos de personas tienen gasto separado para comer contando el de usted? Indique con un numero

O

1.9) ¿Además de esta actividad, hay alguna otra fuente de ingresos en el hogar?

Marca solo un óvalo.

$$
\begin{array}{ll}
\circ & \text { Sí } \\
\circ & \text { No }
\end{array}
$$

1.10) ¿En promedio cual es el ingreso mensual de su hogar?

Marca solo un óvalo.

$\begin{array}{ll}\circ & \$ 0-\$ 2500 \\ \circ & \$ 2500-\$ 5000 \\ \circ & \$ 5000-\$ 7500 \\ \circ & \$ 7500-10000 \\ \circ & \$ 10000-\$ 12500 \\ \circ & \text { Más de } \$ 12500 \\ \circ & \text { Ns/Nc }\end{array}$

1.11) ¿Usted personalmente, RECIBIÓ algún apoyo económico por parte del gobierno en los últimos 12 meses? ¿Este dinero podría ser el pago de gastos educativos o médicos, prestaciones por desempleo, subsidios, o cualquier tipo de BENEFICIO SOCIAL? Por favor NO incluya salario, jubilación ni pagos relacionados con el trabajo Marca solo un óvalo.

- Sí

- No (Pasa a la pregunta 1.13)

- Ns/Nc (Pasa a la pregunta 1.13) 
1.12) ¿Cómo recibió el dinero de esa prestación?

Marca solo un óvalo.

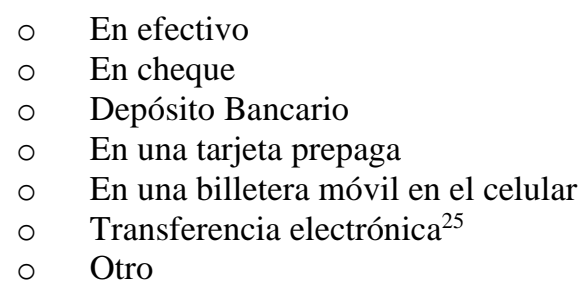

\section{De la actividad económica}

2.1) En cuanto a la estructura comercial de esta actividad económica, usted es: Marca solo un óvalo.

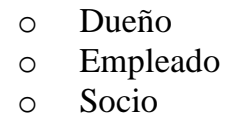

\section{2) A que rubros pertenece esta actividad económica:}

Marca uno o más óvalos según corresponda.

$\begin{array}{cl}\circ & \text { Restaurante } \\ \circ & \text { Comida al paso } \\ \circ & \text { Especias } \\ \circ & \text { Productos de Limpieza } \\ \circ & \text { Indumentaria } \\ \circ & \text { Librería } \\ \circ & \text { Almacén } \\ \circ & \text { Verdulería } \\ \circ & \text { Kiosco } \\ \circ & \text { Panadería } \\ \circ & \text { Peluquería } \\ \circ & \text { Ferretería } \\ \circ & \text { Lavandería } \\ \circ & \text { Otro: }\end{array}$

\footnotetext{
${ }^{25}$ Luego de realizar una prueba piloto del cuestionario, se decidió incorporar las dos opciones "depósito bancario" y "transferencia electrónica" ya que en reiteradas oportunidades había desconocimiento en los encuestados sobre si un depósito en mi cuenta bancaria era una transferencia, o si transferencia electrónica era únicamente cuando mandaba dinero con un celular.
} 
2.3) ¿Hace cuánto tiempo desarrolla esta actividad?:

Marca la opción correcta.

$\begin{array}{ll}\circ & 0-3 \text { meses } \\ \circ & 3-6 \text { meses } \\ \circ & 6-9 \text { meses } \\ \circ & 9-12 \text { meses } \\ \circ & 1-3 \text { años } \\ \circ & 3-5 \text { años } \\ \circ & \text { Entre } 5 \text { y } 10 \text { años } \\ \circ & \text { Más de } 10 \text { años }\end{array}$

2.4) ¿Cuál es el valor medio de lo que usted ofrece para vender?: Marca la opción correcta.
○ $\$ 0-\$ 50$
- $\$ 50-\$ 100$
- $\$ 100-\$ 200$
- $\$ 200-\$ 300$
○ $\$ 300-\$ 400$
○ $\$ 400-\$ 500$
○ Más de $\$ 500$

2.5) La prestación del servicio, o la venta del producto pude comercializarse a domicilio, en un local, en la feria del barrio, etcétera. ¿En qué lugar físico ejerce usted su actividad comercial?

Marca la opción correcta.

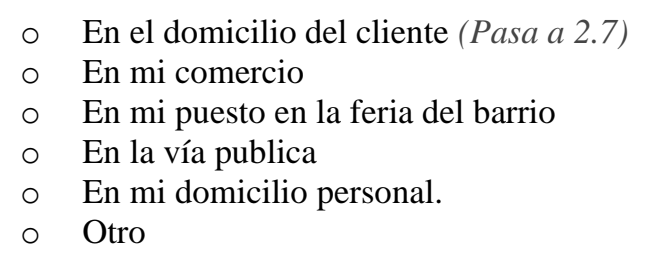

2.6) ¿Cuántas personas visitan su comercio, puesto en la feria o en la vía pública, domicilio por día en promedio? Marca la opción correcta.
- 0-10 personas
- 10-20 personas
- 20-30 personas
○ 30- 40 personas
- Más de 40 personas.

2.7) ¿Cuánto gasta en promedio cada consumidor de su actividad? Marca la opción correcta.
○ $\$ 0-\$ 50$
○ $\$ 50-\$ 150$
○ $\$ 150-\$ 250$
○ $\$ 250-\$ 350$
○ $\$ 350-\$ 450$
○ \$450-\$550
○ Más de $\$ 550$ 
2.8) ¿Cuál es la ganancia mensual promedio que le deja esta actividad económica? Marca la opción correcta

$\begin{array}{ll}\circ & \$ 0-\$ 2500 \\ \circ & \$ 2500-\$ 5000 \\ \circ & \$ 5000-\$ 7500 \\ \circ & \$ 7500-\$ 10000 \\ \circ & \text { Más de } \$ 10000 \\ \circ & \text { Ns/Nc }\end{array}$

2.9) Administrar las cuentas del comercio, anotar pagos a proveedores, pagar los impuestos, compra de mercadería, pago y cobro de deudas, consume un determinado tiempo a diario. ¿En promedio cuanto tiempo dedica por día para a administrar las cuentas de su negocio?

Marca la opción correcta
○ $\quad 10-15$ minutos
○ 16-20 minutos
- 21-30 minutos
- 31-45 minutos
- 46-60 minutos
- Más de 60 minutos
- 0 minutos

2.10) ¿Tiene empleados para el desarrollo de esta actividad económica?

Marca la opción correcta.

$$
\begin{array}{ll}
\circ & \text { Sí } \\
\circ & \text { No (Pasa a 2.12) }
\end{array}
$$

2.11) En relación a la pregunta anterior ¿De qué forma les paga el sueldo a sus empleados? Marca la opción correcta.

$\begin{array}{ll}\circ & \text { En efectivo } \\ \circ & \text { Cheque } \\ \circ & \text { Tarjeta prepaga } \\ \circ & \text { Transferencia electrónica de dinero } \\ \circ & \text { Depósito Bancario } \\ \circ & \text { En una billetera móvil en el celular } \\ \circ & \text { Otro }\end{array}$


2.12) Continuando con el desarrollo de esta actividad comercial. ¿Cómo diría aproximadamente que variaron las ganancias de la actividad en el último año?

Marca la opción correcta.

- Bajaron más de un $10 \%$

- Bajaron un $10 \%$

- Bajaron entre un $3 \%$ y $10 \%$

- Se mantuvieron igual

- Subieron entre un $3 \%$ y $10 \%$

- Subieron más del $10 \%$

○ Ns/Nc.

2.13) ¿Esta actividad económica está registrada oficialmente en alguna de las siguientes categorías? Marca la opción correcta.

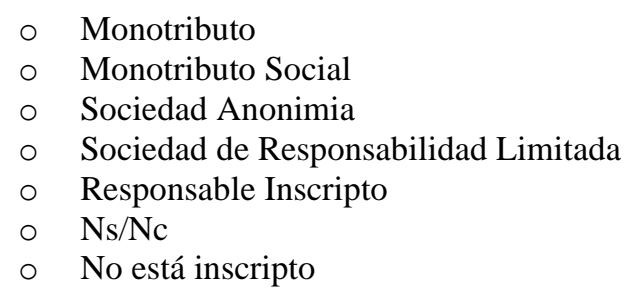

\section{Del acceso a servicios financieros.}

3.1) Una cuenta, caja de ahorro o cuenta corriente, se puede utilizar para, hacer o recibir pagos, para recibir su salario o subsidio, o para ahorrar dinero ¿Tiene usted en la actualidad, ya sea por sí solo o conjuntamente con otra persona, una caja de ahorro o cuenta corriente en alguna de las siguientes instituciones formales? Marca la opción correcta.

\begin{tabular}{|l|l|l|l|l|}
\hline & & $\mathrm{Si}$ & No & Ns/Nc \\
\hline A & Un Banco Publico & & & \\
\hline B & Un Banco Privado & & & \\
\hline C & $\begin{array}{l}\text { Un Billetera Digital (Ej.: Mercado } \\
\text { Pago, Uala, Pago 24, etc.) }\end{array}$ & & & \\
\hline D & Una cooperativa de crédito o ahorro & & & \\
\hline E & Una institución de microfinanzas & & & \\
\hline F & Otro. & & & \\
\hline G & Ns/Nc Ruta: Si alguna "Si" siga a 27, sino pase a 28. & \\
\hline H & \multicolumn{3}{|c|}{} \\
\hline
\end{tabular}


3.2) Pensando en un mes típico, aproximadamente ¿cuántas veces deposita o extrae dinero en su(s) cuenta(s) personal(es)? Esto incluye dinero en efectivo o depósitos/pagos hechos en forma electrónica, o cualquier dinero que usted u otros depositen/extraigan en su(s) cuenta(s).

Marca la opción correcta.

$$
\begin{array}{ll}
\circ & 0 \text { veces } \\
\circ & 1 \text { a } 2 \text { veces } \\
\circ & 3 \text { a } 5 \text { veces } \\
\circ & 6 \text { veces o más } \\
\circ & \text { Ns/Nc }
\end{array}
$$

3.3) En los últimos 12 meses, ¿Usted ha recibido, solo o conjuntamente con otra persona, un préstamo de dinero por alguna de las siguientes razones?

Marca la opción correcta.

\begin{tabular}{|l|l|l|l|l|}
\hline & \multicolumn{1}{|c|}{ Si } & No & Ns/Nc \\
\hline A & Para educación o gastos escolares & & & \\
\hline B & Para cuestiones de salud & & & \\
\hline C & Para viajes o vacaciones & & & \\
\hline D & Para iniciar o hacer crecer un negocio & & & \\
\hline E & Para comprar una casa, un apartamento, o un terreno & & & \\
\hline F & Para refaccionar o ampliar su hogar actual & & & \\
\hline G & Para un funeral, un cumpleaños de 15 o una boda & & & \\
\hline H & Para comprar bienes de consumo durables como heladeras, camas, etc. & & & \\
\hline I & 'Para adquirir prendas de vestir, accesorios, etc. & & & \\
\hline J & Para comprar un vehículo como una motocicleta o un automóvil & & & \\
\hline K & Otro & & & \\
\hline L & Ns/Nc & & & \\
\hline M & No he tomado un crédito & & \\
\hline
\end{tabular}

Nota: En caso de todas las respuestas "No" $\mathrm{o}$ "Ns/Nc" pasar directamente a 3.5 
3.4) ¿En caso de respuesta afirmativa, ha sido de alguna de las siguientes fuentes? Marca la opción correcta.

\begin{tabular}{|l|l|l|l|l|}
\hline & \multicolumn{1}{|c|}{ Si } & No & Ns/Nc \\
\hline A & Un Banco Publico & & & \\
\hline B & Un Banco Privado & & & \\
\hline C & $\begin{array}{l}\text { Una institución microfinanciera } \\
\text { (Semillas, etc.) }\end{array}$ & & & \\
\hline D & Prestamos ANSES / Créditos Argenta & & & \\
\hline E & De una financiera (Coppel,etc) & & & \\
\hline F & $\begin{array}{l}\text { Un Billetera Digital (Ej.: Mercado } \\
\text { Pago, Uala, Pago 24, etc.) }\end{array}$ & & & \\
\hline G & De una casa de empeños & & & \\
\hline H & De un prestamista particular & & & \\
\hline I & De un familiar, pariente, amigos & & & \\
\hline J & De una cooperativa, mutual, & & & \\
\hline K & $\begin{array}{l}\text { De una asociación vecinal, (junta, } \\
\text { pasanaku). }\end{array}$ & & & \\
\hline L & Ns/Nc & & & \\
\hline
\end{tabular}

Nota: Si declaro que tomo un crédito de la fuente "D" "Prestamos ANSES / Créditos Argenta" pasar a 3.6

3.5) ¿En los últimos 12 meses has recibido un adelanto o préstamo de ANSES por la Asignación Universal por Hijo o Jubilación o Programa ARGENTA?

Marca la opción correcta.

$\begin{array}{ll}\circ & \text { Sí } \\ \circ & \text { No }\end{array}$ 
3.6) ¿Actualmente o en los próximos 12 meses, ¿Usted tomaría, solo o conjuntamente con otra persona, un préstamo de dinero por alguna de las siguientes razones? Marcar la opción correcta.

\begin{tabular}{|l|l|l|l|l|}
\hline & & Si & No & Ns/Nc \\
\hline A & Para educación o gastos escolares & & & \\
\hline B & Para cuestiones de salud & & & \\
\hline C & Para viajes o vacaciones & & & \\
\hline D & Para iniciar o hacer crecer un negocio & & & \\
\hline E & Para comprar una casa, un apartamento, o un terreno & & & \\
\hline F & Para refaccionar o ampliar su hogar actual & & & \\
\hline G & Para un funeral, un cumpleaños de 15 o una boda & & & \\
\hline H & Para comprar bienes de consumo durables como heladeras, camas, etc. & & & \\
\hline I & 'Para adquirir prendas de vestir, accesorios, etc. & & & \\
\hline J & Para comprar un vehículo como una motocicleta o un automóvil & & & \\
\hline K & Otro & & & \\
\hline L & Ns/Nc & & & \\
\hline M & No tomaría un crédito & & & \\
\hline
\end{tabular}

3.7) ¿En promedio cuantas veces por mes utiliza un banco o un cajero automático (ATM) u otra Institución Financiera para hacer depósitos o extracciones? Marcar la opción correcta

\begin{tabular}{|l|l|l|l|l|l|l|l|l|l|}
\hline & & 0 & $1-2$ & $3-4$ & $5-6$ & $7-8$ & $9-10$ & $10<$ & $\mathrm{Ns} / \mathrm{Nc}$ \\
\hline A & Banco & & & & & & & & \\
\hline B & $\begin{array}{l}\text { Cajero } \\
\text { (ATM) }\end{array}$ & & & & & & & & \\
\hline C & Otra IMF & & & & & & & & \\
\hline
\end{tabular}

3.8) Una tarjeta de DÉBITO es una tarjeta asociada a una cuenta, caja de ahorro o cuenta corriente, en una institución financiera que le permite hacer compras o retirar dinero y éste es debitado de su CUENTA de inmediato (puede ser de un banco, cooperativa o financiera). ¿Tiene usted actualmente una tarjeta de débito? Marcar la opción correcta

$$
\begin{array}{ll}
\circ & \text { Sí } \\
\circ & \text { No (pasa a 3.10) } \\
\circ & \text { Ns/Nc (pasa a 3.10) }
\end{array}
$$


3.9) Pensando en un mes típico, aproximadamente ¿cuántas veces utiliza su(s) tarjeta(s) de DEBITO? Esto incluye por ejemplo para compras, o extracciones encajeros automáticos (ATM's). Marcar la opción correcta

\begin{tabular}{|l|l|l|}
\hline A & 0 veces & \\
\hline B & 1 -2 veces & \\
\hline C & $3-5$ veces & \\
\hline D & Más de 6 veces & \\
\hline E & Ns/Nc. & \\
\hline
\end{tabular}

3.10) Una tarjeta de CRÉDITO es una tarjeta que le permite PEDIR PRESTADO dinero para hacer pagos o comprar cosas y Usted puede pagar después y en cuotas. ¿Usted tiene su propia tarjeta de crédito? Marcar la opción correcta

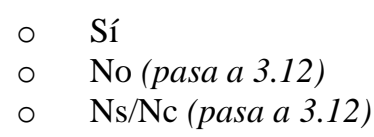

3.11) Pensando en un mes típico, aproximadamente ¿cuántas veces utiliza su(s) tarjeta(s) de CRÉDITO? Esto incluye por ejemplo para compras en locales, on-line o extracciones encajeros automáticos (ATM's). Marcar la opción correcta

\begin{tabular}{|l|l|l|}
\hline A & 0 veces & \\
\hline B & $1-2$ veces & \\
\hline C & $3-5$ veces & \\
\hline D & Más de 6 veces & \\
\hline E & Ns/Nc. & \\
\hline
\end{tabular}

3.12) Una tarjeta prepagada es aquella en la cual se anticipa el importe del consumo que se realizará con la tarjeta y se efectúa una carga de dinero en la tarjeta y pueden realizarse operaciones hasta consumir el total del importe cargado. Ejemplo: Uala, Pago 24, etc. ¿Usted tiene su propia tarjeta prepaga? Marcar la opción correcta
- Sí
- No (pasa a 3.14)
- Ns/Nc (pasa a 3.14) 
3.13) Pensando en un mes típico, aproximadamente ¿cuántas veces utiliza su(s) tarjeta(s) PREPAGA? Esto incluye por ejemplo para compras en locales, on-line o extracciones encajeros automáticos (ATM's). Marcar la opción correcta

\begin{tabular}{|l|l|l|}
\hline A & 0 veces & \\
\hline B & $1-2$ veces & \\
\hline C & $3-5$ veces & \\
\hline D & Más de 6 veces & \\
\hline E & Ns/Nc. & \\
\hline
\end{tabular}

3.14) Una billetera digital permite utilizar el teléfono como monedero virtual. A través de ellas se puede realizar pagos de servicios, envíos de dinero, compras con dinero digital. A diferencia de un banco, las billeteras virtuales no son cuentas bancarias, sino que se pueden asociar a ellas o simplemente puedo invertir dinero en ellas sin ser cliente de un banco. ¿Tiene usted su propia cuenta en una billetera digital, como por ejemplo Mercado Pago, PIM?

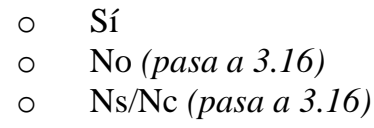

3.15) Pensando en un mes típico, aproximadamente ¿cuántas veces utiliza su(s) billetera(s) virtual? (Marcar la opción correcta).

\begin{tabular}{|l|l|l|}
\hline A & 0 veces & \\
\hline B & $1-2$ veces & \\
\hline C & $3-5$ veces & \\
\hline D & Más de 6 veces & \\
\hline E & Ns/Nc. & \\
\hline
\end{tabular}

3.16) En los últimos 12 meses, ¿usted ha ahorrado o apartado dinero...? (Marcar la opción correcta).

\begin{tabular}{|c|c|c|c|c|}
\hline & & $\mathrm{Si}$ & No & $\mathrm{Ns} / \mathrm{Nc}$ \\
\hline A & $\begin{array}{l}\text { Usando una cuenta (caja de ahorro o cuenta corriente) en un } \\
\text { banco, cooperativa, financiera u otra institución financiera formal }\end{array}$ & & & \\
\hline B & $\begin{array}{l}\text { Usando un grupo de ahorro informal (como el pasanaku, vaquita, } \\
\text { rueda o ronda), asociaciones familiares o vecinales o una persona } \\
\text { fuera de la familia? }\end{array}$ & & & \\
\hline $\mathrm{C}$ & $\begin{array}{l}\text { Guardando billetes y monedas en efectivo, como por ejemplo en la } \\
\text { casa }\end{array}$ & & & \\
\hline
\end{tabular}


3.17) En los últimos 12 meses, ¿ha DADO o ENVIADO usted personalmente DINERO a algún familiar o amigo que viva en otra área DENTRO de Argentina o en el EXTERIOR? Este puede ser dinero que Usted mismo llevó o que envió de alguna otra manera. (Entrevistador: puede ser dinero enviado por cualquier motivo) (Marcar la opción correcta).

\begin{tabular}{|l|l|l|l|}
\hline & \multicolumn{3}{|c|}{ Ruta } \\
\hline A & Si & & \\
\hline B & No & & Pasa a 3.20 \\
\hline C & Ns/Nc & & Pasa a 3.20 \\
\hline
\end{tabular}

3.18) ¿Cuándo envío dinero, lo hizo a alguien que estaba dentro de Argentina, o en el exterior? (Marcar la opción correcta)

\begin{tabular}{|l|l|l|}
\hline A & Dentro de Argentina & \\
\hline B & En el exterior & \\
\hline C & Ns/Nc & \\
\hline
\end{tabular}

3.19) ¿De qué manera ha ENVIADO ese dinero? (Marcar la opción correcta).

\begin{tabular}{|c|c|c|c|c|}
\hline & & $\mathrm{Si}$ & No & $\mathrm{Ns} / \mathrm{Nc}$ \\
\hline A & $\begin{array}{l}\text { Dinero en efectivo que entregó personalmente a esa persona o por } \\
\text { medio de otro conocido. }\end{array}$ & & & \\
\hline B & $\begin{array}{l}\text { A través de un banco o institución financiera. Esto puede ser en el } \\
\text { mostrador de una sucursal, en un cajero automático, mediante } \\
\text { depósito electrónico en una cuenta o corresponsales no bancarios. }\end{array}$ & & & \\
\hline $\mathrm{C}$ & $\begin{array}{l}\text { A través de un servicio de telefonía celular como PIM, Billetera } \\
\text { Rapipago, Mercado Libre, Ualá, aplicación del banco en el celular } \\
\text { (home banking) u otro. }\end{array}$ & & & \\
\hline $\mathrm{D}$ & $\begin{array}{l}\text { A través de un servicio de transferencia de dinero como Western } \\
\text { Union, agencias de transporte o encomiendas. }\end{array}$ & & & \\
\hline
\end{tabular}

3.20) En los últimos 12 meses, ¿ha RECIBIDO usted personalmente DINERO de algún familiar o amigo que viva en otra área DENTRO de Argentina o en el EXTERIOR? (Entrevistador: puede ser dinero enviado por cualquier motivo) (Marcar con una x la opción correcta).

\begin{tabular}{|l|l|l|l|}
\hline & \multicolumn{3}{|c|}{ Ruta } \\
\hline A & Si & & \\
\hline B & No & & Pase a 3.23 \\
\hline C & Ns/Nc & & Pase a 3.23 \\
\hline
\end{tabular}


3.21) ¿Cuándo recibió dinero, lo hizo de alguien que estaba dentro de Argentina, o en el exterior? (Marcar la opción correcta)

\begin{tabular}{|l|l|l|}
\hline A & Dentro de Argentina & \\
\hline B & En el exterior & \\
\hline C & Ns/Nc & \\
\hline
\end{tabular}

3.22) ¿De qué manera ha RECIBIDO ese dinero? (Marcar la opción correcta).

\begin{tabular}{|c|c|c|c|c|}
\hline & & $\mathrm{Si}$ & No & $\mathrm{Ns} / \mathrm{Nc}$ \\
\hline $\mathrm{A}$ & $\begin{array}{l}\text { Dinero en efectivo que entregó personalmente a esa persona o por } \\
\text { medio de otro conocido. }\end{array}$ & & & \\
\hline B & $\begin{array}{l}\text { A través de un banco o institución financiera. Esto puede ser en el } \\
\text { mostrador de una sucursal, en un cajero automático, mediante } \\
\text { depósito electrónico en una cuenta o corresponsales no bancarios. }\end{array}$ & & & \\
\hline $\mathrm{C}$ & $\begin{array}{l}\text { A través de un servicio de telefonía celular como PIM, Billetera } \\
\text { Rapipago, Mercado Libre, Ualá, aplicación del banco en el celular } \\
\text { (home banking) u otro. }\end{array}$ & & & \\
\hline $\mathrm{D}$ & $\begin{array}{l}\text { A través de un servicio de transferencia de dinero como Western } \\
\text { Union, agencias de transporte o encomiendas. }\end{array}$ & & & \\
\hline
\end{tabular}

\section{Del uso de la telefonía móvil e internet.}

4.1) ¿Usted tiene un teléfono celular? (Marcar opción correcta).

\begin{tabular}{|l|l|l|l|}
\hline \multicolumn{3}{|l|}{ Ruta } \\
\hline A & Si & & Siga a 4.2 \\
\hline B & No & & Pase a 4.11 \\
\hline
\end{tabular}

4.2) ¿El teléfono es suyo o lo comparte con algún familiar/amigo/compañero de trabajo? (Marcar la opción correcta).

\begin{tabular}{|l|l|l|}
\hline A & Es mío & \\
\hline B & Lo comparto & \\
\hline
\end{tabular}

4.3) ¿El celular que utiliza permite descargar aplicaciones como WhatsApp, Facebook o Twitter? (Marcar la opción correcta).

\begin{tabular}{|l|l|l|}
\hline $\mathrm{A}$ & $\mathrm{Si}$ & \\
\hline $\mathrm{B}$ & $\mathrm{No}$ & \\
\hline $\mathrm{C}$ & $\mathrm{Ns} / \mathrm{Nc}$ & \\
\hline
\end{tabular}


4.4) ¿Utiliza el mismo teléfono para su vida personal y para su comercio, o tiene un teléfono distinto para su actividad económica? (Marcar la opción correcta)

\begin{tabular}{|c|l|l|}
\hline A & $\begin{array}{l}\text { Uso el mismo para mi vida personal y para la actividad } \\
\text { económica. }\end{array}$ & $\begin{array}{l}\text { Tengo dos teléfonos distintos para cada asunto. Uno para el } \\
\text { negocio y otro para mí. }\end{array}$ \\
\hline B
\end{tabular}

4.5) ¿Considera que dispone de la cantidad de datos móviles necesaria para poder utilizar internet desde el celular durante todo el mes? (Marcar la opción correcta)

\begin{tabular}{|l|l|l|}
\hline A & No, tengo muy pocos datos móviles. & \\
\hline B & Sí, llego con lo justo a fin de mes. & \\
\hline C & Sí, me sobran datos a fin de mes. & \\
\hline
\end{tabular}

4.6) ¿Qué tan seguro se siente con sus capacidades para entender y utilizar la tecnología de un teléfono? (Marcar la opción correcta)

\begin{tabular}{|l|l|l|}
\hline A & Muy seguro & \\
\hline B & Más o menos & \\
\hline C & No me siento seguro & \\
\hline D & Ns/Nc & \\
\hline
\end{tabular}

4.7) ¿En el último mes cuantas veces aproximadamente utilizó su teléfono para alguna de las siguientes acciones? (Marcar la opción correcta)

\begin{tabular}{|c|l|l|l|l|l|l|}
\hline & \multicolumn{1}{|c|}{} & 0 & $1-2$ & $3-5$ & $5-10$ & $10<$ \\
\hline A & Instalar actualizaciones para su sistema o sus aplicaciones. & & & & & \\
\hline B & Cambiar la contraseña de acceso a tu teléfono o a aplicaciones & & & & & \\
\hline D & Enviar o leer un correo electrónico (mail) & & & & & \\
\hline E & Tomarse una auto foto (selfie) & & & & & \\
\hline G & Enviar un video a otra persona & & & & & \\
\hline H & $\begin{array}{l}\text { Reenviar a más de 1 persona al mismo tiempo un mensaje de } \\
\text { WhatsApp. }\end{array}$ & & & & \\
\hline I & Enviar una ubicación por GPS & & & & & \\
\hline J & Conectarse a una red de wifi ingresando usuario y clave. & & & & & \\
\hline K & Leer un diario digital (La Nación, Clarín, Pagina 12) & & & & & \\
\hline
\end{tabular}

Nota: Si respondió que sí en la pregunta 26 acerca de si tiene una cuenta en una entidad bancaria, seguir con la pregunta siguiente, sino pasar a pregunta 58 .

4.8) ¿Tiene descargada la aplicación móvil de su Banco?

\begin{tabular}{|l|l|l|l|}
\hline \multicolumn{4}{|l|}{ Ruta } \\
\hline A & No & & Siga a 4.9 \\
\hline B & Si & & Pase a 4.10 \\
\hline
\end{tabular}


4.9) ¿Cuáles de estas razones justifican su decisión de no usar la app de banca móvil? (Marcar la opción correcta) (Rta. Múltiple)

\begin{tabular}{|l|l|l|}
\hline A & Me preocupa la seguridad de la banca móvil. & \\
\hline B & Mis necesidades bancarias las cubro sin banca móvil & \\
\hline C & No hay un cajero automático cerca para realizar la clave y el usuario & \\
\hline D & La pantalla del teléfono móvil es demasiado pequeña. & \\
\hline E & No tengo un teléfono inteligente & \\
\hline F & No puedo aprender a utilizarla porque es muy difícil & \\
\hline G & No confío en la tecnología & \\
\hline H & No creo que tenga ningún beneficio o facilidad en particular. & \\
\hline I & No tengo un Smartphone & \\
\hline
\end{tabular}

4.10) ¿Cuáles de estas razones justifican su decisión de usar la app banca móvil? (Marcar la opción correcta) (Rta. Múltiple)

\begin{tabular}{|l|l|l|}
\hline A & Mi banco comenzó a ofrecerme el servicio. & \\
\hline B & No hay sucursal bancaria ni cajero automático cerca de mi casa o trabajo. & \\
\hline C & Me sentí cómodo con la seguridad de la banca móvil. & \\
\hline D & Para pagar servicio, como el monotributo, desde el teléfono. & \\
\hline E & Para consultar mis últimos movimientos. & \\
\hline F & Para saber si me depositaron ventas con tarjeta. & \\
\hline G & Para cargar la tarjeta de transporte público (SUBE) desde el teléfono. & \\
\hline H & Para realizar un plazo fijo con Homebanking. & \\
\hline I & Para enviar dinero de forma más rápida. & \\
\hline
\end{tabular}

4.11) ¿Tiene acceso a internet desde donde realizar tu actividad económica? (Marcar la opción correcta)

\begin{tabular}{|l|l|l|}
\hline A & Si & \\
\hline B & No & \\
\hline
\end{tabular}

4.12) ¿Tiene alguno de los siguientes dispositivos informáticos en su casa o en lugar donde realiza su actividad económica, con conexión a internet? (Marcar la opción correcta)

\begin{tabular}{|l|l|l|l|}
\hline & En mi casa & $\begin{array}{l}\text { En donde realizo mi } \\
\text { actividad económica }\end{array}$ & No tengo \\
\hline Computadora & & & \\
\hline Tablet & & & \\
\hline Netbook & & & \\
\hline
\end{tabular}




\section{Del uso de medios de pago digitales.}

5.1) ¿Cuál de los siguientes medios de pagos utiliza más frecuentemente para pagar cada una de las siguientes categorías? (Seleccione una opción para cada categoría).

\begin{tabular}{|c|c|c|c|c|c|c|c|c|}
\hline & & Efectivo & $\begin{array}{l}\text { T. } \\
\text { Debito }\end{array}$ & $\begin{array}{l}\text { Billetera } \\
\text { Móvil }\end{array}$ & $\begin{array}{l}\text { T. } \\
\text { Crédito }\end{array}$ & Cheque & $\begin{array}{l}\text { Transf.- } \\
\text { Electrónica }\end{array}$ & $\begin{array}{l}\text { No } \\
\text { consumo }\end{array}$ \\
\hline A & $\begin{array}{l}\text { Servicios como la } \\
\text { luz, el agua, etc. }\end{array}$ & & & & & & & \\
\hline B & $\begin{array}{l}\text { Cagar la tarjeta de } \\
\text { transporte publico } \\
\text { SUBE }\end{array}$ & & & & & & & \\
\hline $\mathrm{C}$ & $\begin{array}{l}\text { Para pagarle a } \\
\text { alguno de sus } \\
\text { proveedores }\end{array}$ & & & & & & & \\
\hline D & $\begin{array}{l}\text { Hacer las compras } \\
\text { minoristas }\end{array}$ & & & & & & & \\
\hline $\mathrm{E}$ & $\begin{array}{l}\text { Hacer las compras } \\
\text { en el supermercado }\end{array}$ & & & & & & & \\
\hline $\mathrm{F}$ & $\begin{array}{l}\text { Abonar el } \\
\text { Monotributo }\end{array}$ & & & & & & & \\
\hline $\mathrm{G}$ & Pagar los peajes. & & & & & & & \\
\hline $\mathrm{H}$ & $\begin{array}{l}\text { Comprar entradas } \\
\text { al cine. }\end{array}$ & & & & & & & \\
\hline I & $\begin{array}{l}\text { Comprar pasajes en } \\
\text { avión o colectivo } \\
\text { larga distancia. }\end{array}$ & & & & & & & \\
\hline $\mathrm{J}$ & $\begin{array}{l}\text { Para comprar } \\
\text { bienes durables }\end{array}$ & & & & & & & \\
\hline
\end{tabular}

5.2) ¿Cuantas veces por mes carga su tarjeta de transporte? (Marcar la opción correcta)

\begin{tabular}{|l|l|l|l|l|l|l|l|l|l|}
\hline 0 & & $1-2$ & & $3-5$ & & $5-10$ & & $10<$ & \\
\hline
\end{tabular}

5.3) ¿En un día típico cuánto dinero llevas con vos mismo, y cuanto dejas en tu casa? (Seleccione una opción para cada categoría)

\begin{tabular}{|l|l|l|l|l|l|l|l|l|}
\hline & & $\$ 0$ & $\begin{array}{l}\$ 1- \\
\$ 200\end{array}$ & $\begin{array}{l}\$ 200- \\
\$ 400\end{array}$ & $\begin{array}{l}\$ 400- \\
600\end{array}$ & $\begin{array}{l}\$ 600- \\
\$ 800\end{array}$ & $\begin{array}{l}\text { Más de } \\
\$ 800\end{array}$ & Ns/Nc \\
\hline A & Llevo conmigo mismo... & & & & & & & \\
\hline B & Dejo en mi casa... & & & & & & & \\
\hline
\end{tabular}


5.4) ¿Cuánto tiempo gasta mensualmente en hacer los pagos de servicios e impuestos? (Marcar la opción correcta)

\begin{tabular}{|l|l|l|}
\hline A & 0 minutos & \\
\hline B & $10-15$ minutos & \\
\hline C & $16-20$ minutos & \\
\hline D & $21-30$ minutos & \\
\hline E & $31-45$ minutos & \\
\hline F & $46-60$ minutos & \\
\hline G & Más de 60 minutos \\
\hline
\end{tabular}

5.5) En relación a la seguridad del dinero que le genera manejar dinero en efectivo. ¿En los últimos 3 años sufrió alguna de las siguientes situaciones relacionadas al dinero en efectivo? (Marcar la opción correcta) (Rta. Múltiple)

\begin{tabular}{|l|l|l|}
\hline A & Robo en el comercio de la caja del día. & \\
\hline B & Pago con billetes falsos. & \\
\hline C & Perdida de efectivo. & \\
\hline D & Robo mientras se trasladaba de un lugar a otro. & \\
\hline E & Robo en su casa. & \\
\hline F & Robo por parte de alguno de sus empleados. & \\
\hline G & Ns/Nc & \\
\hline H & No he sufrido ninguna & \\
\hline
\end{tabular}

5.6) ¿Qué tan de acuerdo con esta afirmación: "Me siento seguro teniendo el dinero en efectivo”?

\begin{tabular}{|l|l|l|}
\hline A & Muy de acuerdo & \\
\hline B & De acuerdo & \\
\hline C & No estoy de acuerdo & \\
\hline D & Ns/Nc & \\
\hline
\end{tabular}

5.7) ¿En el último año cuantas compras / ventas realizo por internet utilizando su teléfono móvil o su computadora? (Marcar la opción correcta)

\begin{tabular}{|l|l|l|l|l|l|l|}
\hline & & 0 & $1-2$ & $3-5$ & $5-10$ & $10<$ \\
\hline A & Ventas por internet a través del teléfono. & & & & & \\
\hline B & Compras por internet a través del teléfono. & & & & & \\
\hline C & Ventas por internet a través de la computadora. & & & & & \\
\hline D & Compra por internet a través de la computadora. & & & & & \\
\hline
\end{tabular}


5.8) ¿Si sus proveedores más grandes le piden que les pague de forma electrónica, que tan dispuesto estaría a hacerlo? (Marcar la opción correcta)

\begin{tabular}{|l|l|l|}
\hline A & Muy de acuerdo & \\
\hline B & De acuerdo & \\
\hline C & No estoy de acuerdo & \\
\hline D. & Ns/Nc & \\
\hline
\end{tabular}

5.9) Los medios de pagos digitales, realizan la transferencia del dinero en una acción de compra-venta electrónica sin utilizar efectivo, como por ejemplo una compra con tarjeta de débito. ¿Acepta actualmente, o aceptó en el pasado, alguno de los siguientes medios de pago digitales? (Seleccione una opción para cada categoría, en caso de ser "Otro” especificar cuál)

\begin{tabular}{|l|l|l|l|l|}
\hline & & Sí & $\begin{array}{l}\text { Sí, pero lo } \\
\text { deje de hacer. }\end{array}$ & No \\
\hline A & Posnet inalámbrico. & & & \\
\hline B & M-pos con el celular. & & & \\
\hline C & Código QR & & & \\
\hline D & Otro: & & & \\
\hline & Ruta & Siga a 5.10 & Pase a 5.18 & Pase a 5.23 \\
\hline
\end{tabular}

5.10) ¿Aproximadamente cuánto gasta por mes en pagar el servicio de poder ofrecer pagos digitales? (Completar con numero)

5.11) ¿Hace cuánto que acepta medios de pago digitales? (Marcar la opción correcta)

\begin{tabular}{|l|l|l|}
\hline A & $0-3$ meses & \\
\hline B & $3-6$ meses & \\
\hline C & 6-9 meses & \\
\hline D & 9-12 meses & \\
\hline E & $1-3$ años & \\
\hline F & Más de 3 años & \\
\hline G & Ns/Nc & \\
\hline
\end{tabular}

Nota: Si respondió que "Sí" únicamente en la opción C, de pago con QR, en la pregunta 5.9 vaya directamente a la pregunta 75 . 
5.12) ¿Aproximadamente qué porcentaje de sus clientes le pagan con tarjeta de débito? (Marcar con una $x$ la opción correcta):

\begin{tabular}{|l|l|l|}
\hline A & $0 \%$ & \\
\hline B & $10 \%$ & \\
\hline C & $25 \%$ & \\
\hline D & $50 \%$ & \\
\hline E & $75 \%$ & \\
\hline F & $100 \%$ & \\
\hline G & Ns/Nc & \\
\hline H & Otro: & \\
\hline
\end{tabular}

5.13) ¿En el próximo año, aproximadamente, como cree que va a variar la cantidad de clientes que le van a pagar con tarjeta de débito? (Marcar la opción correcta)

\begin{tabular}{|l|l|l|}
\hline A & Va a bajar un 10\% o mas & \\
\hline B & Va a bajar entre un 1\% o 10\% & \\
\hline C & Se va a mantener igual & \\
\hline D & Va a crecer entre un 1\% o 10\% & \\
\hline E & Va a crecer más del 10\% & \\
\hline F & Ns/Nc & \\
\hline
\end{tabular}

5.14) ¿Aproximadamente qué porcentaje de sus clientes le pagan con tarjeta de crédito? (Marcar la opción correcta):

\begin{tabular}{|l|l|l|}
\hline $\mathrm{A}$ & $0 \%$ & \\
\hline $\mathrm{B}$ & $10 \%$ & \\
\hline $\mathrm{C}$ & $25 \%$ & \\
\hline $\mathrm{D}$ & $50 \%$ & \\
\hline $\mathrm{E}$ & $75 \%$ & \\
\hline $\mathrm{F}$ & $100 \%$ & \\
\hline $\mathrm{G}$ & $\mathrm{Ns} / \mathrm{Nc}$ & \\
\hline $\mathrm{H}$ & Otro & \\
\hline
\end{tabular}

5.15) ¿En el próximo año, aproximadamente, como cree que va a variar la cantidad de clientes que le van a pagar con tarjeta de crédito? (Marcar la opción correcta)

\begin{tabular}{|l|l|l|}
\hline $\mathrm{A}$ & Va a bajar un 10\% o mas & \\
\hline $\mathrm{B}$ & Va a bajar entre un 1\% o 10\% & \\
\hline C & Se va a mantener igual & \\
\hline D & Va a crecer entre un 1\% o $10 \%$ & \\
\hline E & Va a crecer más del 10\% & \\
\hline F & Ns/Nc & \\
\hline
\end{tabular}

Nota: Si en la pregunta 5.9 respondió que "No" o que "Sí, pero lo deje de hacer" pagos con código QR pasar a 5.18 
5.16) ¿Aproximadamente qué porcentaje de sus clientes le pagan con código QR? (Marcar la opción correcta)

\begin{tabular}{|l|l|l|}
\hline $\mathrm{A}$ & $0 \%$ & \\
\hline $\mathrm{B}$ & $10 \%$ & \\
\hline $\mathrm{C}$ & $25 \%$ & \\
\hline $\mathrm{D}$ & $50 \%$ & \\
\hline $\mathrm{E}$ & $75 \%$ & \\
\hline $\mathrm{F}$ & $100 \%$ & \\
\hline $\mathrm{G}$ & $\mathrm{Ns} / \mathrm{Nc}$ & \\
\hline $\mathrm{H}$ & Otro & \\
\hline
\end{tabular}

5.17) ¿En el próximo año, aproximadamente, como cree que va a variar la cantidad de clientes que le van a pagar con código QR? (Marcar la opción correcta)

\begin{tabular}{|l|l|l|}
\hline A & Va a bajar un 10\% o mas & \\
\hline B & Va a bajar entre un 1\% o 10\% & \\
\hline C & Se va a mantener igual & \\
\hline D & Va a crecer entre un 1\% o 10\% & \\
\hline E & Va a crecer más del 10\% & \\
\hline F & Ns/Nc & \\
\hline
\end{tabular}

5.18) ¿Por cuál de los siguientes motivos acepta pagos digitales? (Marcar la opción correcta, en caso de ser "Otro" especificar cuál) (Rta. Múltiple)

\begin{tabular}{|l|l|l|}
\hline A & Fue fácil de aprender y entender & \\
\hline B & Me trae más ventas & \\
\hline C & Es más seguro de manejar que el efectivo & \\
\hline D & Redujo mi costo de manejo de efectivo & \\
\hline E & Redujo la molestia de encontrar cambio para los clientes & \\
\hline F & Es más rápido realizar transacciones que con efectivo & \\
\hline G & Los consumidores gastan más dinero & \\
\hline H & La aplicación móvil es fácil de usar & \\
\hline I & Me interesa ser cliente de la institución financiera, un banco, o una aplicación móvil & \\
\hline J & Otros comercios lo tienen y quiero competir & \\
\hline K & Es gratis el mantenimiento & \\
\hline L & Me permite evitar que fíen & \\
\hline M & Es más seguro para cuando los empleados manejan la caja del comercio & \\
\hline N & Ahorro tiempo para hacer el registro de las ventas que hice en el mes. & \\
\hline O & Es mejor para ahorrar porque el dinero va directo a una cuenta & \\
\hline P & Porque me conviene para luego comprar con la tarjeta de débito usando ese dinero & \\
\hline Q & Otro & \\
\hline
\end{tabular}

5.19) ¿En una escala del 1 al 10 , cuanto le recomendaría a un amigo que acepte pagos digitales? (Marcar la opción correcta)

\begin{tabular}{|l|l|l|l|l|l|l|l|l|l|}
\hline 1 & 2 & 3 & 4 & 5 & 6 & 7 & 8 & 9 & 10 \\
\hline & & & & & & & & & \\
\hline
\end{tabular}


5.20) ¿Qué problemas tiene o tuvo con sus medios de pago digitales, por los que no los recomendarías? (Marcar la opción correcta, en caso de ser "Otro” especificar cuál) (Rta. Múltiple).

\begin{tabular}{|l|l|l|}
\hline A & Es difícil de aprender y entender cómo usarlo & \\
\hline B & Los consumidores rara vez lo piden & \\
\hline C & Es demasiado caro dadas mis ventas & \\
\hline D & Toma demasiado tiempo para operar & \\
\hline E & Se tarda demasiado en recibir el pago & \\
\hline F & No es seguro & \\
\hline G & Es muy difícil recibir asistencia técnica & \\
\hline H & Tenes que pagar muchos impuestos (ej.: monotributo) & \\
\hline I & Tengo que hacer pagos en efectivo a proveedores, así que prefiero recibir efectivo & \\
\hline J & Tengo que hacer compras minoristas en efectivo así que prefiero recibir efectivo & \\
\hline K & Es difícil retirar el efectivo de la cuenta & \\
\hline L & La aplicación móvil es muy compleja & \\
\hline M & El sistema se descompone / no siempre funciona & \\
\hline N & Otros, por favor especifique & \\
\hline O & A mi familia no le gusta que lo usemos & \\
\hline P & Otro & \\
\hline Q & No tuve problemas & \\
\hline
\end{tabular}

$5.21)$ ¿Si tiene un problema con su instrumento de pago digital a quien le pidió ayuda? (Marcar la opción correcta, en caso de ser "Otro" especificar cuál) (Rta. Múltiple).

\begin{tabular}{|l|l|l|}
\hline A & Al servicio técnico de la empresa. & \\
\hline B & Dejo de usarlo, esperando que se solucione. & \\
\hline C & A mi hijo o algún familiar/amigo joven & \\
\hline D & A algún colega & \\
\hline E & A la oficina del Gobierno Local que asesora emprendedores (CeDEL) & \\
\hline F & Busco ayuda en internet & \\
\hline G & Otra & \\
\hline
\end{tabular}

Nota: Solo si respondió en la pregunta 5.9 que dejo de utilizar medios de pago digitales. Sino aquí finaliza el cuestionario. 
5.22) En la pregunta 5.9 dijo que había dejado de utilizar medios de pago digitales. ¿Podría a continuación decirnos cuáles de los siguientes motivos justificaron su decisión? (Marcar la opción correcta, en caso de ser "Otro” especificar cuál) (Rta. Múltiple):

\begin{tabular}{|l|l|l|}
\hline A & A mi familia no le gustaba que lo usemos & \\
\hline B & Era difícil de usar & \\
\hline C & Los consumidores rara vez lo pedían & \\
\hline D & Era demasiado caro para mis ventas & \\
\hline E & Tomaba demasiado tiempo para operar & \\
\hline F & Se tardaba demasiado en recibir el pago & \\
\hline G & No era seguro & \\
\hline H & Tenía que pagar más impuestos & \\
\hline I & Necesitaba efectivo para hacer compras, así que prefería recibir efectivo & \\
\hline J & No podía ofrecer promociones / descuentos a los clientes & \\
\hline K & No había buena publicidad de que se podía pagar con tarjeta & \\
\hline L & Los trámites para la instalación eran demasiado complicados & \\
\hline M & Era difícil, después de la venta, retirar el efectivo de la cuenta & \\
\hline N & Era muy complicado recibir asistencia técnica si tenía algún problema \\
\hline O & Tengo que hacer compras minoristas en efectivo así que prefiero recibir efectivo & \\
\hline P & Otro & \\
\hline
\end{tabular}

Nota: Solo si respondió que actualmente no utilizaba ningún medio de pago digital en la pregunta 5.9. Si respondió que sí utiliza algún medio de pago en la actualidad en la pregunta 5.9 aquí finaliza el cuestionario.

5.23) ¿Le interesaría aceptar medios de pago digitales para no tener que usar efectivo? (Marcar la opción correcta)

\begin{tabular}{|l|l|}
\hline \multicolumn{2}{|l|}{ Ruta } \\
\hline Si & \\
\hline No & Siga a 5.24 \\
\hline
\end{tabular}


5.24) ¿Por cuáles de estas razones le interesaría aceptar medios de pagos digitales? (Marcar con una x la opción correcta, en caso de ser "Otro" especificar cuál) (Rta. Múltiple).

\begin{tabular}{|l|l|l|}
\hline A & Es fácil de utilizar. & \\
\hline B & Me puede traer más ventas. & \\
\hline C & Es más seguro de manejar que el efectivo. & \\
\hline D & Reduce mi costo de manejar de efectivo. & \\
\hline E & Reduce la molestia de encontrar cambio para los clientes. & \\
\hline F & Es más rápido realizar transacciones que con efectivo. & \\
\hline G & Los consumidores gastan más dinero. & \\
\hline H & Puedo ofrecer cuotas o/y descuentos a los clientes. & \\
\hline I & Me interesa ser cliente de un Banco o una billetera digital. & \\
\hline J & Otros comercios lo tienen y quiero competir. & \\
\hline K & Es gratis el mantenimiento. & \\
\hline L & Te permite evitar el fiado & \\
\hline M & Es más seguro para cuando los empleados manejan la caja del comercio & \\
\hline N & Ahorro tiempo para hacer el registro de las ventas que hice en el mes. & \\
\hline O & Es mejor para ahorrar porque el dinero va directo a una cuenta. & \\
\hline P & Porque me conviene para luego comprar con la tarjeta de débito usando ese dinero. & \\
\hline Q & Otro & \\
\hline
\end{tabular}

5.25) ¿Si tiene motivos por los cuales le interesa, entonces por qué razón aún no utiliza medios de pagos digitales? (Marcar con una x la opción correcta) (Si es “otro” especifique cual). (Rta. Múltiple)

\begin{tabular}{|l|l|l|}
\hline A & El costo de mantenimiento y acceso es muy alto & \\
\hline B & No me siento capacitado/a para saber cómo usarlo bien & \\
\hline C & Nunca nadie me lo ofreció & \\
\hline D & Es muy difícil acceder a los medios de pago digital & \\
\hline E & No quiero tener problemas con los impuestos fiscales & \\
\hline F & Quiero esperar a que más personas usen la tarjeta & \\
\hline G & Quiero esperar a que más comercios acepten también & \\
\hline H & No tengo cuenta bancaria & \\
\hline I & No tengo habilitación comercial & \\
\hline J & Otro & \\
\hline
\end{tabular}


5.26) ¿Por cuáles de estos motivos no le interesaría aceptar pagos con medios digitales? (Marcar con una x la opción correcta, en caso de ser "Otro" especificar cuál) (Rta. Múltiple):

\begin{tabular}{|l|l|l|}
\hline A & No sé cómo conseguir posnet, o m-pos, o aplicación para aceptar pagos digitales. & \\
\hline B & No conozco a nadie que tenga uno & \\
\hline C & Nunca pensé en usarlo & \\
\hline D & No tengo DNI & \\
\hline E & A mi familia no le gusta que lo usemos. & \\
\hline F & Me resulta difícil de usar & \\
\hline G & Los consumidores rara vez lo piden. & \\
\hline H & Es demasiado caro dadas mis ventas. & \\
\hline I & Toma demasiado tiempo para operar & \\
\hline J & Se tarda demasiado en recibir el pago & \\
\hline K & No es seguro & \\
\hline L & Voy a tener que pagar más impuestos. & \\
\hline M & Tengo que hacer pagos en efectivo, así que prefiero recibir efectivo. & \\
\hline N & No sé para qué puedo usarlo. & \\
\hline O & No puedo ofrecer promociones/ descuentos a los clientes. & \\
\hline P & No hay publicidad de que aceptamos medios de pago digitales y nadie se entera & \\
\hline Q & Los trámites de instalación son demasiado complicados. & \\
\hline R & Es difícil, después de la venta, retirar el efectivo de la cuenta. & \\
\hline S & No me siento cómodo usando el teléfono para cobrar. & \\
\hline T & No me llevo bien con la tecnología. & \\
\hline U & Era muy complicado recibir asistencia técnica si tenía algún problema & \\
\hline V & Tengo que hacer compras minoristas en efectivo así que prefiero recibir efectivo. & \\
\hline W & Tuve una mala experiencia en el pasado & \\
\hline Y & Otro & \\
\hline
\end{tabular}

